\title{
Synthesis, Formulation, and Adjuvanticity of Monodesmosidic Saponins with Olenanolic Acid, Hederagenin and Gypsogenin Aglycones, and some C-28 Ester Derivatives**
}

\author{
Ben W. Greatrex, ${ }^{[\mathrm{a}, \mathrm{b}]}$ Alison M. Daines, ${ }^{[\mathrm{a}]}$ Sarah Hook, ${ }^{[\mathrm{c}]}$ Dirk H. Lenz, ${ }^{[\mathrm{a}]}$ Warren McBurney, ${ }^{[\mathrm{c}]}$ \\ Thomas Rades, ${ }^{[c]}$ and Phillip M. Rendle*[a]
}

\begin{abstract}
In an attempt to discover a new synthetic vaccine adjuvant, the glycosylation of hederagenin, gypsogenin, and oleanolic acid acceptors with di- and trisaccharide donors to generate a range of mimics of natural product QS-21 was carried out. The saponins were formulated with phosphatidylcholine and cholesterol, and the structures analyzed by transmission electron microscopy. 3-O-(Man $p(1 \rightarrow 3)$ Glcp)hederagenin was found to produce numerous ring-like micelles when formulated, while C-28 choline ester derivatives preferred self-assembly and did not interact with the liposomes. When alone and in
\end{abstract}

the presence of cholesterol and phospholipid, the choline ester derivatives produced nanocrystalline rods or helical micelles. The effects of modifying sugar stereochemistry and the aglycone on the immunostimulatory effects of the saponins was then evaluated using the activation markers MHC class II and CD86 in murine bone marrow dendritic cells. The most active saponin, $3-O-(\operatorname{Man} p(1 \rightarrow 3)$ Glcp $)$ hederagenin, was stimulatory at high concentrations in cell culture, but this did not translate to strong responses in vivo.

\section{Introduction}

The safety of prophylactic vaccine formulations is of primary importance because of their widespread use on healthy individuals. Vaccination using subunit antigens, such as peptides, proteins, or DNA, is intrinsically safer than using traditional attenuated or inactivated organisms. However subunit vaccines generally require an adjuvant as subunit antigens have poor immunogenicity. ${ }^{[1]}$ Adjuvants decrease the amount of antigen required for an effective immune response and can bias the immune response down particular pathways. ${ }^{[2]}$ There has been great interest in the complex saponin adjuvant mixture Quil A, isolated from Quillaja saponaria, and its component QS-21 (Figure 1), which invokes a long-lasting antibody and CD8 ${ }^{+}$

[a] Dr. B. W. Greatrex, Dr. A. M. Daines, Dr. D. H. Lenz, Dr. P. M. Rendle

Ferrier Research Institute, Victoria University of Wellington

Gracefield Rd, Lower Hutt 5010 (New Zealand)

E-mail: phillip.rendle@vuw.ac.nz

[b] Dr. B. W. Greatrex

School of Science \& Technology, University of New England Armidale, NSW 2351 (Australia)

[c] Dr. S. Hook, Dr. W. McBurney, Prof. T. Rades School of Pharmacy, University of Otago, Dunedin 9016 (New Zealand)

$\left.{ }^{* *}\right]$ This article is part of the Virtual Special Issue "Carbohydrates in the 21st Century: Synthesis and Applications".

$\square$ Supporting information and ORCIDs from the authors for this article are

(i) available on the WWW under http://dx.doi.org/10.1002/open.201500149.

of ( 2015 The Authors. Published by Wiley-VCH Verlag GmbH \& Co. KGaA. This is an open access article under the terms of the Creative Commons Attribution-NonCommercial-NoDerivs License, which permits use and distribution in any medium, provided the original work is properly cited, the use is non-commercial and no modifications or adaptations are made.

cellular response when given in combination with subunit antigens. ${ }^{[3]}$ Quil A and QS-21 have haemolytic toxicity, however safety is improved and toxicity is nearly absent when QS-21 is incorporated into formulations containing cholesterol and phospholipids, giving nanoparticles known as Immune Stimulating Complexes (ISCOMSTM). ${ }^{[4]}$ These are $40 \mathrm{~nm}$ icosahedral cage-like particles shown in the electron micrograph in Figure $1 .^{[5]}$ The ISCOM cage is proposed to consist of ring-like micelles which further aggregate through hydrogen bonding and hydrophobic interactions. ${ }^{[6]}$

Mixtures of saponin, phospholipid, and cholesterol can form an array of colloidal structures appearing by electron microscopy as helices, worms, lamellar sheets, and ISCOMs. The types of nanostructures formed in these colloids are dependent on concentrations and ratios of the components, the method of formulation, as well as the structure of the saponin. ${ }^{[7]}$ The size and hydrophobicity of the particle allows multiple copies of hydrophobic and amphipathic antigens to associate with each ISCOM particle. There is still a lack of understanding of how the structure of the saponin affects nanostructures formed in solution and how the nanostructure is correlated with activity or toxicity in vaccine formulations.

Most studies on saponins involve natural products; however, a number of reports from the groups of Schmidt ${ }^{[8]}$ and Plée ${ }^{[9]}$ have described the synthesis of oleanolane saponins. ${ }^{[10]}$ Furthermore, while diverse bioactivities of saponins are known, most studies have focused on cytotoxic and haemolytic activity and not on formulation properties. ${ }^{[11]}$ We have previously described the synthesis of a series of mannose-based oleanolane 

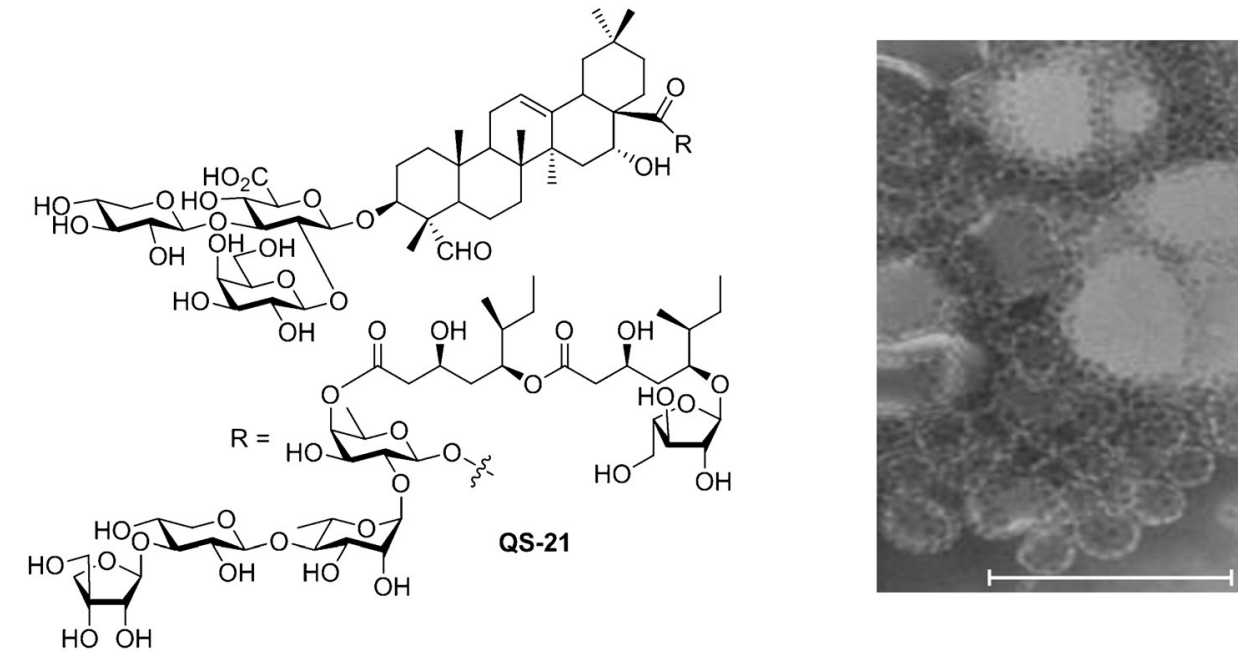

Figure 1. The saponin adjuvant QS-21 and a transmission electron micrograph of ISCOM particles formed from a $20 \%$ formulation of cholesterol, phospholipid, and Quil A (which contains QS-21). Scale bar $=200 \mathrm{~nm}$. trated hydrochloric acid and heating to reflux which gave a precipitate of triterpenes containing predominantly hederagenin $\left(\sim 15 \mathrm{~g} \mathrm{~kg}^{-1}\right.$ wet weight). The triterpenes were collected, dried, and subjected to alkylation with allyl bromide. The resulting crude mixture contained the hederagenin allyl ester $\mathbf{2}$. Following purification of $\mathbf{2}$ by flash chromatography, which removed other oleanolane type triterpenes, the primary alcohol in $\mathbf{2}$ was selectively benzoylated by reaction with pyridine/benzoyl chloride according to the procedure of Plé affording $3 .{ }^{[17]}$ The selective oxidation of hederage- saponins and have studied the nanostructures formed when these are formulated with cholesterol and phospholipid. ${ }^{[12]}$ Mannose is not normally present in saponins, and we hoped to target lectins that recognize this saccharide and are present on dendritic cells. We found that only the monodesmosidic saponins we synthesized formed ring-like micelles in the presence of cholesterol and phosphatidylcholine, and that these ring-like micelles did not further aggregate into ISCOM-like particles. In this current work we have modified the sugar structure, stereochemistry, the C-28 substitution, as well as the triterpene oxidation pattern. The aim of this current work was to improve adjuvant activity and study the effects of molecular structure on nanostructures formed in formulation. We now detail the synthesis, formulation, and bioactivity of these novel constructs and relate chemical structure to the types of nanostructures formed.

\section{Results and Discussion}

\section{Synthesis of the saponins}

The quillaic acid triterpene in the adjuvant QS-21 has a C-23 aldehyde group found in few naturally occurring saponins. This aldehyde was thought to be required for the activity of the Quillaja-derived saponins as its reduction leads to a decrease in the adjuvant activity of the saponin fraction. ${ }^{[13]}$ Gin et al. have, however, recently reported QS-21 derivatives lacking this aldehyde with significant biological activity. ${ }^{[14]}$ Hederagenin (1) and gypsogenin (4 in Scheme 1 where $\mathrm{R}^{1}=\mathrm{H}$ ) are both oxidized at C-23, and 1 is readily available from Hedera helix. We chose this series of triterpenes to approximate the structure of quillaic acid supported by the knowledge that some gypsogenin-based saponins also have immunostimulatory activity. ${ }^{[15]}$

Adapting a procedure from Haynes et al., ${ }^{[16]}$ hot water extraction of Hedera helix (English ivy) leaves and stems gave an aqueous solution of saponins (Scheme 1). Hydrolysis of the saponins was achieved by acidifying the solution with concen-

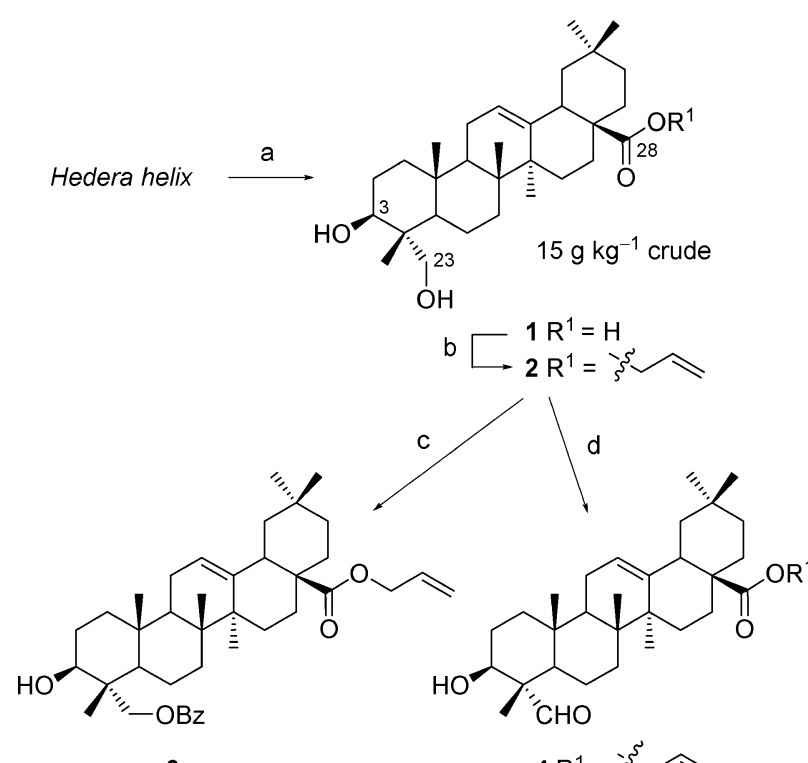

Scheme 1. The preparation of glycosylation acceptors 3 and 4 . Reagents and conditions: a) $\mathrm{H}_{2} \mathrm{O}$, then $1 \mathrm{~N} \mathrm{HCl}, 3 \mathrm{~h}$, reflux; b) allyl bromide, $\mathrm{K}_{2} \mathrm{CO}_{3}, 2 \mathrm{~h}$, $60^{\circ} \mathrm{C}, 39 \%$; c) $\mathrm{BzCl}$, pyridine, $75 \%$; d) TEMPO, BAIB, $\mathrm{CH}_{2} \mathrm{Cl}_{2}, 16 \mathrm{~h}, \mathrm{rt}, 68 \%$.

nin allyl ester 2 to gypsogenin allyl ester 4 using 2,2,6,6-tetramethylpiperidin-1-yl)oxyl (TEMPO)/bis(acetoxy)iodobenzene ${ }^{[18]}$ proceeded in excellent yield providing us with a ready supply of protected hederagenin $\mathbf{3}$ and gypsogenin $\mathbf{4}$ as acceptors for glycosylation. This procedure avoided crystallization of the hederagenin from the solid produced from the acid-catalyzed sugar hydrolysis, which in our hands led to significant loss of hederagenin in the filtrate. Previously synthesized oleanolic acid based acceptor $19^{[12]}$ was also included as a glycosylation acceptor.

A common structural feature of naturally occurring saponins is a $\beta$-glucopyranosyl or $\beta$-glucopyranuronyl residue at the $\mathrm{C}-3$ hydroxyl group of the triterpene. This $\beta$-configuration is con- 
served in many saponin adjuvants even when other sugars are present at this position as in the jujubosides and CP05. ${ }^{[19]}$ For ease of synthesis, our previously prepared mannose-containing saponins were $\alpha$-configured at the attachment to the oxygen at C-3. It seemed wise to modify the anomeric stereochemistry at this primary carbohydrate position in our quest for adjuvant activity. Incorporation of a glucose moiety with participating protection at the C2 hydroxyl was the most straightforward way to achieve this, and so the synthesis of Manp- $(1 \rightarrow 3)-G l c p$ trichloroacetimidate donor 9 was undertaken. Thus, commercially available 1,2:5,6-di-O-isopropylidene- $\alpha$-D-glucofuranose (6) was glycosylated with mannose-derived trichloroacetimidate donor $\mathbf{5}^{[20]}$ affording known disaccharide $7^{[21]}$ in excellent yield (Scheme 2). The isopropylidene protecting groups of 7 were removed and the free sugar peracylated with acetic anhydride to give the pyranose $\mathbf{8}$ in moderate yield. The pyranose was selectively deacetylated at the anomeric position and then the mixture of anomers converted to the $\alpha$-trichloroacetimidate donor 9 .

To examine the importance of the nature of the sugar at the 3 -position of the glucose moiety, replacements for the mannose unit were also examined. Both $\beta$-D-xylopyranosyl and $\beta$ D-galactopyranosyl residues are found on QS-21 and this seemed a rational substitution for the $\alpha$-D-mannopyranosyl unit. Adapting the procedure as described above for the synthesis of $\mathbf{8}$, glycosylation of diisopropylidine-D-glucose 6 with tetra-O-benzoyl- $\alpha$-D-galactopyranosyl trichloroacetimidate $(10)^{[22]}$ yielded the disaccharide 11 (Scheme 2). Formation of the $\beta$-galactosyl linkage in $\mathbf{1 1}$ was evident from the measured ${ }^{1} \mathrm{H}$ NMR $J_{\mathrm{H} 1-\mathrm{H} 2} 8.0 \mathrm{~Hz}$ coupling constant. There are some inconsistencies in the literature regarding spectroscopic data for disaccharide $11 .{ }^{[23]}$ Our data matched that initially reported by
Crich and Smith. ${ }^{[23 a]}$ Acid-promoted hydrolysis of the acetonide protecting groups in $\mathbf{1 1}$ followed by acetylation afforded glucopyranose derivative 12. Anomeric deacetylation using hydrazinium acetate (caution: carcinogenic) to give 13 and conversion to the sugar donor, trichloroacetimidate 14 went in excellent yield. Likewise, the reaction of 6 with tri-O-benzoyl- $\alpha-D-x y-$ lopyranosyl trichloroacetimidate (15) ${ }^{[24]}$ afforded the expected disaccharide 16. $\beta$-Xylopyranoside 16 existed primarily in the all axial conformation due to the presence of the electronwithdrawing benzoyl protecting groups as evidenced by the small $J_{\mathrm{H} 1-\mathrm{H} 2} 3.7 \mathrm{~Hz}$ coupling constant. The sequence for the preparation of the sugar donor was repeated with the disaccharide 16 being carried through to 1-deacylated pyranose 17 and trichloroacetimidate $\mathbf{1 8}$ in acceptable yield.

The results for the glycosylation of the three triterpenoid derived acceptors 3, 4, and 19 with mannose donor 9 are shown in Scheme 3. In the case of hederagenin derivative $\mathbf{3}$, the reaction proceeded well affording the desired glycoside 20 in $77 \%$ yield with no evidence of migration of the 2-acyl group of the donor to acceptor, a known problem when using 2-acetyl protected glycosyl donors with hindered acceptors. ${ }^{[25]}$ From the ${ }^{1} \mathrm{H}$ NMR spectra, the presence of a $\beta$-glycosidic linkage could be inferred due to the large $J_{\mathrm{H} 1-\mathrm{H} 2}$ coupling of $8 \mathrm{~Hz}$. This material was deallylated using catalytic $\mathrm{Pd}^{0}\left(\mathrm{PPh}_{3}\right)_{4}$ and then in the one pot, deacylated under Zemplén conditions ${ }^{[26]}$ giving monodesmoside $\mathbf{2 4}$ which was isolated using silica gel chromatography in excellent yield. To generate structural diversity, the allyl ester $\mathbf{2 5}$ was also prepared by treating glycoside $\mathbf{2 0}$ with catalytic methoxide followed by hydroxide to ensure the removal of all benzoyl groups. There was no evidence of any trans-esterification or hydrolysis involving the allyl ester moiety under these conditions.
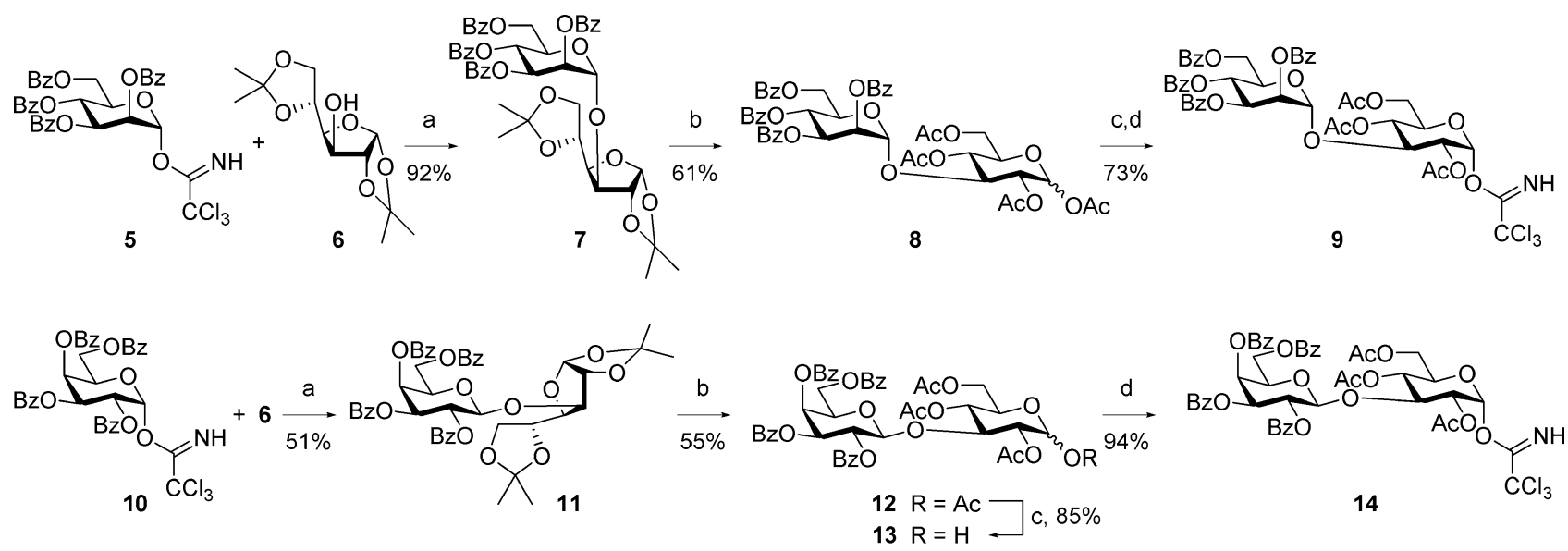

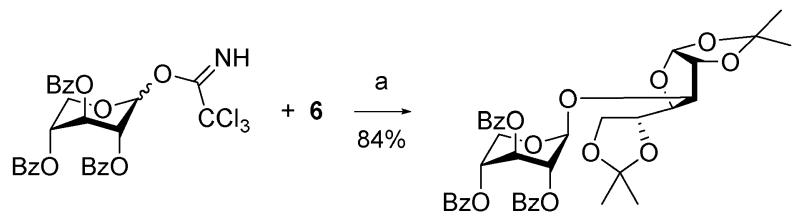

15

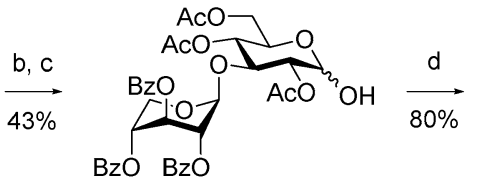

17

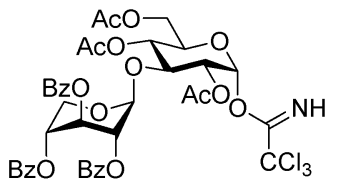

18

Scheme 2. Preparation of sugar donors 9, 14 and 18. Reagents and conditions: a) TMSOTf, $4 \AA$ mol. sieves; b) i) 9:1 TFA/ $\mathrm{H}_{2} \mathrm{O}, \mathrm{ii)}$ pyridine/Ac $\mathrm{O}_{2}$; c) $\mathrm{NH}_{2} \mathrm{NH}_{2} . \mathrm{AcOH}$ DMF; d) $\mathrm{DBU}, \mathrm{CCl}_{3} \mathrm{CN}, \mathrm{CH}_{2} \mathrm{Cl}_{2}$. Specific reaction temperatures and times can be found in the Experimental Section. 


$$
\begin{aligned}
& \text { (1) } \\
& 3 \mathrm{R}^{1}=\mathrm{CH}_{2} \mathrm{OBz} \quad \text { a } \quad 20 \mathrm{R}^{1}=\mathrm{CH}_{2} \mathrm{OBz}, \mathrm{R}^{2}=\mathrm{Ac} \quad 77 \% \\
& 4 \mathrm{R}^{1}=\mathrm{CHO} \quad \stackrel{\mathrm{a}}{\longrightarrow} \quad 21 \mathrm{R}^{1}=\mathrm{CHO}, \mathrm{R}^{2}=\mathrm{Ac} \quad 32 \% \\
& 22 R^{1}=M e, R^{2}=A c+23 R^{1}=M e, R^{2}=H, \\
& (22 / 23,5: 3) \quad 81 \% \\
& 20 \mathrm{R}^{1}=\mathrm{CH}_{2} \mathrm{OBz}, \mathrm{R}^{2}=\mathrm{Ac}
\end{aligned}
$$

Scheme 3. Preparation of saponins 24-27. Reagents and conditions: a) TMSOTf, $4 \AA$ mol. sieves, $\left.\mathrm{CH}_{2} \mathrm{Cl}_{2}, \mathbf{9} ; \mathrm{b}\right) \mathrm{Pd}^{0}\left(\mathrm{PPh}_{3}\right)_{4}, \mathrm{CH}_{2} \mathrm{Cl}_{2} / \mathrm{MeOH}$ c) $\mathrm{NaOMe} / \mathrm{MeOH}_{\text {; }}$ d) $\mathrm{NaOMe}$ then $\mathrm{NaOH} / \mathrm{MeOH} / \mathrm{CH}_{2} \mathrm{Cl}_{2}$. Specific reaction temperatures and times can be found in the Experimental Section.

The reaction of donor 9 with gypsogenin-derived acceptor 4 promoted by trimethylsilyl triflate proceeded in a modest yield of $32 \%$, generating sufficient quantities of $\mathbf{2 1}$ for further elaboration. Glycosylation of oleanolane type triterpenes containing a C-23 aldehyde functional group typically proceeds with poor yield and can require special conditions including nonstandard promoters. In their total synthesis of QS-21, Gin et al. report the use of tris(pentafluorophenyl)borane as Lewis acid combined with a uronyl trichloroacetimidate donor to give the glycoside in good yield. ${ }^{[27]}$ The one-pot removal of allyl ester and acyl protecting groups from $\mathbf{2 1}$ afforded aldehyde containing saponin 26 free from impurities following chromatography in excellent yield. The NMR spectra showed a ${ }^{1} \mathrm{H}$ singlet at $9.38 \mathrm{ppm}$ and $\mathrm{a}{ }^{13} \mathrm{C}$ resonance at $206 \mathrm{ppm}$ consistent with the aldehyde group.

The glycosylation of allyl oleanolate 19 using donor 9 promoted some 2-acyl transfer from donor 9 to acceptor 19 yielding a mixture of desired product 22 and 2-O-deacylated product 23. The 2-deacylated product 23 had only two acetyl groups in the ${ }^{1} \mathrm{H}$ NMR and a molecular ion consistent with the proposed structure. The correct number of anomeric carbons in the ${ }^{13} \mathrm{C}$ NMR ruled out the formation of orthoester and an equivalent amount of acetylated acceptor, namely allyl 3-Oacetyloleanolate was present in the crude reaction mixtures. The mixture of products $\mathbf{2 2}$ and $\mathbf{2 3}$, although separable using chromatography, was subjected without separation to the $\mathrm{Pd}^{0}$ catalyzed deallylation $^{[28]}$ and methanolysis, the mixture giving monodesmonide $\mathbf{2 7}$ in excellent yield.

To examine the contribution of the carboxylic acid to formulation structures observed, the acids in $\mathbf{2 4}$ and $\mathbf{2 7}$ were esterified with a variety of groups (Scheme 4). Alkyl esters 28 and 29 were synthesized as we hoped the addition of lipidic nature at this end of the molecule might promote further aggregation of any colloidal particles into higher order ISCOMlike structures. Undecyl esters $\mathbf{2 8}$ and $\mathbf{2 9}$ were synthesized by alkylating the free acid $\mathbf{2 4}$ and $\mathbf{2 7}$ with undecyl bromide. Ethylamino esters 30-32 were also of interest as these would be cationic under the buffered conditions used to examine saponin/lipid formulations and thus would not interact with the phosphatidylcholine lipid film in the same way as monodesmo-

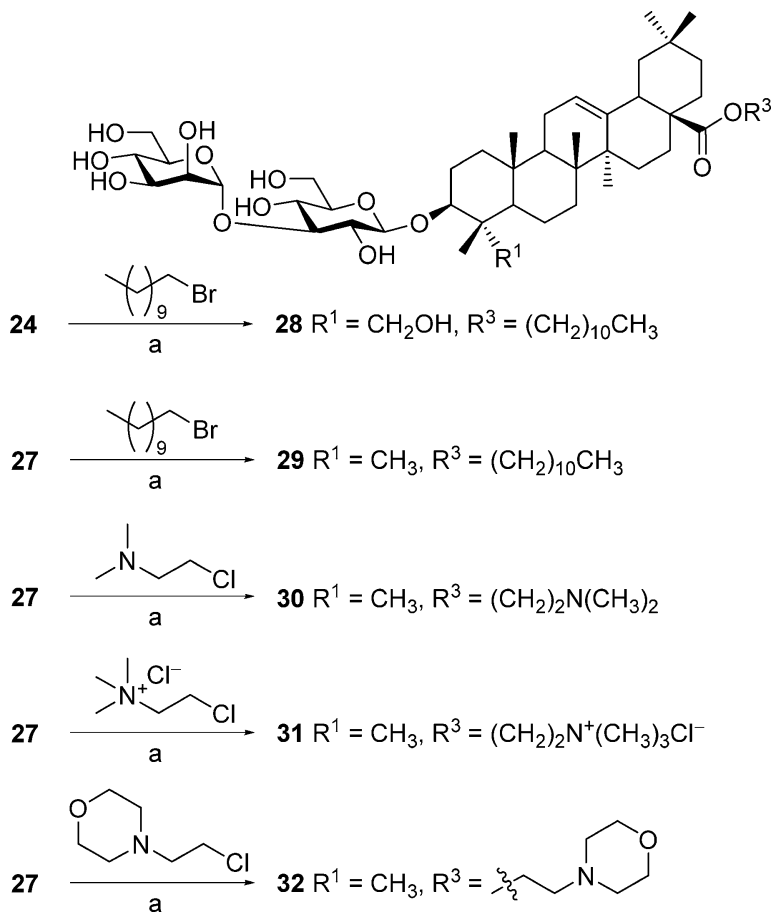

Scheme 4. Alkylation of the C-28 acid in $\mathbf{2 4}$ and 27. Reagents and conditions: a) $\mathrm{K}_{2} \mathrm{CO}_{3}, \mathrm{DMF}, 28: 72 \%, 29: 66 \%, 30: 71 \%, 31: 48 \%, 32: 79 \%$. Specific reaction temperatures and times can be found in the Experimental Section.

sidic saponins which are anionic. Alkylation of the carboxylate in 27 using the secondary amines and ammonium alkyl halides afforded the three esters $\mathbf{3 0}, \mathbf{3 1}$ and $\mathbf{3 2}$ respectively, the products being isolated by preparative reverse-phase highperformance liquid chromatography (RP-HPLC) or normalphase flash chromatography.

To eventually test whether mannose was required for bioactivity in these saponin constructs, hederagenin-based acceptor 3 was glycosylated with either a terminal Galp 14 or Xylp 18 moiety (Scheme 5). The reaction of Galp-containing donor 14 with acceptor $\mathbf{3}$ afforded the expected glycoside $\mathbf{3 3}$ in moderate yield. Some 2-deacylated product $\mathbf{3 4}$ was isolated clean by 

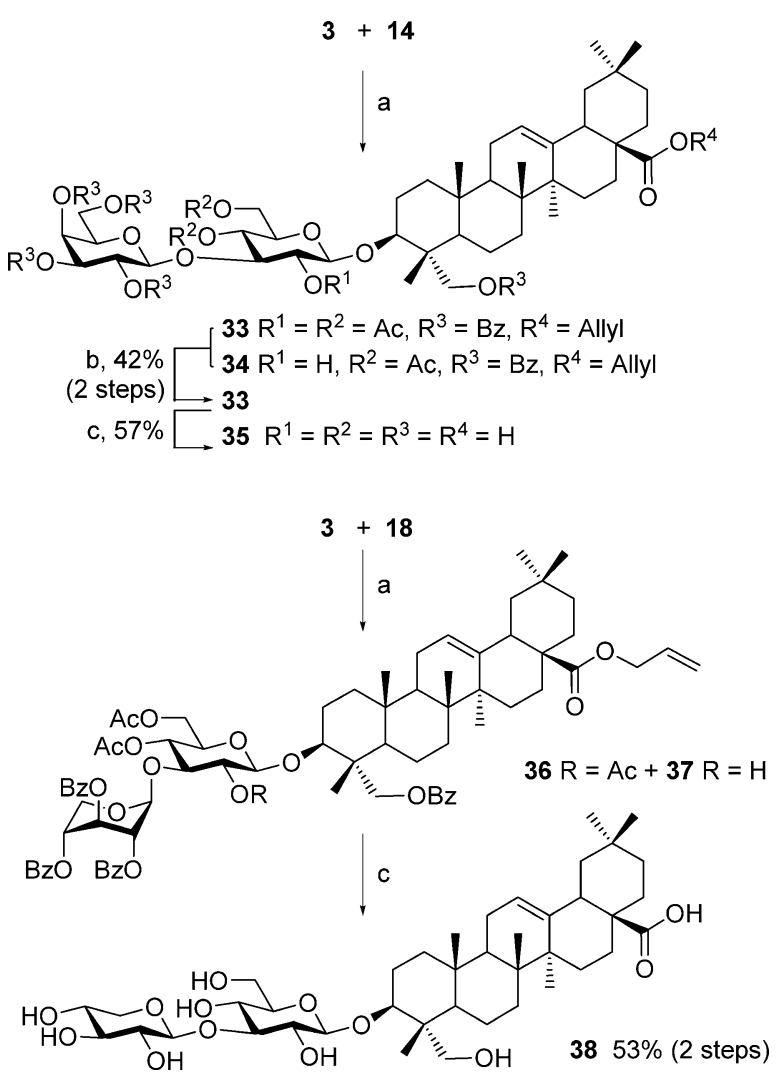

Scheme 5. Preparation of saponins 35 and 38. Reagents and conditions: a) TMSOTf, $4 \AA$ mol. sieves, $\mathrm{CH}_{2} \mathrm{Cl}_{2}$; b) $\mathrm{Ac}_{2} \mathrm{O}$, DMAP, pyridine; c) $\mathrm{Pd}^{0}\left(\mathrm{PPh}_{3}\right)_{4}$ $\mathrm{CH}_{2} \mathrm{Cl}_{2} / \mathrm{MeOH}$ then $\mathrm{NaOMe} / \mathrm{MeOH}$. Specific reaction temperatures and times can be found in the Experimental Section.

chromatography from the reaction mixture following chromatography. This by-product also contaminated some fractions of 33 along with another unidentified impurity in trace amounts. For ease of characterization, the mixture of $33 / 34$ was subjected to acetylation conditions to reacetylate 34 . This treatment also removed the unidentified impurity affording pure 33 following a second round of chromatography. Deprotection of 33 afforded the Galp-(1 $\rightarrow 3)$-Glcp saponin 35 which was purified by flash chromatography and finally by RP-HPLC in moderate yield. Likewise, the Xylp-containing donor $\mathbf{1 8}$ when allowed to react with acceptor $\mathbf{3}$ afforded a mixture of desired glycoside 36 and 2-deacetylated glycoside $\mathbf{3 7}$ which was then deprotected to give $\mathbf{3 8}$ in good yield for the two steps.

Once all acyl groups were removed, the Xylp ring adopted the conformation with all hydroxyl groups equatorial with both $J_{\mathrm{H} 1-\mathrm{H} 2}$ couplings $(7.4$ and $7.8 \mathrm{~Hz})$ in the expected range for $\beta$-pyranosides. To include branched sugars in the library, peracylated trisaccharide $\mathbf{3 9}$ was prepared according to a literature procedure. ${ }^{[29]}$ Trisaccharide 39 was converted to the bromide 40 under standard conditions which was then allowed to react with acceptor $\mathbf{3}$ promoted by silver trifluoromethanesulfonate affording the expected glycoside $\mathbf{4 1}$ in poor yield but in sufficient quantity for further elaboration (Scheme 6). Deprotection using conditions for the in situ generation of $\mathrm{Pd}^{0}$ followed by basic deprotection afforded trisaccharide $\mathbf{4 2}$ in moderate yield.
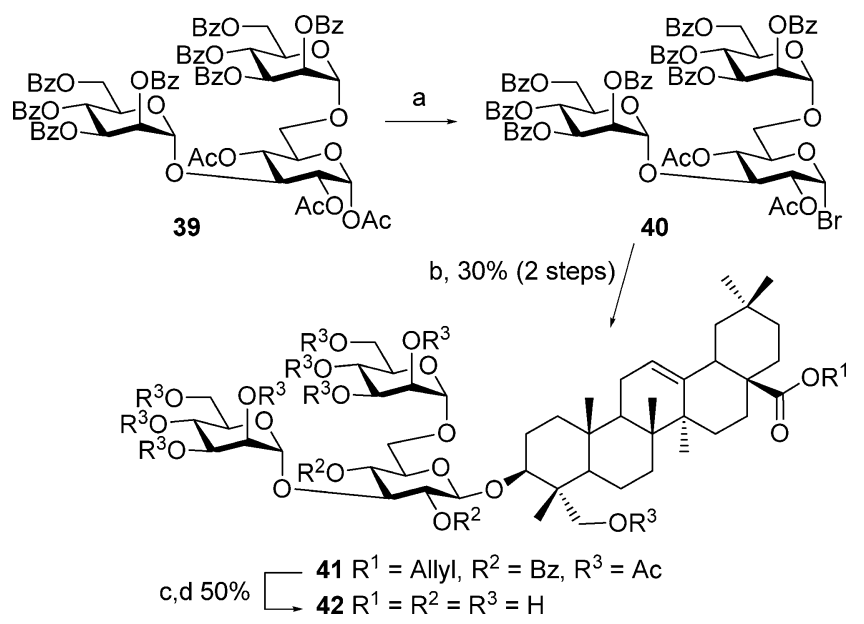

Scheme 6. Preparation of trisaccharide 42. Reagents and conditions: a) $\mathrm{HBr}$ / $\mathrm{AcOH}$; b) 3, AgOTf, $4 \AA$ mol. sieves, $\mathrm{CH}_{2} \mathrm{Cl}_{2}$; c) $\mathrm{Pd}(\mathrm{OAc})_{2}, \mathrm{PPh}_{3}, \mathrm{HCO}_{2} \mathrm{H}, \mathrm{NEt}_{3}$, 1,4-dioxane; d) $\mathrm{NaOMe} / \mathrm{MeOH}$. Specific reaction temperatures and times can be found in the Experimental Section.

\section{Formulation studies}

In order to study the effects of molecular structure on the nanostructures formed, the synthetic saponins were formulated with 3:1 phosphatidylcholine/cholesterol and visualized using transmission electron microscopy (TEM). The results of the study are shown in Table 1, and examples of the TEM images are found in Figure 2 (see Supporting Information for all images). The monodesmosidic saponins 24, 26, 27, 35, 38, and $\mathbf{4 2}$ formed ring-like micelles to different extents. Using 24 as an example, the glycoside formed ring-like micelles which were associated with the liposomes but were also seen free in solution (Figure $2 \mathrm{a}$ ). These ring-like micelles did not further aggregate into the larger regular structures seen in formulations of Quil A.

The presence of cholesterol and phospholipid was required for the formation of these structures which were not seen in solutions of pure saponin, indicating an interaction between the formulation components and the saponin.

The effect of attaching an aliphatic group to the C-28 carboxylic acid can be seen by comparing the structures formed from 24 with those from 25, 28, and 29. The attachment of a long undecyl alkyl chain in $\mathbf{2 8}$ decreased the regularity of the ring-like micelles, and elongated pores were observed (Figure $2 \mathrm{~b}$ ). This could be due to disruption of the saponin/cholesterol or saponin/saponin packing. Interestingly, the ring-like micelles from the oleanolane derivative $\mathbf{2 9}$ were not disrupted to the same extent, the compounds differing by a single $\mathrm{OH}$ group on the aglycone. Minimal ring-like micelles and small lipidic particles were observed with the allyl ester $\mathbf{2 5}$ demonstrating that the length of the alkyl chain is important in mediating these effects.

The addition of a cationic group had a significant effect on the interactions between the saponin and the liposomal formulation. The dimethylamino $\mathbf{3 0}$ and morpholino derivative 32, which are both predominantly protonated at the $\mathrm{pH}$ studied, formed rod-like regular structures on their own and in the 


\begin{tabular}{|c|c|c|c|c|c|c|}
\hline \multirow[t]{3}{*}{ Saponin } & \multirow{3}{*}{$\begin{array}{l}\text { Formulation }^{[a]} \\
\text { [\% saponin] }\end{array}$} & \multirow[t]{3}{*}{ Observed structures } & \multicolumn{4}{|c|}{ BMDC activation ${ }^{[b]}$} \\
\hline & & & \multicolumn{2}{|c|}{ MHC class II } & \multicolumn{2}{|c|}{ CD86 } \\
\hline & & & $1.0 \mu \mathrm{g}$ & $10 \mu \mathrm{g}$ & $1.0 \mu \mathrm{g}$ & $10 \mu \mathrm{g}$ \\
\hline \multirow[t]{2}{*}{24} & $50 \%$ & $\begin{array}{l}\text { Abundant isolated and liposome-associated ring-like } \\
\text { micelles }\end{array}$ & - & - & - & - \\
\hline & $100 \%$ & Worm-like micelles & $<10 \%$ & $+88 \%$ & $<10 \%$ & $+88 \%$ \\
\hline \multirow[t]{3}{*}{25} & $10 \%$ & Scant ring-like micelles associated with liposomes & - & - & - & - \\
\hline & $50 \%$ & Small lipidic particles and liposomes & - & - & - & - \\
\hline & $100 \%$ & $\mathrm{NE}^{[\mathrm{c}]}$ & $<66 \%$ & $+88 \%$ & $<10 \%$ & $<10 \%$ \\
\hline \multirow[t]{2}{*}{26} & $20 \%$ & $\begin{array}{l}\text { Disorganized ring-like micelles associated with } \\
\text { liposomes }\end{array}$ & $<10 \%$ & $+50 \%$ & $<10 \%$ & $+56 \%$ \\
\hline & $100 \%$ & Micellar structure & $<10 \%$ & $<10 \%$ & $<10 \%$ & $<10 \%$ \\
\hline \multirow[t]{2}{*}{27} & $70 \%$ & $\begin{array}{l}\text { Ring-like micelles associated with liposomes and } \\
25 \mathrm{~nm} \times>400 \mathrm{~nm} \text { tubular structures }\end{array}$ & - & - & - & - \\
\hline & $100 \%$ & Irregular micellar structures & $<10 \%$ & $-50 \%$ & $<10 \%$ & $-57 \%$ \\
\hline \multirow[t]{2}{*}{30} & $10 \%$ & $40 \mathrm{~nm} \times 400 \mathrm{~nm}$ rods and liposomes & - & - & - & - \\
\hline & $70 \%$ & $40 \mathrm{~nm} \times 400 \mathrm{~nm}$ rods & - & - & - & - \\
\hline \multirow[t]{2}{*}{31} & $50 \%$ & Liposomes and helical needles $10 \mathrm{~nm} \times 200 \mathrm{~nm}$ & - & - & - & - \\
\hline & $100 \%$ & Helical needles $10 \mathrm{~nm} \times 200 \mathrm{~nm}$ & $<10 \%$ & $<10 \%$ & $<10 \%$ & $<10 \%$ \\
\hline \multirow[t]{2}{*}{32} & $50 \%$ & Liposomal interactions but no ring-like micelles & - & - & - & - \\
\hline & $100 \%$ & $70 \mathrm{~nm} \times>1 \mu \mathrm{m}$ rods & $<10 \%$ & $<10 \%$ & $<10 \%$ & $<10 \%$ \\
\hline \multirow[t]{2}{*}{29} & $10 \%$ & Liposomes only & - & - & - & - \\
\hline & $70 \%$ & Ring-like micelles associated with liposomes & $<10 \%$ & $<10 \%$ & $<10 \%$ & $<10 \%$ \\
\hline \multirow[t]{2}{*}{28} & $10 \%$ & Liposomes only & - & - & - & - \\
\hline & $70 \%$ & $\begin{array}{l}\text { Distorted and elongated ring-like micelles associated } \\
\text { with liposomes }\end{array}$ & - & - & - & - \\
\hline \multirow[t]{2}{*}{35} & $50 \%$ & $\begin{array}{l}\text { Liposomes associated with variably sized disorgan- } \\
\text { ized ring-like micelles }\end{array}$ & $<10 \%$ & $+71 \%$ & $<10 \%$ & $+47 \%$ \\
\hline & $100 \%$ & Worm-like micelles & $<10 \%$ & $<10 \%$ & $<10 \%$ & $<10 \%$ \\
\hline \multirow[t]{2}{*}{38} & $50 \%$ & Disorganized aggregates of ring like micelles & - & - & - & - \\
\hline & $100 \%$ & $\mathrm{NE}^{[c]}$ & $<10 \%$ & $+23 \%$ & $<10 \%$ & $<10 \%$ \\
\hline 42 & $20 \%$ & $\begin{array}{l}\text { Ring-like micelles associated with liposomes, no } \\
\text { aggregation into ISCOMs after } 1 \text { month }\end{array}$ & $<10 \%$ & $<10 \%$ & $<10 \%$ & $<10 \%$ \\
\hline \multirow[t]{2}{*}{ Quil-A } & $20 \%$ & ISCOM icosahedral particles budding from liposomes & - & - & - & - \\
\hline & $100 \%$ & Worm-like micelles & $33 \%$ & $-47 \%$ & $50 \%$ & $-82 \%$ \\
\hline
\end{tabular}

[a] Using the hydration method with the $\mathrm{PC} /$ cholesterol ratio set at 3:1. [b] Murine bone marrow dendritic cell (BMDC) activation expressed as the percentage change in cells gated. Not all formulations were examined. [c] $\mathrm{NE}=$ not examined.
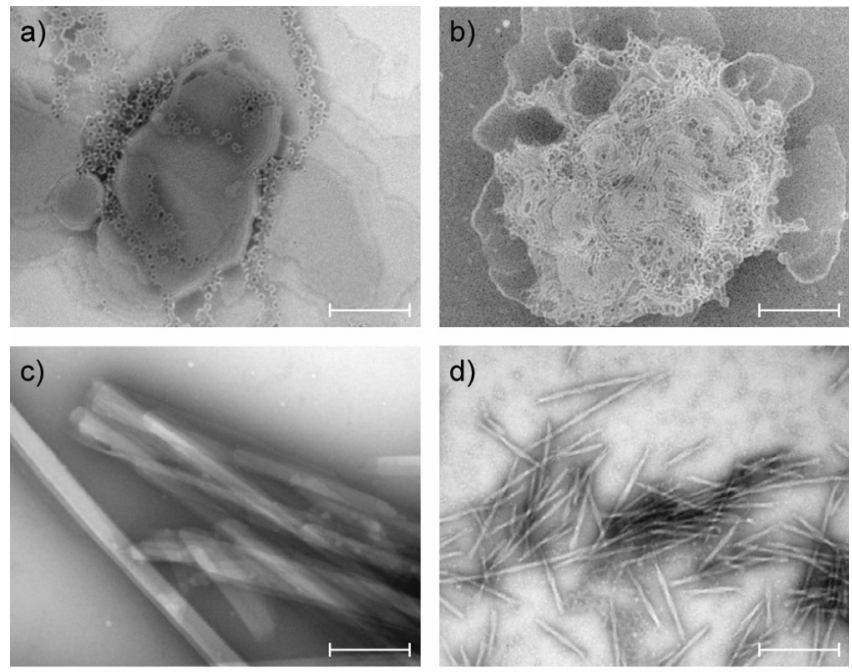

Figure 2. Selection of TEM images formed from saponins, cholesterol, and phospholipid. a) Ring-like micelles observed in formulations of 24. b) Distorted elongated ring-like micelles in formulations of 28. c) Nanocrystalline rods seen in solutions of 32. d) Helical micelles observed in formulations of $\mathbf{3 1}$. Scale bar $=200 \mathrm{~nm}$. presence of the lipid mixture (Figure 2c). Choline ester 31 with a permanent charge selfassociated into smaller regularly sized helical micelles at all concentrations of saponin, and no ring-like micelles were observed. The helices formed from solutions of $\mathbf{3 1}$ in the absence of liposome had a twisted plane morphology with a pitch distance of $65 \mathrm{~nm}$ (Figure 2d). Helical micelles are often seen as components in mixtures of Quil- $A$, cholesterol, and phospholipid but exhibit a strikingly different morphology and small worm-like micelles are observed in neat Quil A. The polycationic charge associated with aggregates of 30-32 may be important in mediating their self-association behavior.

We observed that self-association of the cationic saponins $\mathbf{3 0}$ 32 was more favorable than interaction with the liposomal mixture at all concentrations examined. These saponins may lack the favorable electrostatic interactions that are present between the C-28 carboxylate and the phosphatidylcholine in the lipid mixture. The results indicate that even small changes to the functionality of the C-28 position can affect the selfassociation of saponins and may help to explain the importance of the complex chains in Quillaja saponins.

Heerklotz et al. ${ }^{[30]}$ have proposed that saponins as a class work heterogeneously, creating local areas of high concentration in the lipid bilayer which disrupts its integrity. The incorporation of saponin into the planar topology of a liposome or lipid bilayer can create a locally curved surface resulting in thinning of the hydrophobic core of the membrane which implies that saponins self-associate within the membrane. By comparison with the esters, the interaction of Quil-A as well as the monodesmosidic C-28 acids 24, 26, 27, 35, 38, and 42 with liposomal formulations was more favorable than self-association based upon the nanostructures observed. Self-association of the $\mathrm{C}-28$ acids probably still occurs within the liposome giving the saponin rich regions which form ring-like micelles.

\section{Adjuvanticity of selected saponins}

After investigating the formulation behavior of the synthetic saponins, the ability of some of the formulations to elicit dendritic cell maturation was examined by assessing MHC class II 
and CD86 upregulation by flow cytometry in murine bone marrow derived dendritic cells (BMDC) (Table 1). Neat saponin as well as mixtures of saponin in phosphatidylcholine/cholesterol were analyzed for obvious trends. An increase in the expression of these markers indicates adjuvant activity while a decrease is associated with toxicity. Quil A promotes BMDC activation at low concentrations while, as expected, toxicity is seen at higher concentrations.

The most active synthetic compound was monodesmoside 24 which also formed abundant ring-like micelles in solution and promoted a significant upregulation of both MHC class II and CD86 activation markers at high concentration. Incorporation of the C-23 aldehyde group in the gypsogenin derivative 26 did not improve immunostimulatory activity. The activity of galactosyl derivative $\mathbf{3 5}$ also caused BMDC activation indicating that mannose was not required for activity in $\mathbf{2 4}$. Saponins 31 and $\mathbf{3 2}$ which primarily-self associate had no activity in the BMDC assay, and only some of the other monodesmosidic saponins that formed ring-like micelles exhibited activity. The stereochemistry of the carbohydrate incorporated at the C-3 alcohol is therefore important, and the activity these compounds possess is probably not due to a nonspecific detergency.

The ability of saponin $\mathbf{2 4}$ to elicit specific CD8 + cells against OVA (ovalbumin, albumin from chicken egg white) was also evaluated in an in vivo model. Mice were vaccinated with OVA and one of $\mathbf{2 4}$ in PBS, 24 in Freund's incomplete adjuvant system, 31 in PBS, Freund's incomplete adjuvant, or ISCOMs formed from Quil-A. We chose to evaluate saponin 31 in this assay as well due to the interesting behavior of this saponin in formulation. The lymph nodes and spleens were harvested and the expansion of OVA-specific T-cells was measured by flow cytometry. Saponin 24 in incomplete Freund's system demonstrated CD8 + responses similar to those of the Quil A ISCOMtreated group, in the context of the local draining lymph node response (Figure 3). This was not associated with enhanced responses systemically, as the vaccine did not elicit strong splenic responses (data not shown). In the absence of formulation, 24 did not enhance the CD8 + cellular response. Saponin $\mathbf{2 4}$ in PBS appeared to stimulate a modest expansion of antigen specific CD4+T cells. As incomplete Freund's system on its own also stimulated a CD4 + expansion, it was not possible to determine if inclusion of saponin $\mathbf{2 4}$ had any beneficial effect. The self-associating choline derivative $\mathbf{3 1}$ did not stimulate measureable CD4 or CD8 responses.

\section{Conclusions}

We have developed a routine extraction of hederagenin from Hedera helix and used the hederagenin and oleanolic acid to synthesize a range of QS-21 mimics containing two or three sugar moieties. The synthetic methods described could be used in the preparation of similar triterpenoid saponins for biological studies. We have studied the saponins in formulation with phospholipid and cholesterol and analyzed the structures by cryo-TEM. One of the saponins was found to produce numerous ring-like micelles in the phospholipid/cholesterol formulation and so the saponin was further elaborated by esteri-
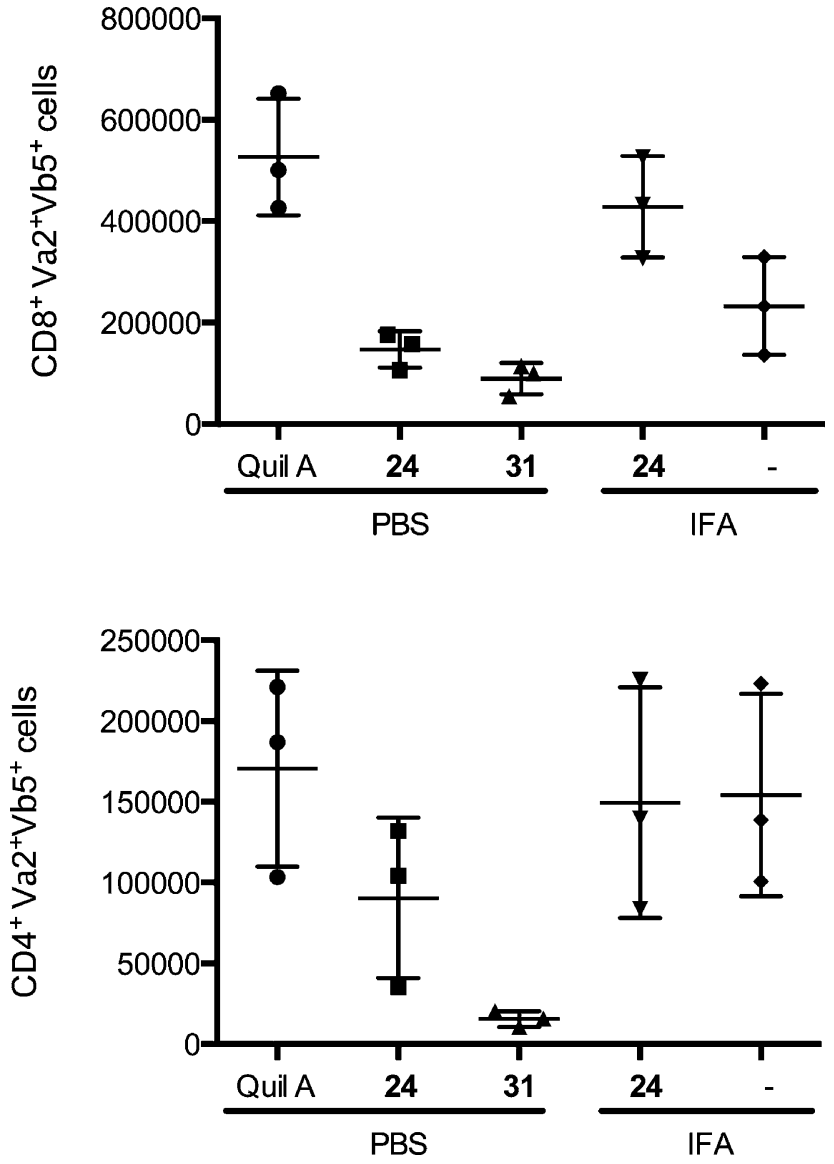

Figure 3. Number of OVA-specific T-cells in lymph nodes of mice immunized with OVA and adjuvant (Quil-A, 24, or 31) or no adjuvant (-) in phosphatebuffered saline (PBS, pH 7.4) or incomplete Freud's adjuvant (IFA). Data shown are from individual mice plus the group mean and S.D. $(n=3)$.

fying the C-28 carboxylic acid group. The addition of alkyl chains at this position increased the disorder in nanostructures formed, while alkylammonium esters preferred to self-assemble into rod-like and helical nanostructures. The most active saponin 24 was stimulatory at high concentrations of saponin in cell culture, but gave only weak responses in vivo. These results highlight the challenges associated with relating formulation studies with activity and in developing immune stimulatory compounds that stimulate cellular immune responses.

\section{Experimental Section}

General experimental: Thin-layer chromatography (TLC) was performed on silica gel $60 \mathrm{~F}_{254}$ aluminium sheets (Merck) and were visualized under UV light and/or with a dip (reagent A: $10 \% \mathrm{w} / \mathrm{V}$ ammonium molybdate and $0.4 \% w / v \mathrm{Ce}\left(\mathrm{SO}_{4}\right)_{2}$ in an aqueous solution of $10 \% \mathrm{H}_{2} \mathrm{SO}_{4}$; reagent $\mathrm{B}$ : $2 \% w / w p$-anisaldehyde, $93 \% \mathrm{w} / w \mathrm{EtOH}$, $5 \% \mathrm{w} / \mathrm{w}$ conc. $\mathrm{H}_{2} \mathrm{SO}_{4}$ ) and subsequent heating. Flash column chromatography was carried out using silica gel 60 (230-400 mesh, Scharlau). All chromatography solvents were reagent grade. Anhydrous solvents were obtained from Aldrich or Acros. Specific optical rotations, given in $10^{-1} \mathrm{deg} \mathrm{cm}^{2} \mathrm{~g}^{-1}$, were measured at ambient temperature using a cell of path length $1.0 \mathrm{dm}$. Melting points (uncorrected) were measured on a Stuart ${ }^{\circ}$ melting point apparatus 
SMP3 (Bibby Sterilin Limited, Staffordshire, UK). NMR spectra were recorded on a Bruker AC-300 (Billerica, USA) or Varian Unity-500 instrument (Palo Alto, USA) at $300 \mathrm{MHz}$ or $500 \mathrm{MHz}\left({ }^{1} \mathrm{H}\right)$ and $75 \mathrm{MHz}$ or $125 \mathrm{MHz}\left({ }^{13} \mathrm{C}\right)$ and referenced to tetramethylsilane (TMS, ${ }^{1} \mathrm{H}, \delta=$ $0.0 \mathrm{ppm})$ or residual solvent $\left({ }^{13} \mathrm{C}, \mathrm{CDCl}_{3} \delta=77.0 \mathrm{ppm} ; \mathrm{CD}_{3} \mathrm{OD} \delta=\right.$ $49.0 \mathrm{ppm}$ ). High-resolution mass spectra (HRMS) were recorded on a Waters Q-TOF Premier Mass Spectrometer with electro-spray ionization (ESI) (Milford, USA).

Allyl hederagenate (2): Freshly harvested Hedera helix (ivy) leaves and leaf stems $(1.0 \mathrm{~kg}$, wet weight) were crushed and suspended in boiling water $(6 \mathrm{~L})$, and the suspension was heated at reflux for $3 \mathrm{~h}$ and then cooled to rt. The suspension was filtered through a course filter to remove large leaves and stems then filtered through Celite. The solution containing saponins was acidified with conc. $\mathrm{HCl}(600 \mathrm{~mL})$ and then heated to reflux for $1 \mathrm{~h}$. After cooling, the precipitated triterpenes consisting primarily of hederagenin were collected on a sintered glass funnel and then dried in the oven at $60^{\circ} \mathrm{C}$ o/n giving a light brown solid $(15 \mathrm{~g}, 1.5 \%$ triterpene yield). The light brown solid thus obtained was dissolved in dimethylformamide (DMF, $60 \mathrm{~mL})$, and $\mathrm{K}_{2} \mathrm{CO}_{3}(6.58 \mathrm{~g}, 47.6 \mathrm{mmol})$ and allyl bromide $(5.49 \mathrm{~mL}, 63.5 \mathrm{mmol})$ were added. The mixture was warmed to $60^{\circ} \mathrm{C}$ for $2 \mathrm{~h}$ and then cooled to rt and poured into water $(300 \mathrm{~mL})$. The mixture was stirred for $15 \mathrm{~min}$ and then the precipitated solid collected, washed with water, and dried under high vacuum. This solid was purified by dry flash chromatography, eluting with a gradient of $3: 1$ to $1: 1$ petroleum ether/ethyl acetate giving a colorless crystalline product $(6.4 \mathrm{~g}, 39 \%):[\alpha]_{D}{ }^{22}=+59.3$ $\left(c=0.97\right.$ in $\left.\mathrm{CHCl}_{3}\right) ; \mathrm{lit}^{[17]}[\alpha]_{\mathrm{D}}=+60.1\left(c=1\right.$ in $\left.\mathrm{CHCl}_{3}\right)$. Spectral data were consistent with that previously published.

Allyl gypsogenate (4): To a stirred solution of allyl hederagenate 2 $(2.0 \mathrm{~g}, 3.90 \mathrm{mmol})$ in $\mathrm{CH}_{2} \mathrm{Cl}_{2}(20 \mathrm{~mL})$ was added bis(acetoxy)iodobenzene (BAIB, $1.25 \mathrm{~g}, 3.90 \mathrm{mmol}$ ) and TEMPO (122 mg, $0.78 \mathrm{mmol}$ ). The reaction mixture was allowed to stir at ambient temperature for $16 \mathrm{~h}$, and then another portion of bis(acetoxy)iodobenzene $(240 \mathrm{mg})$ was added and the reaction was left for a further $1 \mathrm{~h}$. The mixture was concentrated and purified by flash chromatography, eluting with 3:1 petroleum ether/ethyl acetate and the solid thus obtained recrystallized from ethyl acetate/petroleum ether to give white crystals $(1.35 \mathrm{~g}, 68 \%)$ : $\mathrm{mp} 171-173^{\circ} \mathrm{C} ;[\alpha]_{\mathrm{D}}{ }^{20}=$ $+82.0\left(c=1.40\right.$ in $\left.\mathrm{CHCl}_{3}\right)$; ${ }^{1} \mathrm{H}$ NMR $\left(300 \mathrm{MHz}, \mathrm{CDCl}_{3}\right): \delta=9.68$ (s, $1 \mathrm{H}), 5.89$ (dddd, $\left.{ }^{3} J(\mathrm{H}, \mathrm{H})=17.0,10.2,5.5,5.5 \mathrm{~Hz}, 1 \mathrm{H}\right), 5.35-5.26(\mathrm{~m}$, $1 \mathrm{H}), 5.22\left(\mathrm{br} \mathrm{dd},{ }^{3} \mathrm{~J}(\mathrm{H}, \mathrm{H})=3.3,3.3 \mathrm{~Hz}, 1 \mathrm{H}\right), 5.18(\mathrm{~m}, 1 \mathrm{H}), 4.58-4.45$ $(\mathrm{m}, 2 \mathrm{H}), 3.76\left(\mathrm{dd},{ }^{3} \mathrm{~J}(\mathrm{H}, \mathrm{H})=10.6,5.0,1 \mathrm{H}\right), 2.88\left(\mathrm{br} \mathrm{dd},{ }^{3} \mathrm{~J}(\mathrm{H}, \mathrm{H})=13.6\right.$, $4.2 \mathrm{~Hz}, 1 \mathrm{H}), 2.03-1.84(\mathrm{~m}, 23 \mathrm{H}), 1.15(\mathrm{~s}, 3 \mathrm{H}), 1.06(\mathrm{~s}, 3 \mathrm{H}), 0.95(\mathrm{~s}$, $3 \mathrm{H}), 0.92(\mathrm{~s}, 3 \mathrm{H}), 0.74 \mathrm{ppm}(\mathrm{s}, 3 \mathrm{H}) ;{ }^{13} \mathrm{C}$ NMR $\left(75 \mathrm{MHz}, \mathrm{CDCl}_{3}, \mathrm{TMS}\right)$ : $\delta=207.0$, 177.6, 143.8, 132.4, 122.0, 117.7, 71.9, 64.8, 55.1, 48.2, $47.5,46.7,45.9,41.8,41.3,39.7,38.0,36.0,33.9,32.3,32.1,30.6$, 27.6, 26.0, 25.9, 23.6, 23.3, 23.0, 20.7, 16.9, 15.5 ppm; HRMS (ESI) $\mathrm{m} / \mathrm{z}$ calcd for $\mathrm{C}_{33} \mathrm{H}_{50} \mathrm{O}_{4}+\mathrm{Na}^{+}: 533.3607[\mathrm{M}+\mathrm{Na}]^{+}$, found: 533.3614 ; elemental analysis calcd (\%) for $\mathrm{C}_{33} \mathrm{H}_{50} \mathrm{O}_{4}$ : C 77.60, $\mathrm{H}$ 9.87, found: C 77.22, H 9.94.

\section{2,3,4,6-Tetra-O-benzoyl- $\alpha$-D-mannopyranosyl-(1 $\rightarrow 3)-1,2,4,6$ -} tetra-O-acetyl- $\boldsymbol{\alpha} / \boldsymbol{\beta}$-D-glucopyranose (8): Disaccharide $\boldsymbol{7}^{[21]}(3.70 \mathrm{~g}$, $4.41 \mathrm{mmol}$ ) was dissolved in 9:1 trifluoroacetic acid (TFA)/ $\mathrm{H}_{2} \mathrm{O}$ $(10 \mathrm{~mL})$, and the reaction mixture was stirred for $1 \mathrm{~h}$ and then the volatiles removed under reduced pressure. To the residue was added pyridine $(15 \mathrm{~mL})$ and acetic anhydride $(10 \mathrm{~mL})$. The reaction mixture was stirred for $16 \mathrm{~h}$, and then $\mathrm{MeOH}(10 \mathrm{~mL})$ was added. The mixture was concentrated under reduced pressure and the residue purified by flash chromatography, eluting with ethyl acetate/ petroleum ether $2: 3$ to give $8(5: 3 \alpha / \beta)$ as a colorless foam $(2.49 \mathrm{~g}$, $61 \%) ; 8 \alpha:{ }^{1} \mathrm{H}$ NMR (300 MHz, $\left.\mathrm{CDCl}_{3}, \mathrm{TMS}\right): \delta=8.15-8.10(\mathrm{~m}, 2 \mathrm{H})$,
8.03-7.95 (m, 4H), 7.87-7.83 (m, 2H), 7.60-7.20 (m, 12H), $6.37(\mathrm{~d}$, $\left.{ }^{3} \mathrm{~J}(\mathrm{H}, \mathrm{H})=3.8 \mathrm{~Hz}, 1 \mathrm{H}\right), 6.26\left(\mathrm{dd},{ }^{3} \mathrm{~J}(\mathrm{H}, \mathrm{H})=10.2,10.2 \mathrm{~Hz}, 1 \mathrm{H}\right), 5.78(\mathrm{dd}$, $\left.{ }^{3} \mathrm{~J}(\mathrm{H}, \mathrm{H})=10.5,3.0 \mathrm{~Hz}, 1 \mathrm{H}\right), 5.58\left(\mathrm{dd},{ }^{3} J(\mathrm{H}, \mathrm{H})=3.0,2.1 \mathrm{~Hz}, 1 \mathrm{H}\right), 5.34-$ $5.18(\mathrm{~m}, 3 \mathrm{H}), 4.82\left(\mathrm{ddd},{ }^{3} \mathrm{~J}(\mathrm{H}, \mathrm{H})=6.4,6.4,2.1 \mathrm{~Hz}, 1 \mathrm{H}\right), 4.48(\mathrm{ddd}$, $\left.{ }^{3} \mathrm{~J}(\mathrm{H}, \mathrm{H})=10.2,2.6,2.6 \mathrm{~Hz}, 1 \mathrm{H}\right), 4.39-4.29(\mathrm{~m}), 3.87\left(\mathrm{ddd},{ }^{3} J(\mathrm{H}, \mathrm{H})=\right.$ $10.2,3.8,1.9 \mathrm{~Hz}, 1 \mathrm{H}), 3.74\left(\mathrm{br} \mathrm{d},{ }^{3} \mathrm{~J}(\mathrm{H}, \mathrm{H})=13.2 \mathrm{~Hz}, 1 \mathrm{H}\right), 3.67-3.58$ $(\mathrm{m}, 1 \mathrm{H}), 2.32(\mathrm{~s}, 1 \mathrm{H}), 2.13(\mathrm{~s}, 3 \mathrm{H}), 2.12 \mathrm{ppm}(\mathrm{s}, 3 \mathrm{H}) ;{ }^{13} \mathrm{C}$ NMR (75 MHz, $\mathrm{CDCl}_{3}$, TMS) $\delta=171.0,169.7,168.7,165.9,165.4,165.2$, 165.2, 133.4, 133.4, 133.1, 133.0, 129.7-128.0 (m), 99.1, 89.3, 77.5, $72.3,70.5,70.4,69.8,69.7,69.5,66.0,61.9,60.8,20.7$ ppm; 8及: ${ }^{1} \mathrm{H}$ NMR $\left(300 \mathrm{MHz}, \mathrm{CDCl}_{3}\right.$, partial, TMS): $\delta=6.27\left(\mathrm{dd},{ }^{3} \mathrm{~J}(\mathrm{H}, \mathrm{H})=10.2\right.$, $10.2 \mathrm{~Hz}, 1 \mathrm{H}), 5.74\left(\mathrm{dd},{ }^{3} \mathrm{~J}(\mathrm{H}, \mathrm{H})=10.2,3.1 \mathrm{~Hz}, 1 \mathrm{H}\right), 5.68\left(\mathrm{~d},{ }^{3} J(\mathrm{H}, \mathrm{H})=\right.$ $8.2 \mathrm{~Hz}, 1 \mathrm{H}), 5.61\left(\mathrm{dd},{ }^{3} \mathrm{~J}(\mathrm{H}, \mathrm{H})=3.2,2.1 \mathrm{~Hz}, 1 \mathrm{H}\right), 4.79\left(\mathrm{~d},{ }^{3} J(\mathrm{H}, \mathrm{H})=\right.$ $2.5 \mathrm{~Hz}, 1 \mathrm{H}), 4.42\left(\mathrm{ddd},{ }^{3} J(\mathrm{H}, \mathrm{H})=10.2,2.1,2.1 \mathrm{~Hz}, 1 \mathrm{H}\right), 4.09$ (dd, $\left.{ }^{3} \mathrm{~J}(\mathrm{H}, \mathrm{H})=9.7,9.7 \mathrm{~Hz}, 1 \mathrm{H}\right), 2.32(\mathrm{~s}, 3 \mathrm{H}), 2.18(\mathrm{~s}, 3 \mathrm{H}), 2.12 \mathrm{ppm}(\mathrm{s}$, $3 \mathrm{H}) ;{ }^{13} \mathrm{C}$ NMR $\left(75 \mathrm{MHz}, \mathrm{CDCl}_{3}\right.$, partial): $\delta=171.1,169.4,169.1,99.9$, 91.7, 81.8, 75.0, 71.3, 70.2, 70.0, 69.7, 69.2, 65.7, 61.6, 20.9 ppm; HRMS (ESI) $\mathrm{m} / z$ calcd for $\mathrm{C}_{48} \mathrm{H}_{46} \mathrm{O}_{19}+\mathrm{Na}^{+}$: $949.2520[\mathrm{M}+\mathrm{Na}]^{+}$, found: 949.2515 .

2,3,4,6-Tetra-O-benzoyl- $\alpha$-D-mannopyranosyl-(1 $\rightarrow 3$ )-2,4,6-tri-Oacetyl- $\alpha$-D-glucopyranosyl trichloroacetimidate (9): To a stirred solution of disaccharide $8(2.11 \mathrm{~g}, 2.27 \mathrm{mmol})$ dissolved in DMF $(10 \mathrm{~mL})$ was added hydrazinium acetate (caution:carcinogenic) $(0.31 \mathrm{~g}, 3.41 \mathrm{mmol})$. The resulting solution was allowed to stir for $2 \mathrm{~h}$ and then quenched with acetic acid and concentrated under reduced pressure. The residue was dissolved in ether $(100 \mathrm{~mL})$ and washed with water $(2 \times 50 \mathrm{~mL})$ then brine $(2 \times 50 \mathrm{~mL})$, dried, and concentrated under reduced pressure. The residue was purified by flash chromatography, eluting with ethyl acetate/petroleum ether 2:3 then $1: 1$ to give a colorless foam $(1.68 \mathrm{~g}, 83 \%)$. To a stirred solution of this disaccharide $(1.68 \mathrm{~g}, 1.89 \mathrm{mmol})$ dissolved in $\mathrm{CH}_{2} \mathrm{Cl}_{2}$ $(5 \mathrm{~mL})$ was added trichloroacetonitrile $(0.411 \mathrm{~g}, 2.85 \mathrm{mmol})$ followed by 1,8-diazabicyclo[5.4.0]undec-7-ene (DBU, $0.029 \mathrm{~mL}$, $0.190 \mathrm{mmol}$ ). The reaction was stirred for $45 \mathrm{~min}$, and then an additional portion of trichloroacetonitrile $(300 \mathrm{mg}, 2.08 \mathrm{mmol})$ and DBU $(0.10 \mathrm{~mL})$ were added. The reaction mixture was left for another $15 \mathrm{~min}$ and transferred directly to the top of a silica gel column and purified by flash chromatography, eluting with ethyl acetate/ hexane $2: 3$ to give 9 as a colorless foam $(1.42 \mathrm{~g}, 73 \%):[\alpha]_{D}^{22}=$ $+22.5\left(c=1.0\right.$ in $\left.\mathrm{CHCl}_{3}\right) ;{ }^{1} \mathrm{H}$ NMR $\left(300 \mathrm{MHz}, \mathrm{CDCl}_{3}, \mathrm{TMS}\right): \delta=8.69(\mathrm{~s}$, $1 \mathrm{H}), 8.13-8.06(\mathrm{~m}, 2 \mathrm{H}), 8.02-7.91(\mathrm{~m}, 4 \mathrm{H}), 7.87-7.80(\mathrm{~m}, 2 \mathrm{H}), 7.61-$ $7.21(\mathrm{~m}, 12 \mathrm{H}), 6.58\left(\mathrm{~d},{ }^{3} \mathrm{~J}(\mathrm{H}, \mathrm{H})=3.7 \mathrm{~Hz}, 1 \mathrm{H}\right), 6.25\left(\mathrm{dd},{ }^{3} \mathrm{~J}(\mathrm{H}, \mathrm{H})=10.1\right.$, $10.1 \mathrm{~Hz}, 1 \mathrm{H}), 5.75\left(\mathrm{dd},{ }^{3} \mathrm{~J}(\mathrm{H}, \mathrm{H})=10.3,3.1 \mathrm{~Hz}, 1 \mathrm{H}\right), 5.55\left(\mathrm{dd},{ }^{3} \mathrm{~J}(\mathrm{H}, \mathrm{H})=\right.$ 3.0, $2.1 \mathrm{~Hz}, 1 \mathrm{H}), 5.42\left(\mathrm{dd},{ }^{3}(\mathrm{H}, \mathrm{H})=9.9,9.9 \mathrm{~Hz}, 1 \mathrm{H}\right), 5.30-5.24(\mathrm{~m}$, $2 \mathrm{H}), 4.74\left(\mathrm{dd},{ }^{3} \mathrm{~J}(\mathrm{H}, \mathrm{H})=12.4,2.6 \mathrm{~Hz}, 1 \mathrm{H}\right), 4.49\left(\mathrm{ddd},{ }^{3} \mathrm{~J}(\mathrm{H}, \mathrm{H})=10.0\right.$, 2.4, $2.4 \mathrm{~Hz}, 1 \mathrm{H}), 4.42-4.24(\mathrm{~m}, 3 \mathrm{H}), 4.20-4.11(\mathrm{~m}, 2 \mathrm{H}), 2.28(\mathrm{~s}, 3 \mathrm{H})$, $2.12(\mathrm{~s}, 3 \mathrm{H}), 2.12 \mathrm{ppm}(\mathrm{s}, 3 \mathrm{H}) ;{ }^{13} \mathrm{C}$ NMR $\left(75 \mathrm{MHz}, \mathrm{CDCl}_{3}, \mathrm{TMS}\right): \delta=$ $170.6,169.9,169.8,166.0,165.3,160.8,133.4,133.1,133.0,129.8$, 129.1, 128.9, 128.6, 128.4, 128.2, 99.3, 93.3, 77.8, 71.0, 70.4, 69.8, 69.6, 68.5, 66.1, 61.9, 61.5, $21.1 \mathrm{ppm}$; HRMS (ESI) $\mathrm{m} / \mathrm{z}$ calcd for $\mathrm{C}_{48} \mathrm{H}_{44} \mathrm{O}_{18} \mathrm{Cl}_{3}+\mathrm{Na}^{+}:$1050.1522 [M+Na] ${ }^{+}$, found: 1050.1479 .

2,3,4,6-Tetra-O-benzoyl- $\beta$-D-galactopyranosyl-(1 $\rightarrow 3$ )-1:2,5 :6-di-Oisopropylidene- $\boldsymbol{\alpha}$-D-glucofuranose (11): $2,3,4,6$-Tetra-O-benzoyl- $\beta$ D-galactopyranosyl trichloroacetimidate $10^{[22]}(3.36 \mathrm{~g}, 4.53 \mathrm{mmol})$, glucofuranose acceptor $6(1.77 \mathrm{~g}, 6.80 \mathrm{mmol})$, and $4 \AA$ molecular sieves in $\mathrm{CH}_{2} \mathrm{Cl}_{2}(30 \mathrm{~mL})$ were stirred for $45 \mathrm{~min}$ and then trimethylsilyl trifluoromethanesulfonate (TMSOTf, $0.10 \mathrm{~g}, 0.45 \mathrm{mmol}$ ) was added. The mixture was allowed to stir for $30 \mathrm{~min}$ and then the mixture was quenched with triethylamine and then filtered through filter aid. Concentration under reduced pressure and purification by flash chromatography, eluting with ethyl acetate/petroleum ether (1:4 then 3:7) afforded $\mathbf{1 1}$ as a colorless foam 
$(1.92 \mathrm{~g}, 51 \%):[\alpha]_{D}{ }^{20}=+61.3\left(c=1.1\right.$ in $\left.\mathrm{CHCl}_{3}\right)$, Lit. $^{[23 a]}[\alpha]_{D}{ }^{20}=+66$ (c 2.7 in $\left.\mathrm{CHCl}_{3}\right) ;{ }^{1} \mathrm{H} \mathrm{NMR}\left(500 \mathrm{MHz}, \mathrm{CDCl}_{3}, \mathrm{TMS}\right): \delta=8.08-8.06(\mathrm{~m}$, $2 \mathrm{H}), 8.02-8.00(\mathrm{~m}, 2 \mathrm{H}), 7.98-7.96(\mathrm{~m}, 2 \mathrm{H}), 7.79-7.77(\mathrm{~m}, 2 \mathrm{H}), 7.65-$ $7.35(\mathrm{~m}, 12 \mathrm{H}), 5.99\left(\mathrm{~d},{ }^{3} \mathrm{~J}(\mathrm{H}, \mathrm{H})=3.1 \mathrm{~Hz}, 1 \mathrm{H} ; \mathrm{H}-4^{\prime}\right), 5.75\left(\mathrm{dd},{ }^{3} \mathrm{~J}(\mathrm{H}, \mathrm{H})=\right.$ 10.4, $\left.8.1 \mathrm{~Hz}, 1 \mathrm{H} ; \mathrm{H}-2^{\prime}\right), 5.61\left(\mathrm{dd},{ }^{3} \mathrm{~J}(\mathrm{H}, \mathrm{H})=10.4,3.3 \mathrm{~Hz}, 1 \mathrm{H} ; \mathrm{H}-3^{\prime}\right)$, $5.50\left(\mathrm{~d},{ }^{3} J(\mathrm{H}, \mathrm{H})=3.7 \mathrm{~Hz}, 1 \mathrm{H} ; \mathrm{H}-1\right), 4.95\left(\mathrm{~d},{ }^{3} J(\mathrm{H}, \mathrm{H})=8.0 \mathrm{~Hz}, 1 \mathrm{H}\right.$; $\left.\mathrm{H}-1^{\prime}\right), 4.66\left(\mathrm{dd},{ }^{3} \mathrm{~J}(\mathrm{H}, \mathrm{H})=11.3,6.3 \mathrm{~Hz}, 1 \mathrm{H} ; \mathrm{H}-6^{\prime}\right), 4.45\left(\mathrm{ddd},{ }^{3} \mathrm{~J}(\mathrm{H}, \mathrm{H})=\right.$ $6.1,6.1,6.1 \mathrm{~Hz}, 1 \mathrm{H} ; \mathrm{H}-5), 4.44\left(\mathrm{dd},{ }^{3} \mathrm{~J}(\mathrm{H}, \mathrm{H})=11.3,7.1 \mathrm{~Hz}, 1 \mathrm{H} ; \mathrm{H}-6^{\prime}\right)$, 4.36-4.31 (m, 3H; H-2, H-3, H-5'), $4.26\left(\mathrm{dd}^{3}{ }^{3} \mathrm{~J}(\mathrm{H}, \mathrm{H})=5.4,3.0 \mathrm{~Hz}, 1 \mathrm{H}\right.$; $\mathrm{H}-4), 4.12\left(\mathrm{dd},{ }^{3} \mathrm{~J}(\mathrm{H}, \mathrm{H})=8.6,6.9 \mathrm{~Hz}, 1 \mathrm{H} ; \mathrm{H}-6\right), 4.03\left(\mathrm{dd},{ }^{3} \mathrm{~J}(\mathrm{H}, \mathrm{H})=8.6\right.$, $6.1 \mathrm{~Hz}, 1 \mathrm{H} ; \mathrm{H}-6), 1.42(\mathrm{~s}, 3 \mathrm{H}), 1.41(\mathrm{~s}, 3 \mathrm{H}), 1.34(\mathrm{~s}, 3 \mathrm{H}), 1.10 \mathrm{ppm}(\mathrm{s}$, $3 \mathrm{H}) ;{ }^{13} \mathrm{C}$ NMR $\left(125 \mathrm{MHz}, \mathrm{CDCl}_{3}, \mathrm{TMS}\right): \delta=166.4,165.4,164.9,133.6$, 133.5, 129.9, 129.8, 129.1, 128.7, 128.5, 111.9, 108.6, 104.9 (C-1), $100.6\left(\mathrm{C}-1^{\prime}\right), 82.8,81.5,80.4$ (C-4), 73.1 (C-5), 71.7, 71.5 (C-3'), 69.9 (C-2'), $68.0\left(\mathrm{C}-4^{\prime}\right), 66.3(\mathrm{C}-6), 61.8\left(\mathrm{C}-6^{\prime}\right), 26.5,25.9,25.2$ ppm; HRMS (ESI) $\mathrm{m} / \mathrm{z}$ calcd for $\mathrm{C}_{46} \mathrm{H}_{46} \mathrm{O}_{15}+\mathrm{Na}^{+}: 861.2734[\mathrm{M}+\mathrm{Na}]^{+}$, found: 861.2727

\section{2,3,4,6-Tetra-O-benzoyl- $\beta$-D-galactopyranosyl-( $1 \rightarrow 3)-1,2,4,6$ -} tetra-O-acetyl- $\boldsymbol{\alpha} / \boldsymbol{\beta}$-D-glucopyranose (12): Disaccharide 11 (1.80 g, $2.14 \mathrm{mmol})$ was dissolved in $9: 1 \mathrm{TFA} / \mathrm{H}_{2} \mathrm{O}(10 \mathrm{~mL})$, and the resulting solution was stirred for $48 \mathrm{~h}$. The solution was diluted with water $(30 \mathrm{~mL})$ and extracted with $\mathrm{CH}_{2} \mathrm{Cl}_{2}(3 \times 30 \mathrm{~mL})$, and the organic phase dried and concentrated under reduced pressure. The major product was isolated by flash chromatography giving the free sugar as a colorless solid. HRMS (ESI) calcd for $[\mathrm{M}+\mathrm{Na}]^{+}$ $\mathrm{C}_{40} \mathrm{H}_{38} \mathrm{O}_{15} \mathrm{Na}$ : 781.2108 , found: 781.2100 . This solid was taken up in pyridine $(5 \mathrm{~mL})$, and acetic anhydride $(3 \mathrm{~mL})$ was added. The reaction mixture was stirred for $16 \mathrm{~h}$, and then $\mathrm{MeOH}(5 \mathrm{~mL})$ was added and the mixture concentrated under reduced pressure. Residual pyridine and acetic acid were removed by concentrating the mixture from toluene to give a colorless foam $(1.1 \mathrm{~g}, 55 \%, 5: 4 \mathrm{\alpha} /$ $\beta)$; ${ }^{1} \mathrm{H}$ NMR (300 MHz, $\left.\mathrm{CDCl}_{3}, \mathrm{TMS}\right): \delta=8.14-8.04(\mathrm{~m}), 7.91-7.82(\mathrm{~m})$, 7.79-7.72 (m), 7.70-7.20 (m), $6.24\left(\mathrm{~d},{ }^{3} J(\mathrm{H}, \mathrm{H})=3.2 \mathrm{~Hz}, 1 \mathrm{H} ; \mathrm{H}-1 \alpha\right)$,

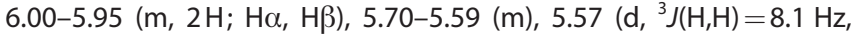
$1 \mathrm{H} ; \mathrm{H}-1 \beta), 5.23-4.91(\mathrm{~m}), 4.76-4.64(\mathrm{~m}), 4.43-3.97(\mathrm{~m}), 3.67(\mathrm{ddd}$, $\left.{ }^{3} \mathrm{~J}(\mathrm{H}, \mathrm{H})=9.8,4.5,2.3 \mathrm{~Hz}, 1 \mathrm{H}\right), 2.12(\mathrm{~s}, 3 \mathrm{H}), 2.12(\mathrm{~s}, 3 \mathrm{H}), 2.11(\mathrm{~s}, 3 \mathrm{H})$, $2.10(\mathrm{~s}, 3 \mathrm{H}), 2.09(\mathrm{~s}, 3 \mathrm{H}), 2.01(\mathrm{~s}, 3 \mathrm{H}), 1.91(\mathrm{~s}, 3 \mathrm{H}), 1.84 \mathrm{ppm}(\mathrm{s}, 3 \mathrm{H})$; ${ }^{13} \mathrm{C} \mathrm{NMR} \quad\left(300 \mathrm{MHz}, \mathrm{CDCl}_{3}, \mathrm{TMS}\right): \delta=170.7,170.6,169.0,168.9$, 168.6, 166.1, 165.9, 165.6, 165.3, 165.0, 164.9, 133.7, 133.4, 133.3, $133.2,133.1,129.9,129.7,129.6,129.4,129.3,128.7,128.5,128.3$, 128.1, 101.1, 91.8, 89.1, 78.1, 75.4, 72.8, 71.6, 71.3, 71.1, 70.8, 70.3, 70.2, 70.0, 67.8, 67.7, 67.6, 61.7, 61.4, 20.8, 20.7, 20.5, 20.2 ppm; HRMS (ESI) $\mathrm{m} / \mathrm{z}$ calcd for $\mathrm{C}_{48} \mathrm{H}_{46} \mathrm{O}_{19}+\mathrm{Na}^{+}: 949.2531[\mathrm{M}+\mathrm{Na}]^{+}$, found: 949.2535 .

\section{2,3,4,6-Tetra-O-benzoyl- $\beta$-D-galactopyranosyl-(1 $\rightarrow 3$ )-2,4,6-tri-O-} acetyl- $\alpha$-D-glucopyranose (13): To a stirred solution of tetraacetate $12(1.10 \mathrm{~g}, 1.18 \mathrm{mmol})$ dissolved in DMF $(5 \mathrm{~mL})$ was added hydrazinium acetate (caution:carcinogenic) $(164 \mathrm{mg}, 1.78 \mathrm{mmol})$. The reaction mixture was allowed to stir for $3 \mathrm{~h}$ and then the mixture was diluted with water. The precipitated white product was collected, washed with water, and then dried under high vacuum. Purification by flash chromatography, eluting with a gradient of ethyl acetate/petroleum ether (3:7 to $1: 1$ ) afforded 13 as a colorless foam (890 mg, 85\%): $[\alpha]_{D}{ }^{20}=+52.7\left(c=1.0\right.$ in $\left.\mathrm{CHCl}_{3}\right) ;{ }^{1} \mathrm{H} \mathrm{NMR}(300 \mathrm{MHz}$, $\left.\mathrm{CDCl}_{3}, \mathrm{TMS}\right): \delta=8.11-8.00(\mathrm{~m}, 4 \mathrm{H}), 7.87-7.81(\mathrm{~m}, 2 \mathrm{H}), 7.78-7.71(\mathrm{~m}$, $2 \mathrm{H}), 7.68-7.31(\mathrm{~m}, 10 \mathrm{H}), 7.25-7.11(\mathrm{~m}, 2 \mathrm{H}), 5.96\left(\mathrm{~d},{ }^{3} \mathrm{~J}(\mathrm{H}, \mathrm{H})=2.1 \mathrm{~Hz}\right.$, $1 \mathrm{H}), 5.68-5.58(\mathrm{~m}, 2 \mathrm{H}), 5.41\left(\mathrm{dd},{ }^{3} \mathrm{~J}(\mathrm{H}, \mathrm{H})=3.6,3.6 \mathrm{~Hz}, 1 \mathrm{H} ; \mathrm{H}-1 \alpha\right)$, $5.11\left(\mathrm{dd},{ }^{3} \mathrm{~J}(\mathrm{H}, \mathrm{H})=9.5,9.5 \mathrm{~Hz}, 1 \mathrm{H}\right), 5.09-4.97(\mathrm{~m}, 1 \mathrm{H}), 4.76$ (ddd, $\left.{ }^{3} \mathrm{~J}(\mathrm{H}, \mathrm{H})=10.2,3.6,1.1 \mathrm{~Hz}, 1 \mathrm{H}\right), 4.70-4.59(\mathrm{~m}, 1 \mathrm{H}), 4.40-4.28(\mathrm{~m}, 3 \mathrm{H})$, 4.22-4.08 (m, 3H), $3.12\left(\mathrm{dd},{ }^{3} \mathrm{~J}(\mathrm{H}, \mathrm{H})=3.7,1.1 \mathrm{~Hz}, 1 \mathrm{H}\right), 2.09(\mathrm{~s}, 3 \mathrm{H})$, $2.07(\mathrm{~s}, 3 \mathrm{H}), 1.90 \mathrm{ppm}(\mathrm{s}, 3 \mathrm{H}) ;{ }^{13} \mathrm{C}$ NMR $\left(75 \mathrm{MHz}, \mathrm{CDCl}_{3}, \mathrm{TMS}\right): \delta=$ $170.8,169.4,169.2,166.0,165.6,165.3,165.1,133.7,133.4,133.3$,
$133.2,129.9,129.8,129.7,129.4,129.3,129.9,128.7,128.6,128.4$, $128.2,101.2,89.9,75.3,73.3,71.7,70.9,70.4,68.1,67.9,67.5,62.2$, 61.6, 20.8, 20.7, 20.6 ppm; HRMS (ESI) $\mathrm{m} / \mathrm{z}$ calcd for $\mathrm{C}_{46} \mathrm{H}_{44} \mathrm{O}_{18} \mathrm{Na}^{+}$: 907.24.25 $[\mathrm{M}+\mathrm{Na}]^{+}$, found: 907.2426; elemental analysis calcd (\%) for $\mathrm{C}_{46} \mathrm{H}_{44} \mathrm{O}_{18}$ : C 62.44, H 5.01, found: C 62.04, H 5.14.

2,3,4,6-Tetra-O-benzoyl- $\beta$-D-galactopyranosyl-( $1 \rightarrow 3)$-2,4,6-tri-Oacetyl- $\alpha$-D-glucopyranosyl trichloroacetimidate (14): Pyranose 13 $(820 \mathrm{mg}, 0.927 \mathrm{mmol})$ was taken up in $\mathrm{CH}_{2} \mathrm{Cl}_{2}(5 \mathrm{~mL})$, and then trichloroacetonitrile $(268 \mathrm{mg}, 1.8 \mathrm{mmol})$ and $\mathrm{DBU}(0.014 \mathrm{~mL}$, $0.093 \mathrm{mmol}$ ) were added. The reaction was allowed to stir at ambient temperature for $1 \mathrm{~h}$ and the product purified by loading directly onto a silica-gel column and eluting with ethyl acetate/hexanes 2:1 to give 14 as a colorless foam $(900 \mathrm{mg}, 94 \%):[\alpha]_{D}{ }^{20}=+68.6$ ( $c=0.93$ in $\left.\mathrm{CHCl}_{3}\right) ;{ }^{1} \mathrm{H} \mathrm{NMR}\left(300 \mathrm{MHz}, \mathrm{CDCl}_{3}, \mathrm{TMS}\right): \delta=8.62(\mathrm{~s}, 1 \mathrm{H}$; $\mathrm{NH}), 8.12-8.02(\mathrm{~s}, 4 \mathrm{H}), 7.87-7.81(\mathrm{~m}, 2 \mathrm{H}), 7.78-7.72(\mathrm{~m}, 2 \mathrm{H}), 7.69$ $7.31\left(\mathrm{~m}, 10 \mathrm{H}, 7.25-7.19(\mathrm{~m}, 2 \mathrm{H}), 6.45\left(\mathrm{~d},{ }^{3} \mathrm{~J}(\mathrm{H}, \mathrm{H})=3.6 \mathrm{~Hz}, 1 \mathrm{H} ; \mathrm{H}-1\right)\right.$, $5.96\left(\mathrm{~d}^{3} \mathrm{3}(\mathrm{H}, \mathrm{H})=2.5 \mathrm{~Hz}, 1 \mathrm{H} ; \mathrm{H}-4^{\prime}\right), 5.70-5.59\left(\mathrm{~m}, 2 \mathrm{H} ; \mathrm{H}-3^{\prime}, \mathrm{H}-2^{\prime}\right)$, $5.24\left(\mathrm{dd},{ }^{3} \mathrm{~J}(\mathrm{H}, \mathrm{H})=9.8,9.8 \mathrm{~Hz}, 1 \mathrm{H} ; \mathrm{H}-4\right), 5.02\left(\mathrm{~d},{ }^{3} \mathrm{~J}(\mathrm{H}, \mathrm{H})=7.4 \mathrm{~Hz}, 1 \mathrm{H}\right.$; $\left.\mathrm{H}-1^{\prime}\right), 4.95\left(\mathrm{dd},{ }^{3} \mathrm{~J}(\mathrm{H}, \mathrm{H})=10.0,3.6 \mathrm{~Hz}, 1 \mathrm{H} ; \mathrm{H}-2\right), 4.60\left(\mathrm{dd},{ }^{3} \mathrm{~J}(\mathrm{H}, \mathrm{H})=\right.$ 10.7, $6.5 \mathrm{~Hz} ; 1 \mathrm{H}), 4.46-4.33(\mathrm{~m}, 2 \mathrm{H}), 4.31-4.06(\mathrm{~m}, 4 \mathrm{H}), 2.10(\mathrm{~s}, 3 \mathrm{H})$, $2.08(\mathrm{~s}, 3 \mathrm{H}), 1.79(\mathrm{~s}, 3 \mathrm{H}) ;{ }^{13} \mathrm{C}$ NMR $\left(75 \mathrm{MHz}, \mathrm{CDCl}_{3}, \mathrm{TMS}\right): \delta=107.6$, $169.1,169.0,166.0,165.6,165.3,165.0,160.6,133.7,133.4,133.3$, $133.2,129.9,129.7,129.3,129.3,128.8,128.7,128.5,128.3,128.3$, 101.4, 93.0, 76.1, 71.9, 71.6, 71.1, 70.3, 70.2, 67.9, 67.5, 61.8, 61.6, 20.8, 20.7, 20.2; HRMS (ESI) $\mathrm{m} / z$ calcd for $\mathrm{C}_{48} \mathrm{H}_{44} \mathrm{~N}_{1} \mathrm{O}_{18} \mathrm{Cl}_{3}+\mathrm{Na}^{+}$: $1050.1522[\mathrm{M}+\mathrm{Na}]^{+}$, found: 1050.1533

2,3,4-Tri-O-benzoyl- $\beta$-D-xylopyranosyl-(1 $\rightarrow 3$ )-1:2,5:6-diisopropylidene- $\alpha$-D-glucofuranose (16): To a stirred solution of 1:2,3:4-diO-isopropylidene-D-glucofuranose $6(220 \mathrm{mg}, 0.86 \mathrm{mmol})$ dissolved in $\mathrm{CH}_{2} \mathrm{Cl}_{2}(10 \mathrm{~mL})$ was added xylopyranosyl donor $15^{[24]}$ (500 mg, $0.84 \mathrm{mmol}$ ) followed by activated $4 \AA$ molecular sieves. The reaction was allowed to stir for $30 \mathrm{~min}$ at ambient temperature and then TMSOTf $(0.02 \mathrm{~mL})$ was added. The reaction was allowed to stir for $20 \mathrm{~min}$ and then quenched with triethylamine $(1 \mathrm{~mL})$. The volatiles were removed under reduced pressure, and then the residue purified by flash chromatography, eluting with ethyl acetate/petroleum ether $3: 7$ to give 16 as a colorless solid (500 mg, $84 \%$ ): $\mathrm{mp}$ $66-68^{\circ} \mathrm{C} ;[\alpha]_{D}^{20}=-42.0\left(c=0.74\right.$ in $\left.\mathrm{CHCl}_{3}\right) ;{ }^{1} \mathrm{H} \mathrm{NMR}(500 \mathrm{MHz}$, $\left.\mathrm{CDCl}_{3}, \mathrm{TMS}\right): \delta=8.10-7.95(\mathrm{~m}, 6 \mathrm{H}), 7.60-7.49(\mathrm{~m}, 3 \mathrm{H}), 7.45-7.29$ $(\mathrm{m}, 6 \mathrm{H}), 5.71\left(\mathrm{~d},{ }^{3} \mathrm{~J}(\mathrm{H}, \mathrm{H})=3.7 \mathrm{~Hz}, 1 \mathrm{H}\right), 5.65\left(\mathrm{dd},{ }^{3} J(\mathrm{H}, \mathrm{H})=5.4,5.4 \mathrm{~Hz}\right.$, $1 \mathrm{H}), 5.28\left(\mathrm{dd},{ }^{3} \mathrm{~J}(\mathrm{H}, \mathrm{H})=5.1,3.6 \mathrm{~Hz}, 1 \mathrm{H}\right) 5.26\left(\mathrm{dd},{ }^{3} J(\mathrm{H}, \mathrm{H})=5.4\right.$, $3.8 \mathrm{~Hz}, 1 \mathrm{H}), 5.05\left(\mathrm{~d},{ }^{3} \mathrm{~J}(\mathrm{H}, \mathrm{H})=3.7 \mathrm{~Hz}, 1 \mathrm{H}\right), 4.65\left(\mathrm{dd},{ }^{3} \mathrm{~J}(\mathrm{H}, \mathrm{H})=12.8\right.$, $3.4 \mathrm{~Hz}, 1 \mathrm{H}), 4.49\left(\mathrm{~d},{ }^{3} \mathrm{~J}(\mathrm{H}, \mathrm{H})=3.7 \mathrm{~Hz}, 1 \mathrm{H}\right), 4.42-4.39(\mathrm{~m}, 2 \mathrm{H}), 4.16$ $\left(\mathrm{dd},{ }^{3} \mathrm{~J}(\mathrm{H}, \mathrm{H})=7.9,3.2 \mathrm{~Hz}, 1 \mathrm{H}\right), 4.00\left(\mathrm{dd},{ }^{3} \mathrm{~J}(\mathrm{H}, \mathrm{H})=8.7,6.2 \mathrm{~Hz}, 1 \mathrm{H}\right)$, $3.97\left(\mathrm{dd},{ }^{3} \mathrm{~J}(\mathrm{H}, \mathrm{H})=8.7,5.5 \mathrm{~Hz}, 1 \mathrm{H}\right), 3.78\left(\mathrm{dd},{ }^{3} \mathrm{~J}(\mathrm{H}, \mathrm{H})=12.5,4.5 \mathrm{~Hz}\right.$, $1 \mathrm{H}), 1.47(\mathrm{~s}, 3 \mathrm{H}), 1.43(\mathrm{~s}, 3 \mathrm{H}), 1.34(\mathrm{~s}, 3 \mathrm{H}), 1.24 \mathrm{ppm}(\mathrm{s}, 3 \mathrm{H})$; ${ }^{13} \mathrm{C}$ NMR $\left(125 \mathrm{MHz}, \mathrm{CDCl}_{3}, \mathrm{TMS}\right): \delta=165.6,165.3,165.2,133.5$, $133.4,133.3,129.9,129.8,129.4,129.1,128.4,111.9,109.1,105.1$, $96.9,82.3,80.7,79.0,72.3,69.4,68.9,68.2,67.2,60.2,26.8,26.7$, 26.1, 25.5 ppm; HRMS (ESI) $\mathrm{m} / \mathrm{z}$ calcd for $\mathrm{C}_{38} \mathrm{H}_{40} \mathrm{O}_{13}+\mathrm{Na}^{+}: 727.2367$ $[\mathrm{M}+\mathrm{Na}]^{+}$, found: 727.2363 .

2,3,4-Tri-O-benzoyl- $\beta$-D-xylopyranosyl-( $1 \rightarrow 3$ )-2,4,6-tri-O-acetyl- $\alpha$ D-glucopyranose (17): Glucofuranose $16(2.07 \mathrm{~g}, 2.86 \mathrm{mmol})$ was dissolved in 9:1 trifluoroacetic acid/water $(10 \mathrm{~mL})$ and the mixture stirred for $4 \mathrm{~h}$. The volatiles were removed under reduced pressure and residual TFA removed by concentrating the residue from toluene. The residue was dissolved in pyridine $(5 \mathrm{~mL})$ and acetic anhydride $(2.5 \mathrm{~g})$ was added. The reaction mixture was stoppered and allowed to stir for $24 \mathrm{~h}$ then concentrated under reduced pressure. Purification of the mixture by flash chromatography, eluting with petroleum ether/ethyl acetate 3:2 afforded 2,3,4-tri-O-benzoyl- $\beta$-Dxylopyranosyl-( $1 \rightarrow 3$ )-1,2,4,6-tetra-O-acetyl-D-glucopyranose (1.25 g) 
as a colorless foam and a mixture of $\alpha$ and $\beta$ anomers. This foam $(1.25 \mathrm{~g}, 1.57 \mathrm{mmol})$ was taken up in DMF $(5 \mathrm{~mL})$, and hydrazinium acetate (caution:carcinogenic) $(174 \mathrm{mg}, 1.89 \mathrm{mmol}$ ) was added. The reaction mixture was allowed to stir for $1 \mathrm{~h}$, and then an additional portion of hydrazinium acetate $(50 \mathrm{mg})$ was added. The reaction mixture was left for a further $30 \mathrm{~min}$, and then the mixture was diluted with water $(50 \mathrm{~mL})$. The precipitated product was collected, washed with a little water, and then air dried. The solid was suspended in warm toluene $(10 \mathrm{~mL})$, hexanes $(5 \mathrm{~mL})$ were added, and then the suspension was allowed to cool. The product was collected by vacuum filtration affording 17 as a colorless crystalline solid (910 mg, 43\%): $\mathrm{mp} \quad 205-207^{\circ} \mathrm{C}$ (from $\mathrm{CH}_{2} \mathrm{Cl}_{2} /$ hexanes); $[\alpha]_{D}^{22}=-20.8\left(c=1.9\right.$ in $\left.\mathrm{CHCl}_{3}\right) ;{ }^{1} \mathrm{H}$ NMR $\left(300 \mathrm{MHz}, \mathrm{CDCl}_{3}, \mathrm{TMS}\right): \delta=$ 8.05-7.86 (m, 6H), 7.59-7.47 (m, 3H), 7.43-7.27 (m, 6H), 5.69 (dd, $\left.{ }^{3} J(H, H)=6.4,6.4 \mathrm{~Hz}, 1 \mathrm{H}\right), 5.42\left(\mathrm{dd},{ }^{3} \mathrm{~J}(\mathrm{H}, \mathrm{H})=3.7,3.7 \mathrm{~Hz}, 1 \mathrm{H}\right), 5.29$ $\left(\mathrm{dd},{ }^{3} \mathrm{~J}(\mathrm{H}, \mathrm{H})=6.7,4.8 \mathrm{~Hz}, 1 \mathrm{H}\right), 5.26-5.20(\mathrm{~m}, 1 \mathrm{H}), 5.15-5.06(\mathrm{~m}, 1 \mathrm{H})$, $5.00\left(\mathrm{~d},{ }^{3} J(\mathrm{H}, \mathrm{H})=4.7 \mathrm{~Hz}, 1 \mathrm{H}\right), 4.66\left(\mathrm{br} d d,{ }^{3} \mathrm{~J}(\mathrm{H}, \mathrm{H})=10.0,3.5,1.0 \mathrm{~Hz}\right.$, $1 \mathrm{H}), 4.41\left(\mathrm{dd},{ }^{3} \mathrm{~J}(\mathrm{H}, \mathrm{H})=12.4,3.8 \mathrm{~Hz}, 1 \mathrm{H}\right), 4.24\left(\mathrm{dd},{ }^{3} J(\mathrm{H}, \mathrm{H})=9.7\right.$, $9.7 \mathrm{~Hz}, 1 \mathrm{H}), 4.20-4.10(\mathrm{~m}, 3 \mathrm{H}), 3.72\left(\mathrm{dd},{ }^{3} \mathrm{~J}(\mathrm{H}, \mathrm{H})=12.4,6.2 \mathrm{~Hz}, 1 \mathrm{H}\right)$ $3.13\left(\mathrm{dd},{ }^{3}(\mathrm{H}, \mathrm{H})=3.6,0.8 \mathrm{~Hz}, 1 \mathrm{H}\right), 2.12(\mathrm{~s}, 3 \mathrm{H}), 2.10(\mathrm{~s}, 3 \mathrm{H})$, $1.90 \mathrm{ppm}(\mathrm{s}, 3 \mathrm{H}) ;{ }^{13} \mathrm{C}$ NMR $\left(75 \mathrm{MHz}, \mathrm{CDCl}_{3}, \mathrm{TMS}\right): \delta=170.8,169.9$, $169.6,165.6,165.3,165.0,133.4,133.4,133.2,129.8,129.7,129.2$ $128.9,128.4,128.3,100.8,89.9,77.1,73.2,69.9,69.5,68.8,68.8$, $67.5,62.2,60.9,20.9,20.7,20.5 \mathrm{ppm}$. HRMS (ESI) $\mathrm{m} / \mathrm{z}$ calcd for $\mathrm{C}_{40} \mathrm{H}_{40} \mathrm{O}_{17}+\mathrm{Na}^{+}$: $815.2163[\mathrm{M}+\mathrm{Na}]^{+}$, found: 815.2167; elemental analysis calcd (\%) for $\mathrm{C}_{40} \mathrm{H}_{40} \mathrm{O}_{17}\left(0.5 \times \mathrm{H}_{2} \mathrm{O}\right)$ : $\mathrm{C} 59.92, \mathrm{H}$ 5.15; found: C 60.07, H, 5.27.

2,3,4-Tri-O-benzoyl- $\beta$-D-xylopyranosyl-( $1 \rightarrow 3)$-2,4,6-tri-O-acetyl- $\alpha$ D-glucopyranosyl trichloroacetimidate (18): Glucopyranose 17 (804 mg, $1.07 \mathrm{mmol}$ ) was dissolved in $\mathrm{CH}_{2} \mathrm{Cl}_{2}(8 \mathrm{~mL})$, and then trichloroacetonitrile (309 mg, $2.1 \mathrm{mmol}$ ) and DBU ( $32 \mu \mathrm{L}, 0.21 \mathrm{mmol}$ ) were added. Treatment as per 14 afforded 18 as a colorless foam (767 mg, 80\%): $[\alpha]_{D}{ }^{21}=+4.6\left(c=1.4\right.$ in $\left.\mathrm{CHCl}_{3}\right) ;{ }^{1} \mathrm{H} \mathrm{NMR}(300 \mathrm{MHz}$, $\left.\mathrm{CD}_{3} \mathrm{OD}, \mathrm{TMS}\right): \delta=8.65(\mathrm{~s}, 1 \mathrm{H}), 8.08-7.88(\mathrm{~m}, 6 \mathrm{H}), 7.61-7.49(\mathrm{~m}, 3 \mathrm{H})$, 7.46-7.28 (m, 6H), $6.51\left(\mathrm{~d},{ }^{3} \mathrm{~J}(\mathrm{H}, \mathrm{H})=3.7 \mathrm{~Hz}, 1 \mathrm{H}\right), 5.73\left(\mathrm{dd},{ }^{3} \mathrm{~J}(\mathrm{H}, \mathrm{H})=\right.$ $6.5 \mathrm{~Hz}, 1 \mathrm{H}), 5.34-5.21(\mathrm{~m}, 3 \mathrm{H}), 5.06\left(\mathrm{~d},{ }^{3} \mathrm{~J}(\mathrm{H}, \mathrm{H})=4.5 \mathrm{~Hz}, 1 \mathrm{H}\right), 4.95$ $\left(\mathrm{dd},{ }^{3} J(\mathrm{H}, \mathrm{H})=9.9,3.7 \mathrm{~Hz}, 1 \mathrm{H}\right), 4.44\left(\mathrm{dd},{ }^{3} J(\mathrm{H}, \mathrm{H})=12.5,3.9 \mathrm{~Hz}, 1 \mathrm{H}\right)$, $4.28\left(\mathrm{dd},{ }^{3} \mathrm{~J}(\mathrm{H}, \mathrm{H})=9.7,9.7 \mathrm{~Hz}, 1 \mathrm{H}\right), 4.26-4.11(\mathrm{~m}, 3 \mathrm{H}), 3.79(\mathrm{dd}$, $\left.{ }^{3} J(\mathrm{H}, \mathrm{H})=12.5,5.7 \mathrm{~Hz}, 1 \mathrm{H}\right), 2.16(\mathrm{~s}, 3 \mathrm{H}), 2.10(\mathrm{~s}, 3 \mathrm{H}), 1.83 \mathrm{ppm}(\mathrm{s}$, $3 \mathrm{H}) ;{ }^{13} \mathrm{C}$ NMR $\left(75 \mathrm{MHz} \mathrm{CDCl}_{3}\right.$, TMS): $\delta=170.5,169.5,169.3,165.5$, $165.2,164.9,160.6,133.4,133.4,133.3,129.8,129.7,129.2,128.8$, $128.4,128.3,100.7,90.7,77.171 .9,70.3,69.8,69.3,68.7,68.0,61.7$, 60.9, 20.9, 20.6, 20.1; HRMS (ESI) $\mathrm{m} / z$ calcd for $\mathrm{C}_{40} \mathrm{H}_{38} \mathrm{O}_{16} \mathrm{Cl}_{3}+\mathrm{Na}^{+}$: $916.1154[\mathrm{M}+\mathrm{Na}]^{+}$, found: 916.1171 .

Allyl 23-O-benzoyl 3-O-[2,3,4,6-tetra-O-benzoyl- $\alpha$-D-mannopyranosyl-( $1 \rightarrow 3)$-2,4,6-tri-O-acetyl- $\beta$-D-glucopyranosyl]hederagenate (20): Allyl 23-O-benzoylhederagenate $3^{[17]}(521 \mathrm{mg}, 0.84 \mathrm{mmol})$ and trichloroacetimidate $9(870 \mathrm{mg}, 0.84 \mathrm{mmol})$ were combined in $\mathrm{CH}_{2} \mathrm{Cl}_{2}(25 \mathrm{~mL})$, and activated $4 \AA$ molecular sieves $(1 \mathrm{~g})$ were added. After $30 \mathrm{~min}$ the mixture was cooled to $-10^{\circ} \mathrm{C}$ in a brine/ ice bath and TMSOTf (19 mg, $0.084 \mathrm{mmol}$ ) was added. After $16 \mathrm{~h}$ treatment as per 11 afforded 20 as a colorless glass (965 mg, 77\%): $[\alpha]_{D}^{22}=+20.2\left(c=0.71\right.$ in $\left.\mathrm{CHCl}_{3}\right) ;{ }^{1} \mathrm{H}$ NMR $\left(300 \mathrm{MHz}, \mathrm{CDCl}_{3}, \mathrm{TMS}\right):$ $\delta=8.15-7.22(\mathrm{~m}, 25 \mathrm{H}), 6.27\left(\mathrm{t},{ }^{3} J(\mathrm{H}, \mathrm{H})=10.2 \mathrm{~Hz}, 1 \mathrm{H}\right), 5.96-5.80(\mathrm{~m}$, $1 \mathrm{H}), 5.70\left(\mathrm{dd},{ }^{3} J(\mathrm{H}, \mathrm{H})=3.3,1 \mathrm{H}\right), 5.55-5.54(\mathrm{~m}, 1 \mathrm{H}), 5.34-5.21(\mathrm{~m}$, $6 \mathrm{H}), 4.90-4.81(\mathrm{~m}, 1 \mathrm{H}), 4.58-4.51(\mathrm{~m}, 2 \mathrm{H}), 4.49\left(\mathrm{~d},{ }^{3} \mathrm{~J}(\mathrm{H}, \mathrm{H})=8.0 \mathrm{~Hz}\right.$, $1 \mathrm{H}), 4.43-4.40(\mathrm{~m}, 1 \mathrm{H}), 4.34-4.25(\mathrm{~m}, 2 \mathrm{H}), 4.18-4.05(\mathrm{~m}, 3 \mathrm{H}), 3.93$ $\left(\mathrm{t},{ }^{3} \mathrm{~J}(\mathrm{H}, \mathrm{H})=9.3 \mathrm{~Hz}, 1 \mathrm{H}\right), 3.61-3.53(\mathrm{~m}, 2 \mathrm{H}), 2.93-2.89(\mathrm{~m}, 1 \mathrm{H}), 2.26$ $(\mathrm{s}, 3 \mathrm{H}), 2.25,(\mathrm{~s}, 3 \mathrm{H}), 2.10(\mathrm{~s}, 3 \mathrm{H}), 2.02-0.74(\mathrm{~m}, 22 \mathrm{H}), 1.10(\mathrm{~s}, 3 \mathrm{H})$, $1.00(\mathrm{~s}, 3 \mathrm{H}), 0.93(\mathrm{~s}, 3 \mathrm{H}), 0.91(\mathrm{~s}, 3 \mathrm{H}), 0.83(\mathrm{~s}, 3 \mathrm{H}), 0.76 \mathrm{ppm}(\mathrm{s}, 3 \mathrm{H})$; ${ }^{13} \mathrm{C}$ NMR $\left(75 \mathrm{MHz}, \mathrm{CDCl}_{3}\right.$, TMS): $\delta=177.61,171.02,170.34,170.24$, 166.39, 166.26, 165.88, 165.74, 165.60, 144.0, 133.8 133.4, 133.2,
$132.9,130.8,130.4,130.1,130.1,129.8,129.4,129.4,128.9,128.8$, $128.6,122.7,118.1,103.0,100.4,83.9,83.0,73.2,72.0,70.8,70.3$ $69.6,66.2,66.0,65.2,62.7,62.0,48.5,48.5,47.1,46.2,42.5,42.0$, $41.8,39.8,38.7,36.8,34.3,33.5,33.0,32.9,31.0,27.9,25.8,25.7$, 24.0, 23.8, 23.4, 21.6, 21.1, 18.4, 17.4, 16.0, 14.5, 13.3 ppm; HRMS (ESI) $\mathrm{m} / \mathrm{z}$ calcd for $\mathrm{C}_{85} \mathrm{H}_{98} \mathrm{O}_{22}+\mathrm{Na}^{+}: 1505.6447[\mathrm{M}+\mathrm{Na}]^{+}$, found: 1505.6432. elemental analysis calcd (\%) for $\mathrm{C}_{85} \mathrm{H}_{98} \mathrm{O}_{22}$ : C 69.62, H 6.66, found: C 69.65, H 6.72 .

Allyl 3-O-[tetra-O-benzoyl- $\alpha$-D-mannopyranosyl-(1 $\rightarrow 3$ )-tri-Oacetyl- $\alpha$-D-glucopyranosyl]gypsogenate (21): To a stirred solution of allyl gypsogenate (4) $(623 \mathrm{mg}, 1219 \mu \mathrm{mol})$ and trichloroacetimidate 9 (920 mg, $894 \mu \mathrm{mol})$ in $\mathrm{CH}_{2} \mathrm{Cl}_{2}(10 \mathrm{~mL})$ under argon was added activated $4 \AA$ molecular sieves. The reaction was allowed to stir at ambient temperature for $30 \mathrm{~min}$ and then TMSOTf $(10 \mu \mathrm{L})$ was added. After $30 \mathrm{~min}$ two new spots were visible by TLC, and a further portion of TMSOTf $(10 \mathrm{uL})$ was added. After a further 30 min only a single major product was apparent, the second spot being consumed. Workup as per 11, eluting with toluene/ethyl acetate 95:5 then 90:10 gave 21 as a colorless foam $(346 \mathrm{mg}$, $32 \%):[\alpha]_{D}^{22}=+38.9\left(c=0.92\right.$ in $\left.\mathrm{CHCl}_{3}\right) ;{ }^{1} \mathrm{H} \mathrm{NMR}\left(300 \mathrm{MHz}, \mathrm{CDCl}_{3}\right)$ : $\delta=9.38(\mathrm{~s}, 1 \mathrm{H}), 8.16-8.10(\mathrm{~m}, 2 \mathrm{H}), 8.00-7.93(\mathrm{~m}, 4 \mathrm{H}), 7.86-7.81(\mathrm{~m}$, $2 \mathrm{H}), 7.61-7.21(\mathrm{~m}, 12 \mathrm{H}), 6.23\left(\mathrm{dd},{ }^{3} \mathrm{~J}(\mathrm{H}, \mathrm{H})=9.8,9.8 \mathrm{~Hz}, 1 \mathrm{H}\right), 5.96-$ $5.82(\mathrm{~m}, 1 \mathrm{H}), 5.67\left(\mathrm{dd},{ }^{3} J(\mathrm{H}, \mathrm{H})=10.3,3.1 \mathrm{~Hz}, 1 \mathrm{H}\right), 5.50\left(\mathrm{dd},{ }^{3} J(\mathrm{H}, \mathrm{H})=\right.$ 2.8, $2.0 \mathrm{~Hz}, 1 \mathrm{H}), 5.35-5.11(\mathrm{~m}, 5 \mathrm{H}), 5.04\left(\mathrm{dd},{ }^{3} \mathrm{~J}(\mathrm{H}, \mathrm{H})=9.1,8.0 \mathrm{~Hz}\right.$, $1 \mathrm{H}), 4.78\left(\mathrm{dd},{ }^{3} \mathrm{~J}(\mathrm{H}, \mathrm{H})=12.6,2.6 \mathrm{~Hz}, 1 \mathrm{H}\right), 4.60-4.44(\mathrm{~m}, 2 \mathrm{H}), 4.40-$ $4.22(\mathrm{~m}, 4 \mathrm{H}), 4.13\left(\mathrm{dd},{ }^{3} \mathrm{~J}(\mathrm{H}, \mathrm{H})=12.2,2.6 \mathrm{~Hz}, 1 \mathrm{H}\right), 3.87\left(\mathrm{dd},{ }^{3} J(\mathrm{H}, \mathrm{H})=\right.$ 11.4, $4.7 \mathrm{~Hz}, 1 \mathrm{H}$ ), 3.57 (ddd, $\left.{ }^{3} \mathrm{~J}(\mathrm{H}, \mathrm{H})=10.0,5.5,3.0 \mathrm{~Hz}, 1 \mathrm{H}\right), 2.94-$ $2.84(\mathrm{~m}, 1 \mathrm{H}), 2.25(\mathrm{~s}, 3 \mathrm{H}), 2.17(\mathrm{~s}, 3 \mathrm{H}), 2.10(\mathrm{~s}, 3 \mathrm{H}), 2.07-1.04(\mathrm{~m}$, $22 \mathrm{H}), 1.13(\mathrm{~s}, 3 \mathrm{H}), 1.09(\mathrm{~s}, 3 \mathrm{H}), 0.96(\mathrm{~s}, 3 \mathrm{H}), 0.92(\mathrm{~s}, 3 \mathrm{H}), 0.90(\mathrm{~s}$, $3 \mathrm{H}), 0.72 \mathrm{ppm}(\mathrm{s}, 3 \mathrm{H}) ;{ }^{13} \mathrm{C} \mathrm{NMR}\left(75 \mathrm{MHz}, \mathrm{CDCl}_{3}\right): \delta=206.7,177.2$, 170.6, 169.8, 165.8, 165.4, 165.3, 165.1143.8, 133.4, 133.0, 132.9, $132.4,129.9,129.7,129.7,129.0,128.9,128.5,128.4,128.2,122.0$, $117.7,102.1,99.7,83.2,82.0,72.2,71.7,70.4,69.8,69.3,65.8,64.8$, $62.3,61.7,54.8,48.8,47.5,46.6,45.9,41.7,41.3,39.6,38.0,35.9$, $33.8,33.0,32.3,32.0,30.6,27.6,25.8,24.8,23.5,23.3,22.9,21.0$, 20.7, 20.3.16.9, 15.4, $10.1 \mathrm{ppm}$. HRMS (ESI) $\mathrm{m} / \mathrm{z}$ calcd for $\mathrm{C}_{79} \mathrm{H}_{92} \mathrm{O}_{21} \mathrm{Na}: 1399.6029[\mathrm{M}+\mathrm{Na}]^{+}$, found: 1399.6046 .

Allyl 3-O-[2,3,4,6-tetra-O-benzoyl- $\alpha$-D-mannopyranosyl-(1 $\rightarrow 3$ 2,4,6-tri-O-acetyl- $\beta$-D-glucopyranosyl]oleanolate (22): To a stirred solution of allyl oleanolate $(19)^{[12]}(1.49 \mathrm{~g}, 3.0 \mathrm{mmol})$ dissolved in $\mathrm{CH}_{2} \mathrm{Cl}_{2}(10 \mathrm{~mL})$ was added trichloroacetimidate donor $9(2.06 \mathrm{~g}$ $2.0 \mathrm{mmol}$ ) followed by $4 \AA$ activated molecular sieves $(1.0 \mathrm{~g})$. The reaction mixture was allowed to stir at ambient temperature for $1 \mathrm{~h}$ and then cooled to $-10^{\circ} \mathrm{C}$ using an ice/MeOH bath. To the reaction mixture was added TMSOTf $(0.044 \mathrm{~mL}, 0.20 \mathrm{mmol})$, and the reaction mixture was allowed to stir for $30 \mathrm{~min}$. Workup as per 11, eluting with ethyl acetate/petroleum ether 3:7 afforded a 5:3 mixture of 22 and 2-deacylated (23) products as a colorless foam $(2.20 \mathrm{~g}, 81 \%)$. The two materials were separable by chromatography eluting with ethyl acetate/toluene gradient. First to elute was 22: $[\alpha]_{D}^{22}=+15.6\left(c=0.8\right.$ in $\left.\mathrm{CHCl}_{3}\right) ;{ }^{1} \mathrm{H}$ NMR $\left(300 \mathrm{MHz}, \mathrm{CDCl}_{3}\right.$, TMS): $\delta=8.19-8.13(\mathrm{~m}, 2 \mathrm{H}), 8.02-7.96(\mathrm{~m}, 4 \mathrm{H}), 7.90-7.82(\mathrm{~m}, 2 \mathrm{H})$, 7.63-7.47 $(\mathrm{m}, 3 \mathrm{H}), 7.47-7.23(\mathrm{~m}, 9 \mathrm{H}), 6.27\left(\mathrm{dd},{ }^{3} \mathrm{~J}(\mathrm{H}, \mathrm{H})=10.1\right.$, $10.1 \mathrm{~Hz}, 1 \mathrm{H}), 5.91$ (dddd, $\left.{ }^{3} J(\mathrm{H}, \mathrm{H})=17.2,10.5,5.7,5.7 \mathrm{~Hz}, 1 \mathrm{H}\right), 5.73$ $\left(\mathrm{dd},{ }^{3} \mathrm{~J}(\mathrm{H}, \mathrm{H})=10.3,3.0 \mathrm{~Hz}, 1 \mathrm{H}\right), 5.56\left(\mathrm{dd},{ }^{3} \mathrm{~J}(\mathrm{H}, \mathrm{H})=2.8,2.1 \mathrm{~Hz}, 1 \mathrm{H}\right)$, 5.38-5.16 $(\mathrm{m}, 6 \mathrm{H}), 4.86\left(\mathrm{dd},{ }^{3} \mathrm{~J}(\mathrm{H}, \mathrm{H})=12.6,2.4 \mathrm{~Hz}, 1 \mathrm{H}\right), 4.62-4.40$ $(\mathrm{m}, 4 \mathrm{H}), 4.35-4.26(\mathrm{~m}, 2 \mathrm{H}), 4.16\left(\mathrm{dd},{ }^{3} \mathrm{~J}(\mathrm{H}, \mathrm{H})=12.2,2.8 \mathrm{~Hz}, 1 \mathrm{H}\right), 3.95$ $\left(\mathrm{dd},{ }^{3} \mathrm{~J}(\mathrm{H}, \mathrm{H})=9.4,9.4 \mathrm{~Hz}, 1 \mathrm{H}\right), 3.63\left(\mathrm{ddd},{ }^{3} \mathrm{~J}(\mathrm{H}, \mathrm{H})=9.8,5.3,2.8 \mathrm{~Hz}\right.$, $1 \mathrm{H}), 3.10\left(\mathrm{dd},{ }^{3} \mathrm{~J}(\mathrm{H}, \mathrm{H})=11.2,4.8 \mathrm{~Hz}, 1 \mathrm{H}\right), 2.91\left(\mathrm{br} \mathrm{dd},{ }^{3} \mathrm{~J}(\mathrm{H}, \mathrm{H})=14.2\right.$, $4.2 \mathrm{~Hz}, 1 \mathrm{H}), 2.29(\mathrm{~s}, 3 \mathrm{H}), 2.18(\mathrm{~s}, 3 \mathrm{H}), 2.12(\mathrm{~s}, 3 \mathrm{H}), 2.06-1.01(\mathrm{~m}$, $22 \mathrm{H}), 1.16(\mathrm{~s}, 3 \mathrm{H}), 0.95(\mathrm{~s}, 3 \mathrm{H}), 0.95(\mathrm{~s}, 3 \mathrm{H}), 0.94(\mathrm{~s}, 3 \mathrm{H}), 0.92(\mathrm{~s}$, $3 \mathrm{H}), 0.79(\mathrm{~s}, 3 \mathrm{H}), 0.76 \mathrm{ppm}(\mathrm{s}, 3 \mathrm{H}) ;{ }^{13} \mathrm{C}$ NMR $\left(75 \mathrm{MHz}, \mathrm{CDCl}_{3}\right): \delta=$ 
177.2, 170.6, 169.7, 169.4, 165.8, 165.4, 165.3, 165.1, 143.6, 133.3 $133.3,133.0,132.8,132.4,129.9,129.7,129.6,129.0,129.0,128.9$ 128.4, 128.3, 128.1, 122.3, 117.6, 103.0, 99.9, 90.4, 82.4, 72.7, 71.6, $70.4,69.9,69.8,69.4,65.8,64.7,62.4,61.6,55.5,47.6,46.6,45.8$, $41.6,41.2,39.3,38.8,38.4,36.6,33.8,33.0,32.7,32.3,30.6,27.7$, $27.6,25.8,25.7,23.5,23.3,23.0,21.2,20.7,18.1,16.9,16.3$, $15.1 \mathrm{ppm}$; HRMS (ESI) $\mathrm{m} / z$ calcd for $\mathrm{C}_{79} \mathrm{H}_{94} \mathrm{O}_{20}+\mathrm{Na}^{+}: 1385.6236$ $\left[\mathrm{M}+\mathrm{Na}^{+}\right]$, found: 1385.6195. Next to elute was Allyl 3-O-[2,3,4,6tetra-O-benzoyl- $\alpha$-D-mannopyranosyl-( $1 \rightarrow 3)-4,6$-di-O-acetyl- $\beta$-Dglucopyranosyl]oleanolate (23): ${ }^{1} \mathrm{H} \mathrm{NMR}$ (300 MHz, CDCl, $\mathrm{TMS}$ ): $\delta=8.14-8.02(\mathrm{~m}, 4 \mathrm{H}), 8.01-7.96(\mathrm{~m}, 2 \mathrm{H}), 7.88-7.82(\mathrm{~m}, 2 \mathrm{H}), 7.60-$ $7.20(\mathrm{~m}, 12 \mathrm{H}), 6.17\left(\mathrm{dd},{ }^{3} J(\mathrm{H}, \mathrm{H})=10.1,10.1 \mathrm{~Hz}, 1 \mathrm{H}\right), 5.98-5.85(\mathrm{~m}$, $2 \mathrm{H}), 5.50\left(\mathrm{dd},{ }^{3} J(\mathrm{H}, \mathrm{H})=3.2,1.7 \mathrm{~Hz}, 1 \mathrm{H}\right), 5.38-5.28(\mathrm{~m}, 3 \mathrm{H}), 5.25-$ $5.13(\mathrm{~m}, 2 \mathrm{H}), 4.94\left(\mathrm{ddd},{ }^{3} J(\mathrm{H}, \mathrm{H})=9.9,2.6,2.6,1 \mathrm{H}\right), 4.75(\mathrm{dd}$, $\left.{ }^{3} \mathrm{~J}(\mathrm{H}, \mathrm{H})=12.5,2.6 \mathrm{~Hz}, 1 \mathrm{H}\right), 4.57-4.51(\mathrm{~m}, 2 \mathrm{H}), 4.43\left(\mathrm{dd},{ }^{3} \mathrm{~J}(\mathrm{H}, \mathrm{H})=\right.$ 12.3, $3.5 \mathrm{~Hz}, 1 \mathrm{H}), 4.38\left(\mathrm{~d},{ }^{3} J(\mathrm{H}, \mathrm{H})=7.5 \mathrm{~Hz}, 1 \mathrm{H}\right), 4.28\left(\mathrm{dd},{ }^{3} J(\mathrm{H}, \mathrm{H})=\right.$ 12.3, $5.7 \mathrm{~Hz}, 1 \mathrm{H}), 4.09\left(\mathrm{~d},{ }^{3} \mathrm{~J}(\mathrm{H}, \mathrm{H})=12.1,2.6 \mathrm{~Hz}, 1 \mathrm{H}\right), 3.89$ (dd, $\left.{ }^{3} J(H, H)=9.2 \mathrm{~Hz}, 1 \mathrm{H}\right), 3.71\left(\mathrm{ddd},{ }^{3} J(\mathrm{H}, \mathrm{H})=9.9,7.7,2.6 \mathrm{~Hz}, 1 \mathrm{H}\right), 3.59$ (ddd, $\left.{ }^{3} J(\mathrm{H}, \mathrm{H})=9.7,5.4,2.5 \mathrm{~Hz}, 1 \mathrm{H}\right), 3.16\left(\mathrm{dd},{ }^{3} J(\mathrm{H}, \mathrm{H})=11.1,4.6 \mathrm{~Hz}\right.$, $1 \mathrm{H}), 2.96-2.86(\mathrm{~m}, 1 \mathrm{H}), 2.75\left(\mathrm{~d},{ }^{3} \mathrm{~J}(\mathrm{H}, \mathrm{H})=2.5 \mathrm{~Hz}, 1 \mathrm{H}\right), 2.22(\mathrm{~s}, 3 \mathrm{H})$, $2.10(\mathrm{~s}, 3 \mathrm{H}), 2.02-1.04(\mathrm{~m}, 22 \mathrm{H}), 1.16(\mathrm{~s}, 3 \mathrm{H}), 1.00(\mathrm{~s}, 3 \mathrm{H}), 0.95(\mathrm{~s}$, $6 \mathrm{H}), 0.91(\mathrm{~s}, 3 \mathrm{H}), 0.85(\mathrm{~s}, 3 \mathrm{H}), 0.75 \mathrm{ppm}(\mathrm{s}, 3 \mathrm{H}) ;{ }^{13} \mathrm{C} \mathrm{NMR}(75 \mathrm{MHz}$, $\left.\mathrm{CDCl}_{3}\right): \delta=177.3,170.7,170.0,166.3,165.5,165.3,163.6,143.6$ 137.7, 133.4, 133.3, 133.1, 132.9, 132.4, 129.9, 129.7, 129.5, 129.1, $128.9,128.1,125.2,122.3,117.6,104.8,98.2,90.2,80.9,73.2,71.6$, $70.9,70.4,69.6,68.9,68.8,64.7,62.7,62.5,55.5,47.6,46.7,45.8$, $41.6,41.3,39.3,38.9,38.4,36.7,33.8,33.0,32.7,32.3,30.6,29.6$, 28.3, 27.6, 25.8, 25.7, 23.5, 23.3, 23.0, 20.7, 16.9, 16.6 ppm; HRMS (ESI) $\mathrm{m} / \mathrm{z}$ calcd for $\mathrm{C}_{77} \mathrm{H}_{92} \mathrm{O}_{19}+\mathrm{Na}^{+}: 1343.6155[\mathrm{M}+\mathrm{Na}]^{+}$, found: 1343.6150 .

3-O-[ $\alpha$-D-Mannopyranosyl-(1 $\rightarrow$ 3)- $\beta$-D-glucopyranosyl]hederagenin (24): A stirred solution of protected saponin 20 (654 mg, $441 \mu \mathrm{mol})$ in $\mathrm{CH}_{2} \mathrm{Cl}_{2}(10 \mathrm{~mL})$ and $\mathrm{MeOH}(10 \mathrm{~mL})$ was degassed using sonication under a constant flow of Ar. To this solution was added triphenylphosphine ( $25 \mathrm{mg}, 95 \mu \mathrm{mol})$ followed by $\mathrm{Pd}^{0}\left(\mathrm{PPh}_{3}\right)_{4}$ (50 mg, $43.3 \mu \mathrm{mol})$. The reaction was allowed to stir for $3 \mathrm{~h}$, and then sodium methoxide ( $30 \% \mathrm{w} / \mathrm{v}$ in $\mathrm{MeOH}, 3 \mathrm{~mL})$ was added, and the reaction mixture allowed to stir $\mathrm{o} / \mathrm{n}$. The mixture was then quenched with Dowex 50WX8 $\left(\mathrm{H}^{+}\right.$-form) and filtered, the resin was washed well with $\mathrm{MeOH}$, and the filtrate concentrated under reduced pressure. Purification of the residue by gradient flash chromatography, eluting with $\mathrm{CHCl}_{3} / \mathrm{MeOH} /$ acetic acid 70:30:1 then 60:40:1 afforded a colorless solid. The product was dissolved in $\mathrm{MeOH}$ and then precipitated with water and collected and dried under vacuum to give 24 as a white amorphous solid (280 mg, $80 \%):[\alpha]_{D}{ }^{22}+60(c=1.7$ in $\mathrm{MeOH}) ;{ }^{1} \mathrm{H} N M R\left(300 \mathrm{MHz}, \mathrm{CD}_{3} \mathrm{OD}\right.$, TMS): $\delta=5.23-5.22(\mathrm{~m}, 2 \mathrm{H}), 4.42\left(\mathrm{~d},{ }^{3} \mathrm{~J}(\mathrm{H}, \mathrm{H})=7.8 \mathrm{~Hz}, 1 \mathrm{H}\right), 4.01-3.92$ $(\mathrm{m}, 2 \mathrm{H}), 3.85-3.60(\mathrm{~m}, 8 \mathrm{H}), 3.58-3.41(\mathrm{~m}, 2 \mathrm{H}), 3.28-3.20(\mathrm{~m}, 3 \mathrm{H})$, 2.96-2.86 (m, 1H), 2.05-0.97 (m, 22H), $1.17(\mathrm{~s}, 3 \mathrm{H}), 0.98(\mathrm{~s}, 3 \mathrm{H})$, $0.94(\mathrm{~s}, 3 \mathrm{H}), 0.91(\mathrm{~s}, 3 \mathrm{H}), 0.82(\mathrm{~s}, 3 \mathrm{H}), 0.70 \mathrm{ppm}(\mathrm{s}, 3 \mathrm{H}) ;{ }^{13} \mathrm{C} N M R$ (75 MHz, CD $\left.\mathrm{CD}_{3} \mathrm{OD}\right): \delta=182.2,145.7,123.9,106.1,102.8,84.9,83.9$, 77.8, 74.7, 73.0, 72.7, 72.3, 68.9, 65.3, 63.1, 62.9, 48.0, 47.7, 44.3, 43.4, 43.2, 41.0, 39.9, 38.1, 35.3, 34.3, 34.0, 32.0, 29.3, 26.9, 26.7, 25.0, 24.4, 19.3, 18.2, 16.8, $13.9 \mathrm{ppm}$; HRMS (ESI) $\mathrm{m} / \mathrm{z}$ calcd for $\mathrm{C}_{42} \mathrm{H}_{68} \mathrm{O}_{14}+\mathrm{Na}^{+}: 819.4507[\mathrm{M}+\mathrm{Na}]^{+}$, found: 819.4530 .

Allyl 3-O-[ $\alpha$-D-mannopyranosyl-( $1 \rightarrow 3$ )- $\beta$-D-glucopyranosyl]hederagenate (25): To a stirred solution of protected saponin 20 (280 $\mathrm{mg}, 0.18 \mathrm{mmol})$ in $\mathrm{MeOH}(10 \mathrm{~mL})$ was added sodium methoxide $(30 \% \mathrm{w} / \mathrm{v}$ in $\mathrm{MeOH}, 0.30 \mathrm{~mL})$. The reaction mixture was stirred for $1 \mathrm{~h}$ then concentrated under reduced pressure. The residue was taken up in $\mathrm{CH}_{2} \mathrm{Cl}_{2}$ (50 mL), and $\mathrm{MeOH}(50 \mathrm{~mL})$ and $\mathrm{NaOH}$ solution $(1.0 \mathrm{M}, 10 \mathrm{~mL})$ were added. The mixture was allowed to stir for
$4 \mathrm{~h}$, and then the mixture concentrated under reduced pressure. The residue was diluted with water $(20 \mathrm{~mL})$, and the precipitated solid collected, washed with water, then dried under high vacuum to give 25 as a colorless solid $\left(124 \mathrm{mg}, 78 \%\right.$ ): $[\alpha]_{\mathrm{D}}^{22}=+58.0(c=$ 0.67 in $\mathrm{MeOH}$ ); ${ }^{1} \mathrm{H}$ NMR (300 MHz, CD $\left.\mathrm{CD}, \mathrm{TMS}\right): \delta=5.92$ (dddd, $\left.{ }^{3} \mathrm{~J}(\mathrm{H}, \mathrm{H})=16.9,10.5,5.9,5.9 \mathrm{~Hz}, 1 \mathrm{H}\right), 5.32\left(\mathrm{dddd},{ }^{3} \mathrm{~J}(\mathrm{H}, \mathrm{H})=16.9,1.5\right.$, 1.0, $1.0 \mathrm{~Hz}, 1 \mathrm{H}), 5.28-5.17(\mathrm{~m}, 3 \mathrm{H}), 4.60-4.44(\mathrm{~m}, 2 \mathrm{H}), 4.40(\mathrm{~d}$, $\left.{ }^{3} \mathrm{~J}(\mathrm{H}, \mathrm{H})=7.7 \mathrm{~Hz}, 1 \mathrm{H}\right), 3.97\left(\mathrm{ddd},{ }^{3} \mathrm{~J}(\mathrm{H}, \mathrm{H})=9.2,5.2,2.4 \mathrm{~Hz}, 1 \mathrm{H}\right), 3.93$ $\left(\mathrm{dd},{ }^{3} J(\mathrm{H}, \mathrm{H})=3.0,1.9 \mathrm{~Hz}, 1 \mathrm{H}\right), 3.86-3.78(\mathrm{~m}, 2 \mathrm{H}), 3.77-3.58(\mathrm{~m}, 6 \mathrm{H})$, $3.52\left(\mathrm{dd},{ }^{3} J(\mathrm{H}, \mathrm{H})=9.0,8.9 \mathrm{~Hz}, 1 \mathrm{H}\right), 3.43\left(\mathrm{dd},{ }^{3} J(\mathrm{H}, \mathrm{H})=9.2,9.0 \mathrm{~Hz}\right.$, $1 \mathrm{H}), 3.28-3.17(\mathrm{~m}, 2 \mathrm{H}), 2.94-2.84(\mathrm{~m}, 1 \mathrm{H}), 2.13-1.00(\mathrm{~m}, 20 \mathrm{H}), 1.17$ $(\mathrm{s}, 3 \mathrm{H}), 0.97(\mathrm{~s}, 3 \mathrm{H}), 0.93(\mathrm{~s}, 3 \mathrm{H}), 0.91(\mathrm{~s}, 3 \mathrm{H}), 0.75(\mathrm{~s}, 3 \mathrm{H}), 0.70(\mathrm{~s}$, $3 \mathrm{H}){ }^{13} \mathrm{C}$ NMR $\left(75 \mathrm{MHz}, \mathrm{CD}_{3} \mathrm{OD}\right): \delta=179.1,145.0,133.7,123.8,118.2$, 105.7, 102.4, 84.5, 83.5, 77.4, 74.3, 72.5, 72.3, 71.9, 68.6, 66.0, 64.8, 62.7, 62.5, 47.1, 43.8, 42.9, 42.8, 40.6, 39.4, 37.6, 34.8, 33.7, 33.4, 31.5, 28.7, 26.4, 26.3, 24.5, 24.1, 23.9, 18.8, 17.8, 16.4, 13.4 ppm; HRMS (ESI) $m / z$ calcd for $\mathrm{C}_{45} \mathrm{H}_{72} \mathrm{O}_{14}+\mathrm{Na}^{+}: 859.4820[\mathrm{M}+\mathrm{Na}]^{+}$ found: 859.4836 .

\section{3-O-[ $\alpha$-D-Mannopyranosyl-( $1 \rightarrow 3$ )- $\beta$-D-glucopyranosyl]gypsoge-}

nin (26): To a stirred solution of protected saponin 21 (186 mg, $0.135 \mathrm{mmol})$ dissolved in $\mathrm{CH}_{2} \mathrm{Cl}_{2} / \mathrm{MeOH}(1: 1,4 \mathrm{~mL})$ was added triphenylphosphine $(35 \mathrm{mg}, 0.13 \mathrm{mmol}$ ) and tetrakis(triphenylphosphine) palladium(0) (25 mg, $0.02 \mathrm{mmol})$. The reaction mixture was stirred for $16 \mathrm{~h}$ at which time no allyl ester remained (TLC) and then sodium methoxide $(30 \% \mathrm{w} / \mathrm{v}$ in $\mathrm{MeOH}, 1.0 \mathrm{~mL})$ was added. After $6 \mathrm{~h}$, some solids began precipitating so the reaction mixture was diluted with $\mathrm{MeOH}(\sim 5 \mathrm{~mL})$ giving a homogenous solution. After a further $3 \mathrm{~h}$, the mixture was diluted with $\mathrm{MeOH}$ and acidified using Amberjet $1200 \mathrm{H}$ (solution $\mathrm{pH} 3-4$ ). The suspension was filtered and the resin washed well with $\mathrm{MeOH}$, then the volatiles removed under reduced pressure and the product absorbed onto silica gel. Purification by flash chromatography, eluting with a gradient of $\mathrm{CHCl}_{3} / \mathrm{MeOH} /$ acetic acid 90:10:1 to 70:30:1 gave a colorless solid. This solid was dissolved in a minimal amount of warm $\mathrm{MeOH}$, cooled, and then precipitated with ethyl acetate to give 26 as a colorless solid (95 mg, 89\%): $[\alpha]_{D}^{22}=+104(c=0.68$ in $\mathrm{MeOH})$; ${ }^{1} \mathrm{H}$ NMR (300 MHz, CD $\left.\mathrm{OD}, \mathrm{TMS}\right): \delta=9.40(\mathrm{~s}, 1 \mathrm{H}), 5.27$ (br dd, $\left.{ }^{3} J(\mathrm{H}, \mathrm{H})=3.0,3.0, \mathrm{~Hz}, 1 \mathrm{H}\right), 5.22\left(\mathrm{~d},{ }^{3} J(\mathrm{H}, \mathrm{H})=1.5 \mathrm{~Hz}, 1 \mathrm{H}\right), 4.22(\mathrm{~d}$, $\left.{ }^{3} J(H, H)=7.8 \mathrm{~Hz}, 1 \mathrm{H}\right), 4.00-3.60(\mathrm{~m}, 9 \mathrm{H}), 3.49\left(\mathrm{dd},{ }^{3} J(\mathrm{H}, \mathrm{H})=9.0\right.$, $8.9 \mathrm{~Hz}, 1 \mathrm{H}), 3.40\left(\mathrm{dd},{ }^{3} J(\mathrm{H}, \mathrm{H})=9.5,9.0 \mathrm{~Hz}, 1 \mathrm{H}\right), 3.23\left(\mathrm{ddd},{ }^{3} J(\mathrm{H}, \mathrm{H})=\right.$ 9.3, 5.6, $2.6 \mathrm{~Hz}, 1 \mathrm{H}), 3.13\left(\mathrm{dd},{ }^{3} J(\mathrm{H}, \mathrm{H})=8.2,8.3 \mathrm{~Hz}, 1 \mathrm{H}\right), 2.93-2.81$ $(\mathrm{m}, 1 \mathrm{H}), 2.09-1.00(\mathrm{~m}), 1.20(\mathrm{~s}, 3 \mathrm{H}), 1.12(\mathrm{~s}, 3 \mathrm{H}), 1.01(\mathrm{~s}, 3 \mathrm{H}), 0.95$ $(\mathrm{s}, 3 \mathrm{H}), 0.92(\mathrm{~s}, 3 \mathrm{H}), 0.83 \mathrm{ppm}(\mathrm{s}, 3 \mathrm{H}) ;{ }^{13} \mathrm{C}$ NMR $\left(75 \mathrm{MHz} \mathrm{CDCl}_{3}\right): \delta=$ 209.0, 145.3, 123.3, 104.7, 102.3, 83.9, 83.0, 77.6, 74.2, 74.0, 72.5, $74.0,72.5,72.3,71.9,68.5,62.7,62.5,58.1,47.6,47.2,42.9,42.7$ $40.8,39.2,37.0,34.9,38.8,33.5,33.3,31.6,28.8,26.4,25.7,24.4$, 24.0, 23.9, 21.7, 21.3, 17.7, 16.0, 10.4 ppm; HRMS (ESI) $\mathrm{m} / \mathrm{z}$ calcd for $\mathrm{C}_{42} \mathrm{H}_{66} \mathrm{O}_{14}+\mathrm{Na}^{+}: 817.4350[\mathrm{M}+\mathrm{Na}]^{+}$, found: 817.4345 ; elemental analysis calcd (\%) for $\left[26 \cdot \mathrm{H}_{2} \mathrm{O}\right] \mathrm{C}_{42} \mathrm{H}_{68} \mathrm{O}_{15}: \mathrm{C} 62.05, \mathrm{H}$ 8.43, found: $\mathrm{C}$ 61.82 , H 8.45 .

\section{3-O-[ $\alpha$-D-Mannopyranosyl-( $1 \rightarrow 3$ )- $\beta$-D-glucopyranosyl]oleanolic} acid (27): A 5:3 mixture of 22 and 23 (2.20 mg, $0.19 \mathrm{mmol}$ ) was dissolved in $\mathrm{MeOH}(10 \mathrm{~mL})$ and $\mathrm{CH}_{2} \mathrm{Cl}_{2}(10 \mathrm{~mL})$. The mixture was degassed by sonication/vacuum and the atmosphere replaced with $\mathrm{Ar}$, and then $\mathrm{Pd}^{0}\left(\mathrm{PPh}_{3}\right)_{4}(400 \mathrm{mg}, 0.35 \mathrm{mmol})$ and triphenylphosphine $(100 \mathrm{mg})$ were added. The reaction was allowed to stir for $3 \mathrm{~h}$, and then sodium methoxide $(30 \% \mathrm{w} / \mathrm{v}$ in $\mathrm{MeOH}, 3 \mathrm{~mL})$ was added and the reaction left for $2 \mathrm{~h}$. The $\mathrm{CH}_{2} \mathrm{Cl}_{2}$ was then removed under reduced pressure, and then water $(30 \mathrm{~mL}), \mathrm{MeOH}(10 \mathrm{~mL})$, and $1 \mathrm{~N}$ aq. $\mathrm{NaOH}(10 \mathrm{~mL})$ were added. The reaction mixture was stirred for $16 \mathrm{~h}$ and then quenched with Dowex 50WX8 $\left(\mathrm{H}^{+}\right)$. The precipitated solids were dissolved by the addition of $\mathrm{MeOH}$ and 
then filtered to remove the resin. Concentration of the filtrate under reduced pressure and purification by flash chromatography, eluting with $\mathrm{CHCl}_{3} / \mathrm{MeOH} /$ acetic acid 80:20:1 afforded 27 as a colorless amorphous solid $(1.08 \mathrm{~g}, 90 \%):[\alpha]_{D}^{22}=+44 \quad(c=0.54$ in $\left.\mathrm{CH}_{3} \mathrm{OH}\right) ;{ }^{1} \mathrm{H}$ NMR $\left(300 \mathrm{MHz}, \mathrm{CD}_{3} \mathrm{OD}, \mathrm{TMS}\right): \delta=5.25(\mathrm{~m}, 2 \mathrm{H}), 4.34(\mathrm{~d}$, $\left.{ }^{3} J(\mathrm{H}, \mathrm{H})=7.8 \mathrm{~Hz}, 1 \mathrm{H}\right), 3.99\left(\mathrm{ddd},{ }^{3} J(\mathrm{H}, \mathrm{H})=9.9,5.6,2.8 \mathrm{~Hz}, 1 \mathrm{H}\right), 3.93$ $\left(\mathrm{dd},{ }^{3} J(\mathrm{H}, \mathrm{H})=3.4,1.8 \mathrm{~Hz}, 1 \mathrm{H}\right), 3.88-3.80(\mathrm{~m}, 2 \mathrm{H}), 3.78-3.62(\mathrm{~m}, 4 \mathrm{H})$, $3.53\left(\mathrm{dd},{ }^{3} \mathrm{~J}(\mathrm{H}, \mathrm{H})=8.9,8.9 \mathrm{~Hz}, 1\right), 3.43\left(\mathrm{dd},{ }^{3} \mathrm{~J}(\mathrm{H}, \mathrm{H})=8.9,8.9 \mathrm{~Hz}, 1 \mathrm{H}\right)$, 3.27-3.15 $(\mathrm{m}, 3 \mathrm{H}), 2.85\left(\mathrm{br} \mathrm{dd},{ }^{3} \mathrm{~J}(\mathrm{H}, \mathrm{H})=13.6,4.0 \mathrm{~Hz}, 1 \mathrm{H}\right), 2.08-0.99$ $(\mathrm{m}, 23 \mathrm{H}), 1.16(\mathrm{~s}, 3 \mathrm{H}), 1.06(\mathrm{~s}, 3 \mathrm{H}), 0.95(\mathrm{~s}, 3 \mathrm{H}), 0.94(\mathrm{~s}, 3 \mathrm{H}), 0.91(\mathrm{~s}$, $3 \mathrm{H}), 0.84(\mathrm{~s}, 3 \mathrm{H}), 0.82 \mathrm{ppm}(\mathrm{s}, 3 \mathrm{H}) ;{ }^{13} \mathrm{C}$ NMR $\left(75 \mathrm{MHz}, \mathrm{CD}_{3} \mathrm{OD}\right): \delta=$ 181.8, 145.2, 123.6, 106.7, 102.3, 90.8, 84.3, 77.4, 74.4, 74.2, 72.5, $72.3,72.1,68.6,62.8,62.6,57.0,47.6,47.2,42.9,42.7,40.5,40.1$, $39.7,37.9,34.9,34.0,33.8,33.5,31.6,28.8,28.6,26.9,26.3,24.5$, 24.0, 23.9, 19.3, 17.7, 17.0, 15.9 ppm; HRMS (ESI) $\mathrm{m} / \mathrm{z}$ calcd for $\mathrm{C}_{42} \mathrm{H}_{68} \mathrm{O}_{13}+\mathrm{Na}^{+}: 803.4558[\mathrm{M}+\mathrm{Na}]^{+}$, found: 803.4572 .

Undecyl 3-O-[ $\alpha$-D-mannopyranosyl-( $1 \rightarrow 3)-\beta$-D-glucopyranosyl]hederagenate (28): To a stirred solution of saponin $24(28 \mathrm{mg}$, $35 \mu \mathrm{mol})$ dissolved in DMF $(0.5 \mathrm{~mL})$ was added 1-bromoundecane $(17 \mathrm{mg}, 70 \mu \mathrm{mol})$ and $\mathrm{K}_{2} \mathrm{CO}_{3}(15 \mathrm{mg}, 0.10 \mathrm{mmol})$. The reaction mixture was warmed to $70^{\circ} \mathrm{C}$ and allowed to stir for $16 \mathrm{~h}$. The volatiles were then removed under reduced pressure, the residue absorbed onto silica and purified by flash chromatography, eluting with $\mathrm{CHCl}_{3} / \mathrm{MeOH} /$ aq. $\mathrm{NH}_{3}$ 80:20:1 to give 28 as a colorless foam (24 mg, 72\%): $[\alpha]_{D}^{22}=+46(c=0.9$ in $\mathrm{MeOH}) ;{ }^{1} \mathrm{H}$ NMR $(300 \mathrm{MHz}$, $\left.\mathrm{CD}_{3} \mathrm{OD}, \mathrm{TMS}\right): \delta=5.30-5.22(\mathrm{br} \mathrm{m}, 2 \mathrm{H}), 4.42\left(\mathrm{~d},{ }^{3} \mathrm{~J}(\mathrm{H}, \mathrm{H})=7.8 \mathrm{~Hz}\right.$, $1 \mathrm{H}), 4.10-3.93(\mathrm{~m}, 4 \mathrm{H}), 3.88-3.62(\mathrm{~m}, 8 \mathrm{H}), 3.58-3.42(\mathrm{~m}, 2 \mathrm{H}), 3.28-$ $3.20(\mathrm{~m}, 2 \mathrm{H}), 2.90\left(\mathrm{br} \mathrm{dd},{ }^{3} \mathrm{~J}(\mathrm{H}, \mathrm{H})=13.5,3.8 \mathrm{~Hz}, 1 \mathrm{H}\right), 2.14-1.84 \mathrm{~m}$, $4 \mathrm{H}), 1.83-0.86(\mathrm{~m}, 37 \mathrm{H}), 1.19(\mathrm{~s}, 3 \mathrm{H}), 1.00(\mathrm{~s}, 3 \mathrm{H}), 0.96(\mathrm{~s}, 3 \mathrm{H}), 0.92$ $(\mathrm{s}, 3 \mathrm{H}), 0.92\left(\mathrm{t},{ }^{3} \mathrm{~J}(\mathrm{H}, \mathrm{H})=6.6 \mathrm{~Hz}, 3 \mathrm{H}\right), 0.78(\mathrm{~s}, 3 \mathrm{H}), 0.72 \mathrm{ppm}(\mathrm{s}, 3 \mathrm{H})$; ${ }^{13} \mathrm{C}$ NMR $\left(75 \mathrm{MHz}, \mathrm{CD}_{3} \mathrm{OD}\right): \delta=179.6,145.1,123.8,105.7,102.4$, $84.5,83.4,77.5,74.3,72.5,72.3,71.9,68.6,65.5,64.8,62.7,62.5$, $47.1,43.8,42.9,42.8,40.6,39.4,37.6,34.8,33.7,33.4,33.4,33.1$, $31.6,30.8,30.7,30.5,30.2,29,6 \mathrm{~m} \mathrm{28.7,} 27.2,26.4,26.3,24.6,24.0$, 23.9, 23.7, 18.8, 17.9, 16.4, 14.4, 13.4 ppm; HRMS (ESI) $\mathrm{m} / \mathrm{z}$ calcd for $\mathrm{C}_{53} \mathrm{H}_{90} \mathrm{O}_{14}+\mathrm{Na}^{+}: 973.6228[\mathrm{M}+\mathrm{Na}]^{+}$, found: 973.6243 .

Undecyl 3-O-[ $\alpha$-D-mannopyranosyl-( $1 \rightarrow 3)-\beta$-D-glucopyranosyl]oleanolate (29): To a stirred solution of saponin 27 (127 mg, $0.16 \mathrm{mmol})$ dissolved in DMF $(4 \mathrm{~mL})$ was added 1-bromoundecane $(382 \mathrm{mg}, 0.16 \mathrm{mmol})$ and $\mathrm{K}_{2} \mathrm{CO}_{3}(120 \mathrm{mg}, 0.86 \mathrm{mmol})$, and the solution warmed to $50{ }^{\circ} \mathrm{C}$ for $16 \mathrm{~h}$. Workup as per 28 afforded 29 as a colorless foam $(100 \mathrm{mg}, 66 \%):[\alpha]_{D}^{24}=+46$ (c $\left.0.48, \mathrm{MeOH}\right)$; ${ }^{1} \mathrm{H}$ NMR (300 MHz, CD $\left.\mathrm{OD}, \mathrm{TMS}\right): \delta=5.33-5.20(\mathrm{~m}, 2 \mathrm{H}), 4.36(\mathrm{~d}$, $\left.{ }^{3} \mathrm{~J}(\mathrm{H}, \mathrm{H})=7.8 \mathrm{~Hz}, 1 \mathrm{H}\right), 4.11-3.96(\mathrm{~m}, 3 \mathrm{H}), 3.94\left(\mathrm{dd},{ }^{3} \mathrm{~J}(\mathrm{H}, \mathrm{H})=3.2\right.$, $1.8 \mathrm{~Hz}, 1 \mathrm{H}), 3.88-3.82(\mathrm{~m}, 2 \mathrm{H}), 3.79-3.63(\mathrm{~m}, 4 \mathrm{H}), 3.57-3.41(\mathrm{~m}$, $2 \mathrm{H}), 3.29-3.15(\mathrm{~m}, 3 \mathrm{H}), 2.96-2.86(\mathrm{~m}, 1 \mathrm{H}), 2.12-0.97(\mathrm{~m}, 40 \mathrm{H}), 1.18$ $(\mathrm{s}, 3 \mathrm{H}), 1.08(\mathrm{~s}, 3 \mathrm{H}), 0.96(\mathrm{~s}, 3 \mathrm{H}), 0.95(\mathrm{~s}, 3 \mathrm{H}), 0.93(\mathrm{~s}, 3 \mathrm{H}), 0.92(\mathrm{t}$, $\left.{ }^{3} \mathrm{~J}(\mathrm{H}, \mathrm{H})=7.0 \mathrm{~Hz}, 3 \mathrm{H}\right), 0.86(\mathrm{~s}, 3 \mathrm{H}), 0.78 \mathrm{ppm} \quad(\mathrm{s}, 3 \mathrm{H}) ;{ }^{13} \mathrm{C} \mathrm{NMR}$ (75 MHz, CD $\mathrm{OD}$ ): $\delta=179.6,145.0,123.8,106.7,102.3,90.7,84.3$, $77.4,74.4,77.2,72.5,72.3,72.0,68.6,65.5,62.8,62.6,57.0,47.1$, $42.8,42.7,40.7,40.1,39.7,37.9,34.8,34.0,33.7,33.4,33.1,31.5$, $30.7,30.5,30.2,29.6,28.7,28.6,27.2,26.9,26.3,24.5,24.0,23.9$, $23.7,23.5,19.3,17.9,17.0,15.9,14.4$; HRMS (ESI) $\mathrm{m} / \mathrm{z}$ calcd for $[\mathrm{M}+$ $\mathrm{Na}]^{+} \mathrm{C}_{53} \mathrm{H}_{90} \mathrm{O}_{13} \mathrm{Na}_{1}$ : 957.6313, found: 957.6279 .

(2-\{3-O-[ $\alpha$-D-Mannopyranosyl-( $1 \rightarrow 3$ )- $\beta$-D-glucopyranosyl]oleanol-28-yl\}ethyl) dimethylammonium acetate (30): To a stirred solution of saponin $27(64 \mathrm{mg}, 0.08 \mathrm{mmol})$ dissolved in DMF (1 mL) was added $\mathrm{K}_{2} \mathrm{CO}_{3}(30 \mathrm{mg}, 0.21 \mathrm{mmol})$ and dimethylaminoethyl chloride hydrochloride $(20 \mathrm{mg}, 0.18 \mathrm{mmol})$. After $16 \mathrm{~h}$, the reaction was incomplete so an additional portion of $\mathrm{K}_{2} \mathrm{CO}_{3}(50 \mathrm{mg})$ and dimethylaminoethylchloride hydrochloride $(50 \mathrm{mg})$ was added followed by tetrabutylammonium iodide $(75 \mathrm{mg})$. The mixture was stirred for $72 \mathrm{~h}$ and then purified by flash chromatography, eluting with $\mathrm{CHCl}_{3} / \mathrm{MeOH} /$ acetic acid 70:30:1 to give 30 as an amorphous white solid (53 mg, 71\%); ${ }^{1} \mathrm{H}$ NMR ( $\left.300 \mathrm{MHz}, \mathrm{CD}_{3} \mathrm{OD}, \mathrm{TMS}\right): \delta=5.25$ (br dd, $\left.{ }^{3} \mathrm{~J}(\mathrm{H}, \mathrm{H})=3.1,3.1 \mathrm{~Hz}, 1 \mathrm{H}\right), 5.23\left(\mathrm{~d},{ }^{3} \mathrm{~J}(\mathrm{H}, \mathrm{H})=1.7 \mathrm{~Hz}, 1 \mathrm{H}\right), 4.34$ $\left(d^{3}{ }^{3} J(H, H)=7.6 \mathrm{~Hz}, 1 \mathrm{H}\right), 4.27-4.13(\mathrm{~m}, 2 \mathrm{H}), 3.98\left(\mathrm{ddd},{ }^{3} J(\mathrm{H}, \mathrm{H})=9.5\right.$, 5.3, $2.3 \mathrm{~Hz}, 1 \mathrm{H}), 3.93\left(\mathrm{dd},{ }^{3} J(\mathrm{H}, \mathrm{H})=3.3,1.8 \mathrm{~Hz}, 1 \mathrm{H}\right), 3.86-3.79(\mathrm{~m}$, $2 \mathrm{H}), 3.78-3.60(\mathrm{~m}, 4 \mathrm{H}), 3.52\left(\mathrm{dd},{ }^{3} \mathrm{~J}(\mathrm{H}, \mathrm{H})=9.0,9.0 \mathrm{~Hz}, 1 \mathrm{H}\right), 3.43(\mathrm{dd}$, $\left.{ }^{3} \mathrm{~J}(\mathrm{H}, \mathrm{H})=9.4,9.4 \mathrm{~Hz}, 1 \mathrm{H}\right), 3.28-3.14(\mathrm{~m}, 2 \mathrm{H}), 2.92-2.83(\mathrm{~m}, 1 \mathrm{H}), 2.80$ $\left(\mathrm{t},{ }^{3} \mathrm{~J}(\mathrm{H}, \mathrm{H})=5.4 \mathrm{~Hz}, 2 \mathrm{H}\right), 2.45(\mathrm{~s}, 6 \mathrm{H}), 1.94(\mathrm{~s}, 3 \mathrm{H}), 1.80-1.08(\mathrm{~m}$, $23 \mathrm{H}), 1.16(\mathrm{~s}, 3 \mathrm{H}), 1.06(\mathrm{~s}, 3 \mathrm{H}), 0.95(\mathrm{~s}, 3 \mathrm{H}), 0.93(\mathrm{~s}, 3 \mathrm{H}), 0.91(\mathrm{~s}$, $3 \mathrm{H}), 0.84(\mathrm{~s}, 3 \mathrm{H}), 0.76 \mathrm{ppm}(\mathrm{s}, 3 \mathrm{H}) ;{ }^{13} \mathrm{C} \mathrm{NMR}\left(75 \mathrm{MHz}, \mathrm{CD}_{3} \mathrm{OD}\right): \delta=$ 178.8, 144.9, 12.40, 106.7, 102.4, 90.8, 84.4, 77.4, 74.4,74.2, 72.4, $72.3,72.0,68.5,62.5,62.0,57.9,57.0,47.0,45.1,42.8,42.7,40.6$, $40.1,39.7,37.8,34.7,33.9,33.4,31.5,28.7,28.6,26.9,26.4,24.5$, 23.9, 23.6, 22.9, 22.8, 19.3, 17.8, 17.0, 15.9 ppm; HRMS (ESI) $\mathrm{m} / \mathrm{z}$ calcd for $\mathrm{C}_{46} \mathrm{H}_{77} \mathrm{~N}_{1} \mathrm{O}_{13}+\mathrm{H}^{+}$: $852.5473[\mathrm{M}+\mathrm{H}]^{+}$, found: 852.5501 .

\section{(2-\{3-O-[ $\alpha$-D-Mannopyranosyl-(1 $\rightarrow 3$ )- $\beta$-D-glucopyranosyl]-} oleanol-28-yl\}ethyl) trimethylammonium trifluoroacetate (31): To a stirred solution of saponin $27(150 \mathrm{mg}, 0.19 \mathrm{mmol})$ dissolved in DMF ( $2 \mathrm{~mL}$ ) was added (2-chloroethyl)trimethylammonium chloride $(259 \mathrm{mg}, 1.39 \mathrm{mmol})$ and $\mathrm{K}_{2} \mathrm{CO}_{3}(133,0.96 \mathrm{mmol})$. The reaction was stirred at ambient temperature for $16 \mathrm{~h}$ and then warmed to $50^{\circ} \mathrm{C}$ $\mathrm{o} / \mathrm{n}$. The reaction mixture was concentrated under reduced pressure, absorbed onto silica, and purified by dry flash chromatography, eluting with 70:30:1 $\mathrm{CHCl}_{3} / \mathrm{MeOH} /$ acetic acid. The product obtained after flash chromatography was further purified by RP-HPLC $(50: 50 \rightarrow 0: 1000.1 \%$ TFA in water/MeOH), and the fractions containing product were lyophilized to give 31 as a colorless amorphous solid (91 mg, 48\%): $[\alpha]_{D}{ }^{22}=+52(c=0.9$ in $\mathrm{MeOH}) ;{ }^{1} \mathrm{H}$ NMR (300 MHz, CD $\left.\mathrm{CD}_{3}, \mathrm{TMS}\right): \delta=5.28\left(\mathrm{brt},{ }^{3} \mathrm{~J}(\mathrm{H}, \mathrm{H})=3.0 \mathrm{~Hz}, 1 \mathrm{H}\right), 5.24(\mathrm{~d}$, $\left.{ }^{3} \mathrm{~J}(\mathrm{H}, \mathrm{H})=1.5 \mathrm{~Hz}, 1 \mathrm{H}\right), 5.60-4.43(\mathrm{~m}, 2 \mathrm{H}), 4.35\left(\mathrm{~d},{ }^{3} \mathrm{~J}(\mathrm{H}, \mathrm{H})=7.7 \mathrm{~Hz}\right.$, $1 \mathrm{H}), 4.00\left(\mathrm{ddd},{ }^{3} \mathrm{~J}(\mathrm{H}, \mathrm{H})=9.5,5.3,2.1 \mathrm{~Hz}, 1 \mathrm{H}\right), 3.94\left(\mathrm{dd},{ }^{3} \mathrm{~J}(\mathrm{H}, \mathrm{H})=3.2\right.$, $1.9 \mathrm{~Hz}, 1 \mathrm{H}), 3.88-3.80(\mathrm{~m}, 2 \mathrm{H}), 3.79-3.62(\mathrm{~m}, 6 \mathrm{H}), 3.54(\mathrm{dd}$, $\left.{ }^{3} J(\mathrm{H}, \mathrm{H})=8.9 \mathrm{~Hz}, 1 \mathrm{H}\right), 3.43\left(\mathrm{dd},{ }^{3} J(\mathrm{H}, \mathrm{H})=9.3 \mathrm{~Hz}, 1 \mathrm{H}\right), 3.29-3.17(\mathrm{~m}$, $2 \mathrm{H}), 3.23(\mathrm{~s}, 9 \mathrm{H}), 2.91-2.81(\mathrm{~m}, 1 \mathrm{H}), 2.19-2.05(\mathrm{~m}, 1 \mathrm{H}), 2.01-1.01$ $(\mathrm{m}, 22 \mathrm{H}), 1.19(\mathrm{~s}, 3 \mathrm{H}), 1.08(\mathrm{~s}, 3 \mathrm{H}), 0.97(\mathrm{~s}, 3 \mathrm{H}), 0.95(\mathrm{~s}, 3 \mathrm{H}), 0.93(\mathrm{~s}$, $3 \mathrm{H}), 0.85(\mathrm{~s}, 3 \mathrm{H}), 0.79 \mathrm{ppm}(\mathrm{s}, 3 \mathrm{H}) ;{ }^{13} \mathrm{C}$ NMR $\left(75 \mathrm{MHz}, \mathrm{CD}_{3} \mathrm{OD}\right): \delta=$ 178.1, 161.6, (q, $\left.{ }^{3} \mathrm{~J}(\mathrm{H}, \mathrm{H})=37.0 \mathrm{~Hz}, 1 \mathrm{H}\right), 144.7,124.2,106.7,102.3$, $90.7,84.3,77.4,74.4,74.3,72.5,72.3,72.0,68.6,66.1,62.8,62.6$, $58.9,56.9,54.5,47.0,42.9,42.7,40.6,40.1,39.7,37.8,34.7,33.9$, $33.4,31.5,28.7,28.6,26.9,26.4,24.5,24.1,23.9,19.2,17.9,17.0$, $15.9 \mathrm{ppm}$; HRMS (ESI) $\mathrm{m} / \mathrm{z}$ calcd for $\mathrm{C}_{47} \mathrm{H}_{80} \mathrm{O}_{13} \mathrm{~N}_{1}: 866.5630$ $\left[\mathrm{M}-\mathrm{CF}_{3} \mathrm{CO}_{2}^{-}\right]^{+}$, found: 866.5607 .

\section{4-(2-\{3-O-[ $\alpha$-D-mannopyranosyl-( $1 \rightarrow 3)-\beta$-D-glucopyranosyl]-} oleanol-28-yl\}ethyl)morpholin-4-ium acetate (32): To a stirred solution of saponin 27 ( $272 \mathrm{mg}, 0.38 \mathrm{mmol})$ dissolved in DMF $(5 \mathrm{~mL})$ was added 4-(2-chloroethyl)morpholine hydrochloride $(259 \mathrm{mg}$, $1.39 \mathrm{mmol})$ and $\mathrm{K}_{2} \mathrm{CO}_{3}(241 \mathrm{mg}, 1.74 \mathrm{mmol})$. The reaction mixture was warmed to $50^{\circ} \mathrm{C}$ and left $\mathrm{o} / \mathrm{n}$ before concentrating under reduced pressure. The residue was dissolved in $\mathrm{EtOH}$ and absorbed onto silica gel, then the product was purified by flash chromatography, eluting with $\mathrm{CHCl}_{3} / \mathrm{MeOH} /$ acetic acid 70:30:1. The solid obtained was suspended in ethyl acetate, and an equal volume of petroleum ether was added. The precipitate was filtered through a porosity 4 sintered glass funnel, dissolved in ethanol, then dried under high vacuum to give 32 as an amorphous white solid (245 mg, 79\%): $[\alpha]_{D}{ }^{22}=+40.8(c=1.2$ in $\mathrm{MeOH}) ;{ }^{1} \mathrm{H} \mathrm{NMR}(300 \mathrm{MHz}$, $\left.\mathrm{CD}_{3} \mathrm{OD}, \mathrm{TMS}\right): \delta=5.27-5.20(\mathrm{~m}, 2 \mathrm{H}), 4.34\left(\mathrm{~d},{ }^{3} \mathrm{~J}(\mathrm{H}, \mathrm{H})=7.7 \mathrm{~Hz}, 1 \mathrm{H}\right)$, 4.25-4.10 (m, 2H), 4.02-3.95 (m, $1 \mathrm{H}), 3.93\left(\mathrm{dd},{ }^{3} \mathrm{~J}(\mathrm{H}, \mathrm{H})=2.9,1.9 \mathrm{~Hz}\right.$, $1 \mathrm{H}), 3.87-3.78(\mathrm{~m}, 2 \mathrm{H}), 3.78-3.61(\mathrm{~m}, 9 \mathrm{H}), 3.52\left(\mathrm{dd},{ }^{3} \mathrm{~J}(\mathrm{H}, \mathrm{H})=8.9\right.$, $8.9 \mathrm{~Hz}, 1 \mathrm{H}), 3.42\left(\mathrm{dd},{ }^{3} \mathrm{~J}(\mathrm{H}, \mathrm{H})=8.9,8.9 \mathrm{~Hz}, 1 \mathrm{H}\right), 2.92-2.83(\mathrm{~m}, 1 \mathrm{H})$, 2.76-2.68 (m, 2H), $2.65\left(\mathrm{t},{ }^{3} J(\mathrm{H}, \mathrm{H})=5.5 \mathrm{~Hz}, 2 \mathrm{H}\right), 2.58-2.47(\mathrm{~m}, 4 \mathrm{H})$, 
2.10-1.85 (m, 3H), $1.96(\mathrm{~s}, 3 \mathrm{H}), 1.80-0.79(\mathrm{~m}, 27 \mathrm{H}), 1.16(\mathrm{~s}, 3 \mathrm{H})$ $1.06(\mathrm{~s}, 3 \mathrm{H}), 0.95(\mathrm{~s}, 3 \mathrm{H}), 0.93(\mathrm{~s}, 3 \mathrm{H}), 0.91(\mathrm{~s}, 3 \mathrm{H}), 0.84(\mathrm{~s}, 3 \mathrm{H})$, 0.76 ppm (s, $3 \mathrm{H}) ;{ }^{13} \mathrm{C}$ NMR (75 MHz, CD $\left.\mathrm{OD}\right): \delta=179.2,145.0,123.9$, 106.7, 102.3, 90.7, 84.3, 77.4, 74.4, 74.2, 72.4, 72.3, 72.0, 68.6, 67.7, $66.4,62.9,62.7,62.6,57.9,57.0,54.9,54.3,47.1,42.8,42.7,40.6$, $40.1,39.7,37.8,34.7,33.9,33.6,33.4,31.5,28.7,28.6,26.9,26.4$, $24.5,24.0,23.9,19.2,17.8,17.0,15.9,14.4$. HRMS (ESI) $\mathrm{m} / \mathrm{z}$ calcd for $\mathrm{C}_{48} \mathrm{H}_{80} \mathrm{O}_{14} \mathrm{~N}: 894.5579$ [M-OAC] $^{+}$, found: 894.5585 .

Allyl 24-benzoyl-3-O-[2,3,4,6-tetra-O-benzoyl- $\beta$-D-galactopyranosyl-(1 $\rightarrow 3)-2,4,6$-triacetyl- $\alpha$-D-glucopyranosyl]hederagenate (33): A solution of acceptor $3^{[17]}(739 \mathrm{mg}, 1.19 \mathrm{mmol})$ and Galp-containing disaccharide donor 14 (822 $\mathrm{mg}, 0.79 \mathrm{mmol})$ in $\mathrm{CH}_{2} \mathrm{Cl}_{2}(10 \mathrm{~mL}$ ) were stirred with powdered activated $4 \AA$ molecular sieves (500 mg) for $1 \mathrm{~h}$, and then TMSOTf $(0.014 \mathrm{~mL}, 0.08 \mathrm{mmol})$ was added. After $1 \mathrm{~h}$, the reaction mixture was quenched with $\mathrm{NEt}_{3}$ (0.5 mL) diluted with $\mathrm{CH}_{2} \mathrm{Cl}_{2}$ and filtered through Celite. The mixture was concentrated under reduced pressure, and the residue was purified by flash chromatography, eluting with a gradient from $20: 1$ to $10: 1$ toluene/ethyl acetate to give a colorless solid. This solid was taken up in pyridine $(2 \mathrm{~mL})$, and acetic anhydride $(1 \mathrm{~mL})$ and 4-dimethylaminopyridine $(50 \mathrm{mg})$ were added. The mixture was stirred for $16 \mathrm{~h}$ and then concentrated under reduced pressure, and the product was isolated by flash chromatography, eluting with petroleum ether/ethyl acetate 2:1 to give 33 as a colorless solid $(493 \mathrm{mg}, 42 \%)$ : $[\alpha]_{D}{ }^{22}=+41.4\left(c=1.0\right.$ in $\left.\mathrm{CHCl}_{3}\right) ;{ }^{1} \mathrm{H} \mathrm{NMR}$ (300 MHz, $\left.\mathrm{CDCl}_{3}, \mathrm{TMS}\right): \delta=8.12-8.00(\mathrm{~m}, 6 \mathrm{H}), 7.88-7.83(\mathrm{~m}, 2 \mathrm{H})$, 7.77-7.72 (m, 2H), 7.68-7.32 (m, 13H), 7.25-7.19 (m, 2H), $5.97(b r$ d, $\left.{ }^{3} J(H, H)=2.8 \mathrm{~Hz}, 1 \mathrm{H}\right), 5.90\left(\mathrm{dddd},{ }^{3} J(\mathrm{H}, \mathrm{H})=17.3,10.5,5.4,5.4 \mathrm{~Hz}\right.$, $1 \mathrm{H}), 5.69-5.56(\mathrm{~m}, 2 \mathrm{H}), 5.32$ (dddd, ${ }^{3} J(\mathrm{H}, \mathrm{H})=17.2,1.5,1.5,1.5 \mathrm{~Hz}$, $1 \mathrm{H}), 5.32\left(\mathrm{br} d d,{ }^{3} J(\mathrm{H}, \mathrm{H})=3.0,3.0 \mathrm{~Hz}, 1 \mathrm{H}\right), 5.20\left(\mathrm{dddd},{ }^{3} J(\mathrm{H}, \mathrm{H})=\right.$ 10.5, 1.3, 1.3, $1.3 \mathrm{~Hz}, 1 \mathrm{H}), 5.04\left(\mathrm{dd},{ }^{3} J(\mathrm{H}, \mathrm{H})=9.3,9.3 \mathrm{~Hz}, 1 \mathrm{H}\right), 5.00$ $\left(\mathrm{dd},{ }^{3} \mathrm{~J}(\mathrm{H}, \mathrm{H})=9.5,3.8 \mathrm{~Hz}, 1 \mathrm{H}\right), 4.97\left(\mathrm{dd},{ }^{3} \mathrm{~J}(\mathrm{H}, \mathrm{H})=7.3,7.3 \mathrm{~Hz}, 1 \mathrm{H}\right)$, 4.70-4.60 (m, 1 H), 4.60-4.44 (m, 2H), 4.42-4.28 (m, 3H), 4.20-4.10 $(\mathrm{m}, 2 \mathrm{H}), 4.06-3.84(\mathrm{~m}, 3 \mathrm{H}), 3.51-3.41(\mathrm{~m}, 2 \mathrm{H}), 2.94-2.85(\mathrm{~m}, 1 \mathrm{H})$, $2.08(\mathrm{~s}, 3 \mathrm{H}), 2.04(\mathrm{~s}, 3 \mathrm{H}), 2.00(\mathrm{~s}, 3 \mathrm{H}), 1.97-0.96(\mathrm{~m}), 1.08(\mathrm{~s}, 3 \mathrm{H})$, $0.95(\mathrm{~s}, 3 \mathrm{H}), 0.95(\mathrm{~s}, 3 \mathrm{H}), 0.91(\mathrm{~s}, 3 \mathrm{H}), 0.74(\mathrm{~s}, 3 \mathrm{H}), 0.71 \mathrm{ppm}(\mathrm{s}, 3 \mathrm{H})$; ${ }^{13} \mathrm{C}$ NMR (75 MHz, $\left.\mathrm{CDCl}_{3}\right): \delta=177.2,170.6,169.0,168.3,166.0$, $165.9,165.5,165.3,143.6,133.6,133.2,133.1,132.4,129.9,129.7$, $129.6,129.4,128.9,128.8,128.7,128.5,128.4,128.2,128.1,122.3$, 117.6, 102.6, 100.9, 83.1, 78.2, 72.8, 71.7, 71.5, 70.9, 70.1, 68.6, 67.8, $65.6,64.7,62.3,61.5,48.0,46.7,45.8,41.9,41.6,41.3,39.3,38.3$, $36.5,36.4,33.8,33.0,32.4,32.3,30.6,27.5,25.3,25.2,23.5,23.3$, 22.9, 20.8, 20.7, 18.0, 16.9, 15.5, 12.8 ppm; HRMS (ESI) $\mathrm{m} / \mathrm{z}$ calcd for $\mathrm{C}_{86} \mathrm{H}_{98} \mathrm{O}_{22}+\mathrm{Na}^{+}: 1505.6447[\mathrm{M}+\mathrm{Na}]^{+}$, found: 1505.6483 .

3-O-[ $\beta$-D-Galactopyranosyl-( $1 \longrightarrow 3$ )- $\alpha$-D-glucopyranosyl]hederagenin (35): To a stirred degassed solution of protected glycoside 33 (384 mg, $0.25 \mathrm{mmol}$ ) in $\mathrm{CH}_{2} \mathrm{Cl}_{2} / \mathrm{MeOH}(1: 1,8 \mathrm{~mL})$ under $\mathrm{Ar}$ was added triphenylphosphine $(50 \mathrm{mg}, 0.19 \mathrm{mmol})$ and $\mathrm{Pd}^{0}\left(\mathrm{PPh}_{3}\right)_{4}$ (50 mg, $43.3 \mu \mathrm{mol}$ ). The mixture was stirred $\mathrm{o} / \mathrm{n}$ and then sodium methoxide $(30 \% \mathrm{w} / \mathrm{v}$ in $\mathrm{MeOH}, 1.0 \mathrm{~mL})$ was added, and the mixture was left for a further $24 \mathrm{~h}$. The mixture was diluted with $\mathrm{MeOH}$ to dissolve the precipitate and left for a further $4 \mathrm{~h}$. The solution was acidified with Amberjet $1200 \mathrm{H}$ and filtered to remove resin. The volatiles were removed under reduced pressure, and the product was isolated by flash chromatography, eluting with $\mathrm{CHCl}_{3} / \mathrm{MeOH} /$ $7 \mathrm{~N} \mathrm{NH}_{3} /$ methanol 80:20:10. The product was then further purified by RP-HPLC $\left(T_{R} 40 \mathrm{~min}, C_{18}, 1: 1 \rightarrow 1: 0 \mathrm{MeOH} / 0.1 \%\right.$ TFA in water over $70 \mathrm{~min})$ to give 35 as a colorless solid (86 mg, $57 \%$ ): $[\alpha]_{\mathrm{D}}^{22}=$ +42.7 ( $c=0.54$ in $\mathrm{MeOH}) ;{ }^{1} \mathrm{H}$ NMR (500 MHz, CD $\left.\mathrm{OD}\right): \delta=5.26$ (dd $\left.{ }^{3} J(\mathrm{H}, \mathrm{H})=2.8,2.8 \mathrm{~Hz}, 1 \mathrm{H}\right), 4.58\left(\mathrm{~d},{ }^{3} J(\mathrm{H}, \mathrm{H})=7.7 \mathrm{~Hz}, 1 \mathrm{H}\right), 4.50(\mathrm{~d}$ $\left.{ }^{3} J(H, H)=7.9 \mathrm{~Hz}, 1 \mathrm{H}\right), 3.86\left(\mathrm{dd},{ }^{3} \mathrm{~J}(\mathrm{H}, \mathrm{H})=11.9,2.2 \mathrm{~Hz}, 1 \mathrm{H}\right), 3.83-3.76$ (m, 2 H), 3.73-3.53 (m, 7H), $3.52\left(\mathrm{dd},{ }^{3} J(\mathrm{H}, \mathrm{H})=9.7,3.3 \mathrm{~Hz}, 1 \mathrm{H}\right), 3.43$ $\left(\mathrm{dd},{ }^{3} J(\mathrm{H}, \mathrm{H})=9.5,8.9 \mathrm{~Hz}, 1 \mathrm{H}\right), 3.39\left(\mathrm{dd},{ }^{3} J(\mathrm{H}, \mathrm{H})=9.0,8.0 \mathrm{~Hz}, 1 \mathrm{H}\right)$, $2.86\left(\mathrm{br} \mathrm{dd},{ }^{3} J(\mathrm{H}, \mathrm{H})=13.6,4.1 \mathrm{~Hz}, 1 \mathrm{H}\right), 2.03\left(\mathrm{ddd},{ }^{3} J(\mathrm{H}, \mathrm{H})=13.5\right.$, $13.5,4.0 \mathrm{~Hz}, 1 \mathrm{H}), 1.98-1.88(\mathrm{~m}, 3 \mathrm{H}), 1.83-1.47(\mathrm{~m}, 10 \mathrm{H}, 1.43-1.38$ $(\mathrm{m}, 2 \mathrm{H}), 1.30-1.08(\mathrm{~m}, 5 \mathrm{H}), 1.19(\mathrm{~s}, 3 \mathrm{H}), 1.00(\mathrm{~s}, 3 \mathrm{H}), 0.95(\mathrm{~s}, 3 \mathrm{H})$, $0.92(\mathrm{~s}, 3 \mathrm{H}), 0.83(\mathrm{~s}, 3 \mathrm{H}), 0.72 \mathrm{ppm}(\mathrm{s}, 3 \mathrm{H}) ;{ }^{13} \mathrm{C} N M R(125 \mathrm{MHz}$, $\left.\mathrm{CD}_{3} \mathrm{OD}\right): \delta=181.9,145.3,105.8,105.3,88.1,83.6,77.4,77.2,74.9$, $74.8,73.1,70.4,70.0,65.1,62.6,48.3,47.7,47.3,43.9,43.0,42.8$, $40.6,39.5,37.7,34.9,33.8,33.6,33.5,31.6,28.9,26.5,26.3,24.6$, 24.1, 24.0, 18.9, 17.8, 16.4, 13.4 ppm; HRMS (ESI) $\mathrm{m} / \mathrm{z}$ calcd for $\mathrm{C}_{42} \mathrm{H}_{68} \mathrm{O}_{14}+\mathrm{Na}^{+}: 819.4507[\mathrm{M}+\mathrm{Na}]^{+}$, found: 819.4510 .

\section{3-O-[ $\beta$-D-Xylopyranosyl-( $1 \rightarrow 3)$ - $\beta$-D-glucopyranosyl]hederagenin} (38): To a stirred solution of imidate donor $18(730 \mathrm{mg}, 0.81 \mathrm{mmol})$ and acceptor $3^{[17]}(540 \mathrm{mg}, 0.87 \mathrm{mmol})$ in dry $\mathrm{CH}_{2} \mathrm{Cl}_{2}(10 \mathrm{~mL})$ under Ar was added activated $4 \AA$ molecular sieves $(1 \mathrm{~g})$. The reaction was allowed to stir at ambient temperature for $30 \mathrm{~min}$, and then TMSOTf $(20 \mu \mathrm{L})$ was added. The reaction mixture was left to stir at ambient temperature for a further $15 \mathrm{~min}$ and then quenched by the addition of $\mathrm{NEt}_{3}(1.0 \mathrm{~mL})$. The mixture was filtered through filter aid to remove sieves and then concentrated under reduced pressure. Purification by flash chromatography afforded a virtually inseparable 4:1 mixture $(750 \mathrm{mg}$ ) of allyl 24-O-benzoyl-3-O-[2,3,4tribenzoyl- $\beta$-D-xylopyranosyl-( $1 \rightarrow 3$ )-2,4,6-triacetyl- $\alpha$-D-glucopyranosyl]hederagenate (36) contaminated with allyl 24-O-benzoyl-3-O[2,3,4-tribenzoyl- $\beta$-D-xylopyranosyl-( $1 \rightarrow 3)$-4,6-diacetyl- $\alpha$-D-glucopyranosyl]hederagenate (37). 36: ${ }^{13} \mathrm{CNMR}\left(75 \mathrm{MHz}, \mathrm{CDCl}_{3}\right): \delta=$ $177.1,170.5,169.4,168.8,166.0,165.5,165.3,164.9,143.6,133.3$, $133.1,133.0,132.4,130.3,129.8,129.8,129.4,129.2,128.9,128.4$ $128.3,128.1,122.3,117.8,102.6,100.6,83.3,80.6,72.7,71.5,69.9$, $69.3,68.7,65.5,64.7,62.4,60.7,48.0,46.7,45.8,41.9,41.6,41.3$, $39.3,38.2,36.4,33.8,33.0,32.4,32.3,30.6,27.5,25.3,25.2,23.5$, 23.3, 22.9, 20.9, 20.7, 18.0, 16.9, 15.5, 12.8 ppm; HRMS (ESI) $\mathrm{m} / \mathrm{z}$ calcd for $\mathrm{C}_{78} \mathrm{H}_{92} \mathrm{O}_{20}+\mathrm{Na}^{+}: 1371.6080[\mathrm{M}+\mathrm{Na}]^{+}$, found: 1371.6089 . 37: HRMS (ESI) $\mathrm{m} / z$ calcd for $\mathrm{C}_{76} \mathrm{H}_{90} \mathrm{O}_{19}+\mathrm{Na}^{+}: 1329.5974[\mathrm{M}+\mathrm{Na}]^{+}$, found: 1329.6184 . The mixture $(750 \mathrm{mg})$ was taken up in $\mathrm{MeOH}$ $(5 \mathrm{~mL})$, and $\mathrm{CH}_{2} \mathrm{Cl}_{2}(5 \mathrm{~mL})$ and $\mathrm{Pd}^{0}\left(\mathrm{PPh}_{3}\right)_{4}(200 \mathrm{mg})$ were added. The reaction was allowed to stir under $\mathrm{Ar}$ o/n and then sodium methoxide ( $30 \% \mathrm{w} / \mathrm{v}$ in $\mathrm{MeOH}, 3 \mathrm{~mL}$ ) was added. The reaction mixture was left for $6 \mathrm{~h}$ over which time a white precipitate formed. The reaction mixture was diluted with water $(5 \mathrm{~mL}), 2 \mathrm{~N}$ aq. $\mathrm{NaOH}$ solution $(3 \mathrm{~mL})$, and then $\mathrm{MeOH}$ was added until a homogenous solution was obtained. The reaction mixture was left to stir for a further $16 \mathrm{~h}$ and then quenched with Amberjet $1200 \mathrm{H}$ resin. The reaction mixture was filtered and the resin washed well with $\mathrm{EtOH}$ to dissolve all products. Concentration of the filtrate under reduced pressure and purification by flash chromatography afforded 38 as a colorless amorphous solid (334 mg, $53 \%):[\alpha]_{D}{ }^{22}=+34(c=0.8$ in $\mathrm{MeOH}) ;{ }^{1} \mathrm{H}$ NMR (300 MHz, CD $\left.\mathrm{OD}, \mathrm{TMS}\right): \delta=5.25\left(\mathrm{br} \mathrm{dd},{ }^{3} \mathrm{~J}(\mathrm{H}, \mathrm{H})=\right.$ $3.2,3.2 \mathrm{~Hz}, 1 \mathrm{H}), 4.50(\mathrm{~d}, 3 \mathrm{3}(\mathrm{H}, \mathrm{H})=7.4 \mathrm{~Hz}, 1 \mathrm{H}), 4.46\left(\mathrm{~d},{ }^{3} \mathrm{~J}(\mathrm{H}, \mathrm{H})=\right.$ $7.8 \mathrm{~Hz}, 1 \mathrm{H}), 3.92\left(\mathrm{dd},{ }^{3} J(\mathrm{H}, \mathrm{H})=11.4,5.3 \mathrm{~Hz}, 1 \mathrm{H}\right), 3.85\left(\mathrm{dd},{ }^{3} J(\mathrm{H}, \mathrm{H})=\right.$ $11.8,2.1 \mathrm{~Hz}, 1 \mathrm{H}), 3.73-3.61(\mathrm{~m}, 3 \mathrm{H}), 3.57-3.46(\mathrm{~m}, 2 \mathrm{H}), 3.42-3.21$ $(\mathrm{m}, 5 \mathrm{H}), 2.91-2.82(\mathrm{~m}, 1 \mathrm{H}), 1.19(\mathrm{~s}, 3 \mathrm{H}), 0.99(\mathrm{~s}, 3 \mathrm{H}), 0.95(\mathrm{~s}, 3 \mathrm{H})$, $0.92(\mathrm{~s}, 3 \mathrm{H}), 0.83(\mathrm{~s}, 3 \mathrm{H}), 0.72 \mathrm{ppm}(\mathrm{s}, 3 \mathrm{H}) ;{ }^{13} \mathrm{C} \mathrm{NMR}\left(75 \mathrm{MHz}, d_{5^{-}}\right.$ pyridine) $\delta=180.8,145.3,122.8,106.6,105.9,88.3,82.4,78.5,78.3$, $75.6,75.0,71.2,69.7,67.7,74.7,62.8,48.5,47.9,47.0,46.8,43.8$, $42.5,42.4,40.1,39.0,37.3,34.6,33.6,33.2,31.3,28.7,26.5,26.3$, 24.2, 18.5, 17.9, 16.4, $14.0 \mathrm{ppm}$; HRMS (ESI) $\mathrm{m} / \mathrm{z}$ calcd for $\mathrm{C}_{41} \mathrm{H}_{66} \mathrm{O}_{13}+\mathrm{Na}^{+}$: $789.4401[M+\mathrm{Na}]^{+}$, found: 789.4406; elemental analysis calcd (\%) for $\left(38.2 \mathrm{H}_{2} \mathrm{O}\right) \mathrm{C}_{41} \mathrm{H}_{70} \mathrm{O}_{15}: \mathrm{C} 61.33, \mathrm{H} 8.79$, found: $\mathrm{C}$ $61.59, \mathrm{H} 8.48$.

Allyl 3-O-\{2,3,4,6-Tetra-O-benzoyl- $\alpha$-D-mannopyranosyl-( $1 \rightarrow 6)$ [2,3,4,6-tetra-O-benzoyl- $\alpha$-D-mannopyranosyl-(1 $\rightarrow 3)]-2,4$-di-Oacetyl- $\beta$-D-glucopyranosyl\}-hederagenate $\quad(41)$ : $\quad 2,3,4,6$-tetra-O- 
benzoyl- $\alpha$-D-mannopyranosyl-( $1 \rightarrow 6)$-[2,3,4,6-tetra-O-benzoyl- $\alpha$-Dmannopyranosyl-( $1 \rightarrow 3)]-1,2,4$-tri-O-acetyl- $\beta$-D-glucopyranose $(39)^{[20]}$ $(2.0 \mathrm{~g}, 1.36 \mathrm{mmol})$ was dissolved in $\mathrm{CH}_{2} \mathrm{Cl}_{2}(10 \mathrm{~mL})$, and $\mathrm{HBr}$ in acetic acid $(30 \% w / v, 10 \mathrm{~mL})$ and acetic anhydride $(2 \mathrm{~mL})$ were added. After $30 \mathrm{~min}$, the mixture was diluted with $\mathrm{CH}_{2} \mathrm{Cl}_{2}(150 \mathrm{~mL})$ and washed with ice/water $(150 \mathrm{~mL})$ then sat. $\mathrm{NaHCO}_{3}$ solution $(150 \mathrm{~mL})$, dried $\left(\mathrm{MgSO}_{4}\right)$, and concentrated under reduced pressure to give $\mathbf{4 0}$ as a colorless solid. A portion of this crude bromide (926 mg, $0.62 \mathrm{mmol})$ and hederagenate $3^{[17]}$ (350 mg, $\left.567 \mu \mathrm{mol}\right)$ were combined in toluene $(10 \mathrm{~mL})$ and concentrated and further dried under high vacuum for $1 \mathrm{~h}$ to give a foam. To this was added $4 \AA$ molecular sieves, and the mixture was dissolved in dry $\mathrm{CH}_{2} \mathrm{Cl}_{2}$ (30 mL). The solution was cooled to $-20^{\circ} \mathrm{C}$, and silver trifluoromethanesulfonate $(175 \mathrm{mg}, 681 \mu \mathrm{mol})$ was added. The reaction was stirred at this temperature for $2 \mathrm{~h}$, diluted with $\mathrm{CH}_{2} \mathrm{Cl}_{2}$, and filtered through a pad of Celite. The organic phase was washed with saturated aq $\mathrm{NaHCO}_{3}$ then brine and dried $\left(\mathrm{MgSO}_{4}\right)$ and concentrated under reduced pressure. The residue was purified by flash chromatography, eluting with a gradient of ethyl acetate/petroleum ether 1:9 to 1:1 to afford title compound $\mathbf{4 1}$ as an off-white solid (336 mg, 30\%): ${ }^{1} \mathrm{H}$ NMR (300 MHz, CDCl $\left.3, \mathrm{TMS}\right): \delta=8.15-8.09$ (m, $6 \mathrm{H}), 8.05-8.02(\mathrm{~m}, 2 \mathrm{H}), 8.0-7.94(\mathrm{~m}, 6 \mathrm{H}), 7.87-7.83(\mathrm{~m}, 4 \mathrm{H}), 7.64-$ $7.20(\mathrm{~m}, 27 \mathrm{H}), 6.25\left(\mathrm{t},{ }^{3} \mathrm{~J}(\mathrm{H}, \mathrm{H})=10.2 \mathrm{~Hz}, 1 \mathrm{H}\right), 6.12\left(\mathrm{t},{ }^{3} \mathrm{~J}(\mathrm{H}, \mathrm{H})=9.6 \mathrm{~Hz}\right.$, $1 \mathrm{H}), 5.92-5.82(\mathrm{~m}, 1 \mathrm{H}), 5.81-5.76(\mathrm{~m}, 1 \mathrm{H}), 5.76(\mathrm{~s}, 1 \mathrm{H}), 5.70(\mathrm{dd}$, $\left.{ }^{3} \mathrm{~J}(\mathrm{H}, \mathrm{H})=10.2,3.1 \mathrm{~Hz} \mathrm{~Hz}, 1 \mathrm{H}\right), 5.55\left(\mathrm{t},{ }^{3} \mathrm{~J}(\mathrm{H}, \mathrm{H})=2.4 \mathrm{~Hz}, 1 \mathrm{H}\right), 5.27(\mathrm{dd}$, $\left.{ }^{3} \mathrm{~J}(\mathrm{H}, \mathrm{H})=17.1,1.5 \mathrm{~Hz}, 1 \mathrm{H}\right), 5.19-5.13(\mathrm{~m}, 4 \mathrm{H}), 5.03\left(\mathrm{t},{ }^{3} \mathrm{~J}(\mathrm{H}, \mathrm{H})=\right.$ $9.6 \mathrm{~Hz}, 1 \mathrm{H}), 4.84-4.72(\mathrm{~m}, 3 \mathrm{H}), 4.54-4.47(\mathrm{~m}, 5 \mathrm{H}), 4.42-4.32(\mathrm{~m}$, $2 \mathrm{H}), 4.07-3.91(\mathrm{~m}, 2 \mathrm{H}), 3.75-3.69(\mathrm{~m}, 2 \mathrm{H}), 3.53\left(\mathrm{~d},{ }^{3} \mathrm{~J}(\mathrm{H}, \mathrm{H})=8.4 \mathrm{~Hz}\right.$, $1 \mathrm{H}), 2.73\left(\mathrm{dd},{ }^{3} \mathrm{~J}(\mathrm{H}, \mathrm{H})=13.4,3.6 \mathrm{~Hz}, 1 \mathrm{H}\right), 2.27(\mathrm{~s}, 3 \mathrm{H}), 2.26(\mathrm{~s}, 3 \mathrm{H})$, 2.22-2.17 (m), 1.98-1.82 (m), 1.70-1.47 (m), 1.42-1.14 (m), 1.07$0.82(\mathrm{~m}), 0.98(\mathrm{~s}, 3 \mathrm{H}), 0.93(\mathrm{~s}, 3 \mathrm{H}), 0.92(\mathrm{~s}, 3 \mathrm{H}), 0.85(\mathrm{~s}, 3 \mathrm{H}), 0.82(\mathrm{~s}$, $3 \mathrm{H}), 0.59 \mathrm{ppm}(\mathrm{s}, 3 \mathrm{H}) ;{ }^{13} \mathrm{C} \mathrm{NMR}\left(75 \mathrm{MHz}, \mathrm{CDCl}_{3}\right): \delta=177.1,170.0$, $169.9,166.2,166.0,165.8,165.5,165.4(\times 2), 165.3,165.2,143.0$, $133.4,133.1,133.0,132.9,132.5,130.3,130.0,129.8,129.5,129.1$, $129.0,128.9,128.5,128.4,128.2,122.4,117.6,103.0,99.9,97.5,84.5$, $82.3,72.6,72.4,70.5,70.3,70.2,69.9,69.1,67.4,66.5,65.8,64.7$, $62.7,61.6,48.0,47.7,46.6), 45.8,42.0,41.4,41.1,39.1,38.0,36.3$, $33.8,33.1,32.3,30.6,27.4,25.6,25.4,23.6,22.8,21.3,20.8,18.0$ $16.8,15.6,12.9 \mathrm{ppm}$; HRMS (ESI, negative mode) $\mathrm{m} / \mathrm{z}$ calcd for $\mathrm{C}_{119} \mathrm{H}_{123} \mathrm{O}_{32} 2063.7998\left[\mathrm{M}+\mathrm{HCO}_{2}\right]^{-}$, found 2063.8040 .

3-O-\{ $\alpha$-D-Mannopyranosyl-( $1 \rightarrow 6)$-[ $\alpha$-D-mannopyranosyl-( $1 \rightarrow 3)]-$ $\beta$-D-glucopyranosyl\}hederagenin (42): A mixture of saponin 41 (305 mg, $0.15 \mathrm{mmol}$ ) and triphenylphosphine $(99 \mathrm{mg}, 0.38 \mathrm{mmol}$ ) was dissolved in 1,4-dioxane $(10 \mathrm{~mL})$ containing formic acid (0.093 mL, $2.42 \mathrm{mmol}$ ) and triethylamine $(0.318 \mathrm{~mL}, 2.27 \mathrm{mmol})$. To this solution was added palladium(II) acetate $(17 \mathrm{mg}, 0.75 \mathrm{mmol})$, and the yellow solution was stirred at $\mathrm{rt}$ under $\mathrm{Ar} \mathrm{o} / \mathrm{n}$. Solvent was removed under reduced pressure, and crude product was purified by flash chromatography, eluting with a gradient of ethyl acetate/ petroleum ether 2:3 $\rightarrow$ 1:0 to give the free acid as an off-white solid (258 mg, 86\%); ${ }^{1} \mathrm{H}$ NMR (300 MHz, $\left.\mathrm{CDCl}_{3}, \mathrm{TMS}\right): \delta=8.15-8.09$ $(\mathrm{m}, 6 \mathrm{H}), 8.05-8.02(\mathrm{~m}, 2 \mathrm{H}), 7.98-7.94(\mathrm{~m}, 6 \mathrm{H}), 7.86-7.83(\mathrm{~m}, 4 \mathrm{H})$, 7.74-7.68 $(\mathrm{m}, 4 \mathrm{H}), 7.61-7.18(\mathrm{~m}, 23 \mathrm{H}), 6.25\left(\mathrm{t},{ }^{3} \mathrm{~J}(\mathrm{H}, \mathrm{H})=10.2 \mathrm{~Hz}\right.$, $1 \mathrm{H}), 6.12\left(\mathrm{t},{ }^{3} \mathrm{~J}(\mathrm{H}, \mathrm{H})=9.7 \mathrm{~Hz}, 1 \mathrm{H}\right), 5.80-5.76(\mathrm{~m}, 1 \mathrm{H}), 5.76(\mathrm{~s}, 1 \mathrm{H})$, $5.70\left(\mathrm{dd},{ }^{3} \mathrm{~J}(\mathrm{H}, \mathrm{H})=10.2,3.1 \mathrm{~Hz}, 1 \mathrm{H}\right), 5.68\left(\mathrm{~d},{ }^{3} J(\mathrm{H}, \mathrm{H})=3.1 \mathrm{~Hz}, 1 \mathrm{H}\right)$, $5.55\left(\mathrm{t},{ }^{3} \mathrm{~J}(\mathrm{H}, \mathrm{H})=2.5 \mathrm{~Hz}, 1 \mathrm{H}\right), 5.19-5.13(\mathrm{~m}, 3 \mathrm{H}), 5.03\left(\mathrm{t},{ }^{3} \mathrm{~J}(\mathrm{H}, \mathrm{H})=\right.$ $9.6 \mathrm{~Hz}, 1 \mathrm{H}), 4.83-4.72(\mathrm{~m}, 3 \mathrm{H}), 4.55-4.32(\mathrm{~m}, 5 \mathrm{H}), 4.03-3.91(\mathrm{~m}$, $2 \mathrm{H}), 3.75-3.67(\mathrm{~m}, 2 \mathrm{H}), 3.54(\mathrm{~d}, 3 \mathrm{~J}(\mathrm{H}, \mathrm{H})=8.4 \mathrm{~Hz}, 1 \mathrm{H}), 2.65(\mathrm{~d}$, $\left.{ }^{3} \mathrm{~J}(\mathrm{H}, \mathrm{H})=13.6 \mathrm{~Hz}, 1 \mathrm{H}\right), 2.27(\mathrm{~s}, 3 \mathrm{H}), 2.26(\mathrm{~s}, 3 \mathrm{H}), 2.23-2.22(\mathrm{~m}), 2.08-$ $1.82(\mathrm{~m}), 1.74-1.65(\mathrm{~m}), 1.55-1.47(\mathrm{~m}), 1.39-1.14(\mathrm{~m}), 1.07-0.74(\mathrm{~m})$, $0.98(\mathrm{~s}, 3 \mathrm{H}), 0.93(\mathrm{~s}, 3 \mathrm{H}), 0.92(\mathrm{~s}, 3 \mathrm{H}), 0.85(\mathrm{~s}, 3 \mathrm{H}), 0.83(\mathrm{~s}, 3 \mathrm{H})$, $0.62 \mathrm{ppm}(\mathrm{s}, 3 \mathrm{H}) ;{ }^{13} \mathrm{C}$ NMR $\left(75 \mathrm{MHz}, \mathrm{CDCl}_{3}\right): \delta=182.0(\mathrm{C}), 171.2(\mathrm{C})$, 170.1 (C), 170.0 (C), 166.2 (C), 166.1 (C), 165.9 (C), 165.4 (C), 165.2
(C), $142.9(\mathrm{C}), 135.1(\mathrm{CH}), 133.4(\mathrm{CH}), 133.2(\mathrm{CH}), 133.1(\mathrm{CH}), 132.9$ $(\mathrm{CH}), 130.5(\mathrm{CH}), 129.9(\mathrm{CH}), 129.2(\mathrm{CH}), 120.1(\mathrm{CH}), 128.6(\mathrm{CH})$, $128.5(\mathrm{CH}), 128.3(\mathrm{CH}), 128.1(\mathrm{CH}), 122.6(\mathrm{CH}), 103.1(\mathrm{CH}), 100.0$ $(\mathrm{CH}), 97.6(\mathrm{CH}), 84.5(\mathrm{CH}), 82.4(\mathrm{CH}), 72.6(\mathrm{CH}), 72.5(\mathrm{CH}), 70.4(\mathrm{CH})$, $70.2(\mathrm{x} 2, \mathrm{CH}), 70.0(\mathrm{CH}), 69.2(\mathrm{CH}), 67.6\left(\mathrm{CH}_{2}\right), 66.6(\mathrm{CH}), 65.9(\mathrm{x} 2$, $\left.\mathrm{CH}, \mathrm{CH}_{2}\right), 62.8\left(\mathrm{CH}_{2}\right), 61.7\left(\mathrm{CH}_{2}\right), 60.4\left(\mathrm{CH}_{2}\right), 48.1(\mathrm{CH}), 47.8(\mathrm{CH}), 46.4$ $\left(\mathrm{CH}_{2}\right), 45.9(\mathrm{C}), 42.1(\mathrm{C}), 41.5(\mathrm{CH}), 41.0(\mathrm{C}), 39.1(\mathrm{C}), 38.1\left(\mathrm{CH}_{2}\right), 36.4$ (C), $33.8\left(\mathrm{CH}_{2}\right), 33.2\left(\mathrm{CH}_{3}\right), 32.4\left(\mathrm{CH}_{2}\right), 30.7(\mathrm{C}), 29.7\left(\mathrm{CH}_{2}\right), 27.5\left(\mathrm{CH}_{2}\right)$, $25.7\left(\mathrm{CH}_{2}\right), 25.5\left(\mathrm{CH}_{3}\right), 23.6\left(\mathrm{CH}_{3}\right), 22.9\left(\mathrm{CH}_{2}\right), 21.3\left(\mathrm{CH}_{3}\right), 21.0\left(\mathrm{CH}_{3}\right)$, $20.9\left(\mathrm{CH}_{3}\right), 18.1\left(\mathrm{CH}_{2}\right), 16.8\left(\mathrm{CH}_{3}\right), 15.7\left(\mathrm{CH}_{3}\right), 14.2\left(\mathrm{CH}_{3}\right), 13.0 \mathrm{ppm}$ $\left(\mathrm{CH}_{3}\right)$; To a stirred solution of this acid $(235 \mathrm{mg}, 0.12 \mathrm{mmol})$ dissolved in $\mathrm{MeOH}(25 \mathrm{~mL})$ was added sodium methoxide $(30 \% \mathrm{w} / \mathrm{v}$ solution in $\mathrm{MeOH}, 5 \mathrm{~mL}$ ). The reaction was stirred at $\mathrm{rt} \mathrm{o} / \mathrm{n}$ under $\mathrm{Ar}$ atmosphere then neutralized via dropwise addition of glacial acetic acid, and the solvent was removed under reduced pressure. Crude product was preadsorbed onto silica and purified by flash chromatography eluting with a gradient from $\mathrm{CHCl}_{3} / \mathrm{MeOH} 3: 2 \rightarrow$ $\mathrm{CHCl}_{3} / \mathrm{MeOH} /$ water 6:4:1 $\rightarrow \mathrm{CHCl}_{3} / \mathrm{MeOH} /$ aq. $\mathrm{NH}_{3}$ 6:4:1. The desired product $\mathbf{4 2}$ was isolated as a white solid after freeze drying (66 mg, $58 \%$ yield); ${ }^{1} \mathrm{H}$ NMR ( $300 \mathrm{MHz}, \mathrm{CD}_{3} \mathrm{OD}, \mathrm{TMS}$ ): $\delta=5.21$ (brs, $2 \mathrm{H}), 4.40\left(\mathrm{~d},{ }^{3} \mathrm{~J}(\mathrm{H}, \mathrm{H})=7.8 \mathrm{~Hz}, 1 \mathrm{H}\right), 4.01-3.95(\mathrm{~m}, 2 \mathrm{H}), 3.89-3.81(\mathrm{~m}$, $3 \mathrm{H}), 3.78-3.62(\mathrm{~m}, 9 \mathrm{H}), 3.58-3.43(\mathrm{~m}, 4 \mathrm{H}), 3.32-3.30(\mathrm{~m}, 3 \mathrm{H}), 3.25-$ $3.19(\mathrm{~m}, 1 \mathrm{H}), 2.88\left(\mathrm{dd},{ }^{3} \mathrm{~J}(\mathrm{H}, \mathrm{H})=13.5,3.4 \mathrm{~Hz}, 1 \mathrm{H}\right), 1.92-1.84(\mathrm{~m})$, $1.79-1.53(\mathrm{~m}), 1.49-1.21(\mathrm{~m}), 1.16(\mathrm{~s}, 3 \mathrm{H}), 1.13-1.00(\mathrm{~m}), 0.97(\mathrm{~s}$, $3 \mathrm{H}), 0.94(\mathrm{~s}, 3 \mathrm{H}), 0.88(\mathrm{~s}, 3 \mathrm{H}), 0.85(\mathrm{~s}, 3 \mathrm{H}), 0.70(\mathrm{~s}, 3 \mathrm{H}) ;{ }^{13} \mathrm{C}$ NMR $\left(75 \mathrm{MHz}, \mathrm{CD}_{3} \mathrm{OD}\right) \delta=184.5$ (c), $146.3(\mathrm{C}), 123.1(\mathrm{CH}), 106.1(\mathrm{CH})$, 102.6 (CH), 101.7 (CH), 84.8 (CH), 84.2 (CH), 76.1 (CH), $74.5(\times 2, \mathrm{CH})$, $72.8(\mathrm{CH}), 72.6(\mathrm{CH}), 72.5(\mathrm{CH}), 72.2(\mathrm{CH}), 72.0(\mathrm{CH}), 68.6(\mathrm{x2}, \mathrm{CH})$, $67.5\left(\mathrm{CH}_{2}\right), 65.1\left(\mathrm{CH}_{2}\right), 64.6(\mathrm{CH}), 62.9\left(\mathrm{CH}_{2}\right), 62.8\left(\mathrm{CH}_{2}\right), 49.2(\mathrm{CH})$, $48.4(\mathrm{CH}), 48.0\left(\mathrm{CH}_{2}\right), 44.0(\mathrm{C}), 43.4(\mathrm{CH}), 43.2(\mathrm{C}), 40.7(\mathrm{C}), 39.6$ $\left(\mathrm{CH}_{2}\right), 37.9(\mathrm{C}), 35.4\left(\mathrm{CH}_{2}\right), 34.3\left(\mathrm{CH}_{2}\right), 34.0\left(\mathrm{CH}_{3}\right), 33.7\left(\mathrm{CH}_{2}\right), 31.9(\mathrm{C})$, $29.3\left(\mathrm{CH}_{2}\right), 26.7\left(\times 2, \mathrm{CH}_{2}, \mathrm{CH}_{3}\right), 24.7\left(\mathrm{CH}_{2}\right), 24.5\left(\mathrm{CH}_{2}\right), 24.4\left(\mathrm{CH}_{3}\right)$, $19.1\left(\mathrm{CH}_{2}\right), 18.2\left(\mathrm{CH}_{3}\right), 16.6\left(\mathrm{CH}_{3}\right), 13.6 \mathrm{ppm}\left(\mathrm{CH}_{3}\right)$; HRMS (ESI, negative mode) $\mathrm{m} / \mathrm{z}$ calcd for $\mathrm{C}_{48} \mathrm{H}_{78} \mathrm{O}_{19}-\mathrm{H}^{+}: 957.5059[\mathrm{M}-\mathrm{H}]^{-}$; found 957.5087.

\section{Formulation of saponins}

Colloidal systems were prepared as previously described. ${ }^{[12]}$ Briefly, $10 \mathrm{mg} \mathrm{mL}^{-1}$ stock solutions of cholesterol (Sigma) and phosphatidylcholine ( $\mathrm{PC}$, Sigma) were prepared in $\mathrm{CHCl}_{3}$. The ratio of the lipids (PC:cholesterol) was kept constant at 3:1, which has previously been demonstrated to be optimal for the formation of ISCOM-like particles, ${ }^{[31]}$ while the synthetic saponin was incorporated as $10 \%, 20 \%, 50 \%, 70 \%$, or $100 \%$ of the total lipids in the formulation.

Synthetic saponins were prepared as either $10 \mathrm{mg} \mathrm{mL}^{-1}$ solutions in $145 \mathrm{~mm}$ Tris buffer ( $\mathrm{pH} 7.4)$ or $\mathrm{EtOH}$, dependent on solubility. Lipids were pipetted into sterile glass vials and made up to a total volume of $1 \mathrm{~mL}$ with $\mathrm{CHCl}_{3}$. The solvent was evaporated at low temperature using a Speedvac (Savant Industries, NY). The obtained lipid films were hydrated with solutions of the synthetic saponins +/- OVA (ovalbumin, albumin from chicken egg white, Grade $\mathrm{Vl}, \geq 98 \%$, Sigma-Aldrich, USA), made up to $1.5 \mathrm{~mL}$ with $145 \mathrm{~mm}$ Tris buffer, and stirred via magnetic fleas at rt for $24 \mathrm{~h}$. The samples were subsequently freeze dried (Feezone, Labconco, MO), at a condenser temperature of $-82^{\circ} \mathrm{C}$ and a pressure of less than 0.1 millibar. Freeze-dried samples were then resuspended in $1.5 \mathrm{~mL}$ of sterile Milli-Q water (Milli-Q water systems, Millipore Corp., MA, USA) and stirred via magnetic fleas for a further $24 \mathrm{~h}$ to facilitate mixing. The final total lipid concentration including cholesterol, phosphatidylcholine, and saponin in all systems was $6.67 \mathrm{mg} \mathrm{mL}^{-1}$. 
The particulate nature of the formulations was investigated by TEM. Briefly, samples were coated onto glow-discharged, carboncoated copper grids and negatively stained with $2 \%$ phosphotungstic acid ( $\mathrm{pH}$ 5.2). Samples were investigated using a Phillips CM100 electron microscope (Philips/FEl, Eindhoven, The Netherlands) with an acceleration voltage of $100 \mathrm{kV}$ and a magnification of 93,000 . Samples were investigated within $24 \mathrm{~h}$ of formulation and later as specified.

\section{Dendritic cell activation studies}

Mice (OT-I, OT-II, and C57BI/6 J) were obtained from the HTRU (University of Otago, Dunedin, New Zealand) and were maintained under specific-pathogen-free (SPF) conditions with free access to food and water. All experiments were approved by the University of Otago Animal Ethics Committee.

Activation studies were carried out as previously described. ${ }^{[12]}$ Murine BMDC were generated by culturing bone-marrow-derived stem cells from C57BI/6 J mice in complete Iscove's Modified Dulbecco's Medium (cIMDM; IMDM supplemented with 5\% foetal bovine serum, $1 \%$ penicillin/streptomycin, 1\% glutamax, and $0.01 \%$ 2-mercaptoethanol; all from Invitrogen, CA, USA) with $20 \mathrm{ng} \mathrm{mL}^{-1}$ recombinant granulocyte/macrophage colony stimulating factor (clone kindly supplied by Dr. G. Buchan, University of Otago) for six days at $37^{\circ} \mathrm{C}, 5 \% \mathrm{CO}_{2}$. Cells were seeded at $5 \times$ $10^{5}$ cells $/ \mathrm{mL}$ in cIMDM for pulsing with colloidal formulations. Activation of BMDC was measured by flow cytometric analysis (FACScalibur, BD, USA). Propidium iodide was added to the cells to determine cell viability, and the cells were stained with the BMDC marker CD11c. The expression of costimulatory activation markers CD86 and MHCII on propidium iodide ${ }^{-v e}, C D_{11} c^{+v e}$ cells was investigated $48 \mathrm{~h}$ after the addition of titrations of Quil A, Quil-A mimic or equivalent amounts of saponin in particulate formulations or $10 \mu \mathrm{gL}^{-1}$ lipopolysaccharide (LPS) as a positive control. Data were analyzed using CellQuest Pro (BD, USA). The percentage change in the mean fluorescence intensity (MFI) of activation marker expression was determined by dividing the difference between the MFI of each sample and the negative control by that of the negative control (media only, no formulation).

\section{Vaccine study}

The ability of the synthetic saponin vaccine formulations to stimulate in vivo immune responses was investigated by vaccinating $6-$ 8-week-old C57BL/6 J mice.

At day -1 , mice were adoptively transferred with $8 \times 10^{6}$ OVA-specific CD4 and CD8 T cells from congenic OT-I and OT-II donors by intravenous injection via the tail vein. At days 0 and 14 groups of mice $(n=3)$ were immunized by subcutaneous injection with a) OVA $(10 \mu \mathrm{g}$, albumin from chicken egg white, Grade $\mathrm{VI}, \geq 98 \%$, Sigma) in QA ISCOM in phosphate-buffered saline (PBS, $100 \mu \mathrm{g}$ saponin), b) OVA $(10 \mu \mathrm{g})$ in 24 (50\%):PC:cholesterol particles in PBS or Freund's incomplete adjuvant (Sigma-Aldrich, USA), c) OVA $(10 \mu \mathrm{g})$ in 31 (50\%):PC:cholesterol particles in PBS, or d) OVA $(10 \mu \mathrm{g})$ in Freund's incomplete adjuvant. On day 28 , all mice were euthanized, and single-cell suspensions were then prepared from the harvested lymphoid tissues.

\section{Acknowledgements}

The authors thank the New Zealand Foundation for Research Science and Technology for funding, Grant No. C08X0303.

Keywords: carbohydrates - glycosylation - immunostimulatory effects $\cdot$ saponins $\cdot$ vaccine adjuvants

[1] a) D. T. O'Hagan, N. M. Valiante, Nat. Rev. Drug Discovery 2003, 2, 727 735; b) R. K. Gupta, E. H. Relyveld, E. B. Lindblad, B. Bizzini, S. BenEfraim, C. K. Gupta, Vaccine 1993, 11, 293-306.

[2] A. C. Allison, Arch. Immunol. Ther. Exp. 1997, 45, 141-147.

[3] a) A. Fernández-Tejada, E. K. Chea, C. George, J. R. Gardner, P. O. Livingston, G. Ragupathi, D. S. Tan, D. Y. Gin, Bioorg. Med. Chem. 2014, 22 5917-5923; b) G. Ragupathi, J. R. Gardner, P. O. Livingston, D. Y. Gin, Expert Rev. Vaccines 2011, 10, 463-470; c) H. X. Sun, Y. Xie, Y. P. Ye, Vaccine 2009, 27, $1787-1796$.

[4] B. Morein, Immunol. Lett. 1990, 25, $281-283$.

[5] a) P. Demana, B. Berger, U. Vosgerau, T. Rades, N. Davies, J. Pharm. Pharmacol. 2004, 56, 573-580; b) J. Myschik, D. G. Lendemans, W. T. McBurney, P. H. Demana, S. Hook, T. Rades, Micron 2006, 37, 724-734.

[6] a) G. F. Kersten, A. Spiekstra, E. Coen Beuvery, D. J. Crommelin, Biochim. Biophys. Acta 1991, 1062, 165-171; b) M. Özel, S. Höglund, H. R. Gelderblom, B. Morein, J. Ultrastruct. Mol. Struct. Res. 1989, 102, 240-248.

[7] P. H. Demana, N. M. Davies, U. Vosgerau, T. Rades, Int. J. Pharm. 2004 270, 229-239.

[8] a) J. Schimmel, M. I. Passos Eleutério, G. Ritter, R. R. Schmidt, Eur. J. Org. Chem. 2006, $1701-1721$; b) M. I. P. Eleutério, Synthesis of Active Analogs of Adjuvant Quillaja Saponins in Order to Determine the Structure-Activity Correlation. Studies towards the Synthesis QS-21, University of Konstanz, Göttingen (Germany), 2005.

[9] K. Plé, M. Chwalek, L. Voutquenne-Nazabadioko, Tetrahedron 2005, 61, 4347-4362.

[10] For a review of saponin synthesis see C. Gauthier, J. Legault, A. Pichette, Mini-Rev. Org. Chem. 2009, 6, 321-344.

[11] a) M. Chwalek, N. Lalun, H. Bobichon, K. Plé, L. Voutquenne-Nazabadioko, Biochim. Biophys. Acta Gen. Subj. 2006, 1760, 1418-1427; b) I. Podolak, A. Galanty, D. Sobolewska, Phytochem. Rev. 2010, 9, 425-474; c) Y. Wang, Y. Zhang, Z. Zhu, S. Zhu, Y. Li, M. Li, B. Yu, Bioorg. Med. Chem. 2007, 15, 2528-2532; d) P. Cmoch, Z. Pakulski, J. Swaczynová, M. Strnad, Carbohydr. Res. 2008, 343, 995-1003.

[12] A. M. Daines, B. W. Greatrex, C. M. Hayman, S. M. Hook, W. T. McBurney, T. Rades, P. M. Rendle, I. M. Sims, Bioorg. Med. Chem. 2009, 17, 52075218.

[13] S. Soltysik, J.-Y. Wu, J. Recchia, D. A. Wheeler, M. J. Newman, R. T. Coughlin, C. R. Kensil, Vaccine 1995, 13, $1403-1410$.

[14] A. Fernández-Tejada, E. K. Chea, C. George, N. Pillarsetty, J. R. Gardner, P. O. Livingston, G. Ragupathi, J. S. Lewis, D. S. Tan, D. Y. Gin, Nat. Chem 2014, 6, 635.

[15] G. Gaidi, T. Miyamoto, A. Rustaiyan, V. Laurens, M.-A. Lacaille-Dubois, J. Nat. Prod. 2000, 63, 1497-1502.

[16] L. J. Haynes, J. R. Plimmer, W. M. Sue-Ho, J. Chem. Soc. 1963, 744-745.

[17] K. Plé, M. Chwalek, L. Voutquenne-Nazabadioko, Eur. J. Org. Chem. 2004, $1588-1603$.

[18] A. De Mico, R. Margarita, L. Parlanti, A. Vescovi, G. Piancatelli, J. Org. Chem. 1997, 62, 6974-6977.

[19] D. Nico, F. Santos, G. Borja-Cabrera, M. Palatnik, C. Palatnik de Sousa, Vaccine 2007, 25, 649-658.

[20] a) I. Matsuo, M. Isomura, T. Miyazaki, T. Sakakibara, K. Ajisaka, Carbohydr. Res. 1997, 305, 401; b) M. Upreti, D. Ruhela, R. A. Vishwakarma, Tetrahe dron 2000, 56, 6577.

[21] Z. Wu, F. Kong, Carbohydr. Res. 2004, 339, 377-384.

[22] W. Pilgrim, P. V. Murphy, J. Org. Chem. 2010, 75, 6747-6755.

[23] a) D. Crich, M. Smith, J. Am. Chem. Soc. 2001, 123, 9015-9020; b) D. Crich, A. Banerjee, W. Li, Q. Yao, J. Carbohydr. Chem. 2005, 24, 415-424.

[24] J. Zhang, C. Li, L. Sun, G. Yu, H. Guan, Eur. J. Org. Chem. 2015, $4246-$ 4253. 
[25] A. Bérces, D. M. Whitfield, T. Nukada, I. do Santos, Z. A. Obuchowska, J. J. Krepinsky, Can. J. Chem. 2004, 82, 1157-1171.

[26] Z. Wang, Comprehensive Organic Name Reactions and Reagents, Vol. 691 , John Wiley \& Sons, Inc., Hoboken, NJ, 2010, pp. 3123-3128.

[27] P. Wang, Y.-J. Kim, M. Navarro-Villalobos, B. D. Rohde, D. Y. Gin, J. Am. Chem. Soc. 2005, 127, 3256-3257.

[28] P. D. Jeffrey, S. W. McCombie, J. Org. Chem. 1982, 47, 587-590.

[29] Z. Wu, F. Kong, Carbohydr. Res. 2003, 338, 1727-1735.
[30] M. Nazari, M. Kurdi, H. Heerklotz, Biophys. J. 2012, 102, 498-506.

[31] I. Kitagawa, K. Hori, T. Taniyama, J.-L. Zhou, M. Yoshikawa, Chem. Pharm. Bull. 1993, 41, 43.

Received: May 31, 2015

Revised: August 20, 2015

Published online on September 30, 2015 